\title{
The Role of Glycolysis in shaping the Autoimmune Potential of Myelin-Reactive T Cells in the Course of Experimental Autoimmune Encephalomyelitis
}

\author{
Doctoral thesis \\ In partial fulfillment of the requirements for the degree \\ "Doctor rerum naturalium (Dr. rer. nat.)“ \\ in the Molecular Medicine Study Program \\ at the Georg-August University Göttingen
}

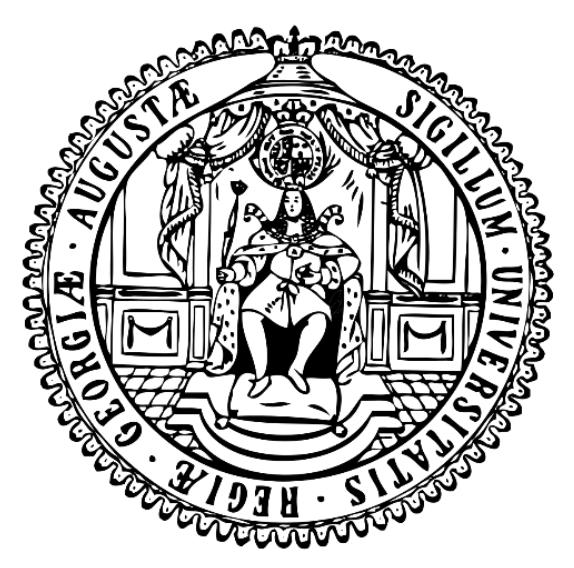

Submitted by

Giuseppe Chiappetta

Born in Cosenza

Göttingen, September 2018 


\section{Members of the Thesis Committee:}

\section{Supervisor:}

\section{Prof. Dr. Alexander Flügel}

University Medical Center Göttingen

Institute for Multiple Sclerosis Research

Dept. of Neuroimmunology

Von-Siebold-Str. 3a, 37075, Göttingen, Germany.

Second member of the Thesis Committee:

Prof. Dr. Mikael Simons

German Center for Neurodegenerative Diseases (DZNE)

Feodor-Lynen Str. 17, 81377 München, Germany.

$\&$

Technische Universität München

Biedersteiner Str. 29, 80802, München, Germany.

Third member of the Thesis Committee:

Prof. Dr. Holger Reichardt

University of Göttingen Medical School

Institute of Cellular and Molecular Immunology

Humboldtallee 34, 37073, Göttingen, Germany. 


\section{TABLE OF CONTENTS}

LIST OF FIGURES

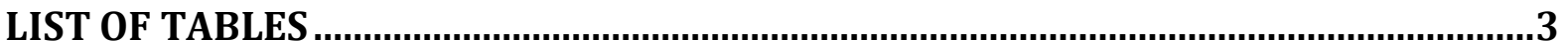

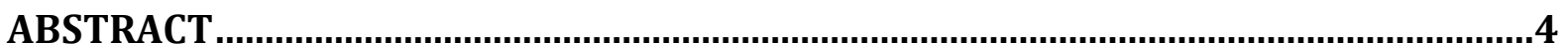

1. INTRODUCTION.....................................................................................................6

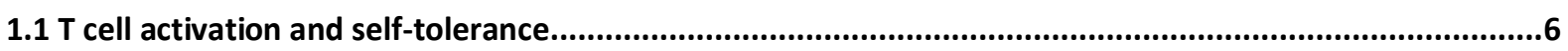

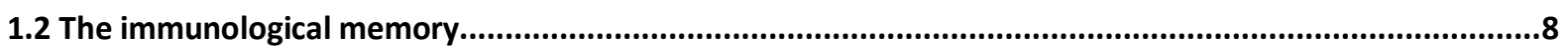

1.3 Metabolism and T cell function: the role of glycolysis .............................................................................10

1.4 Multiple sclerosis, an autoimmune disease.................................................................................................16

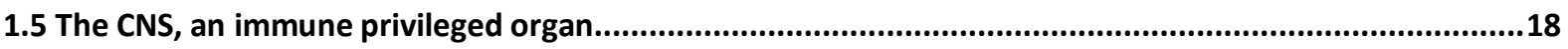

1.6 Experimental autoimmune encephalomyelitis (EAE)...........................................................................20

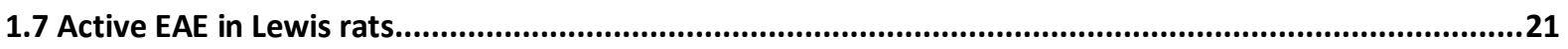

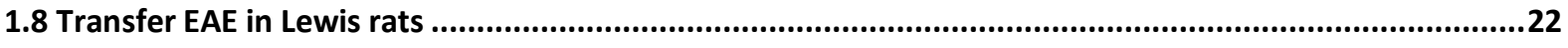

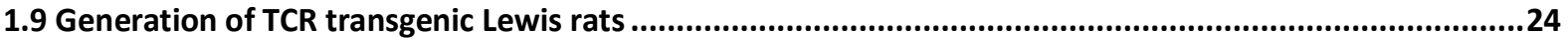

1.10 Generation of "memory" Lewis rats ...........................................................................................................27

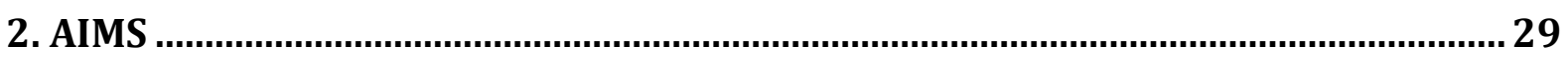

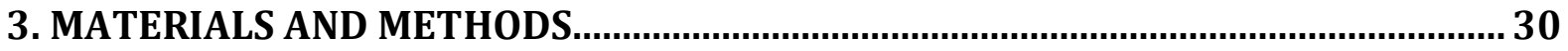

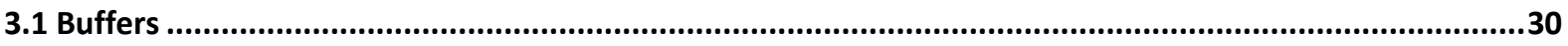

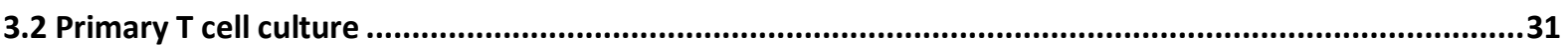

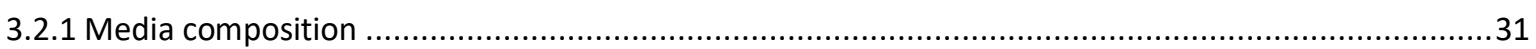

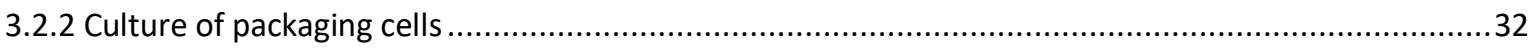

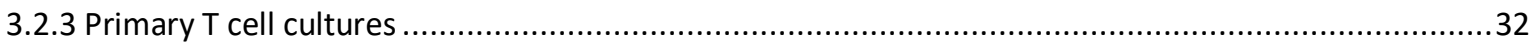

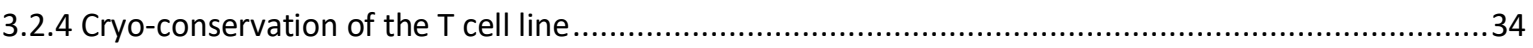

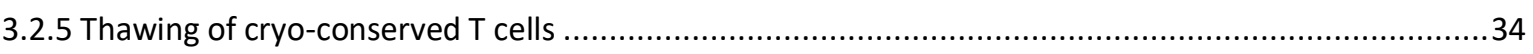

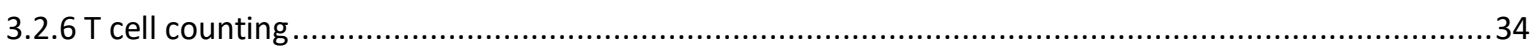

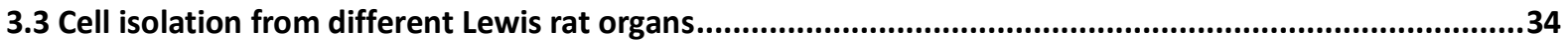

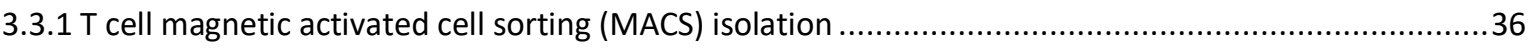

3.4 Characterization of T cell phenotype and activation ...........................................................................37

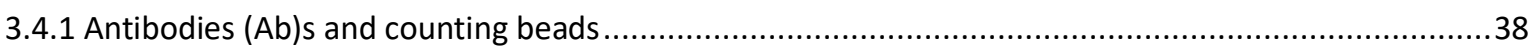

3.4.2 FACS analysis of the antibody staining of cell surface markers and cell count ...............................39

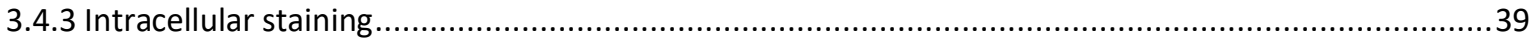

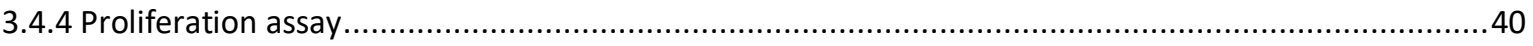

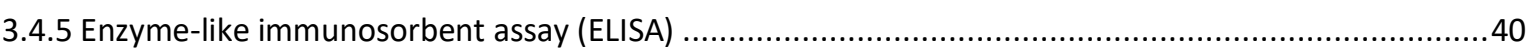

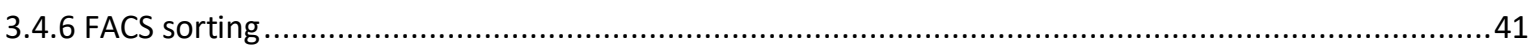

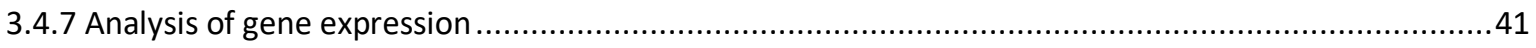


3.4.7.1 RNA extraction.

3.4.7.2 Reverse transcription: complementary DNA (cDNA) synthesis ...........................................42

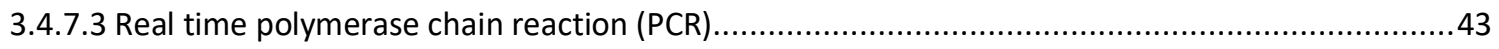

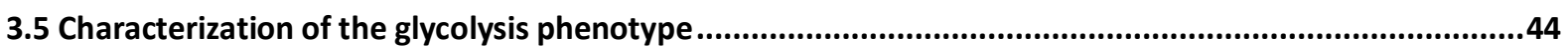

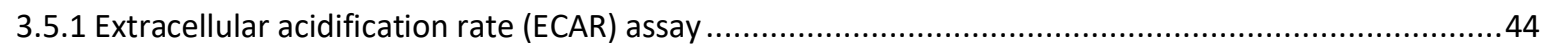

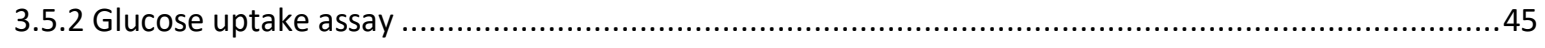

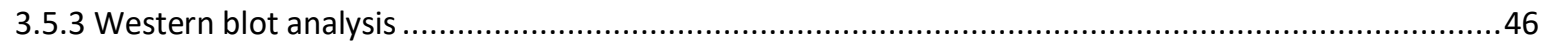

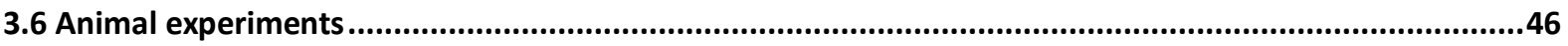

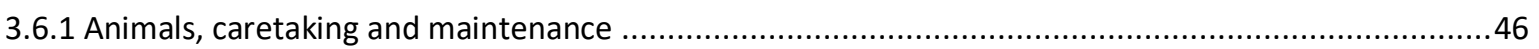

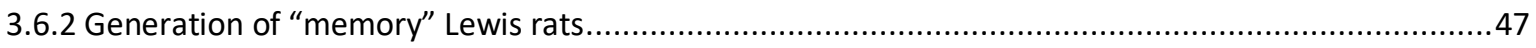

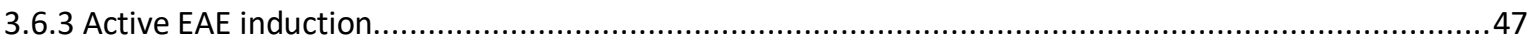

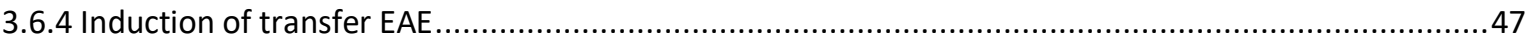

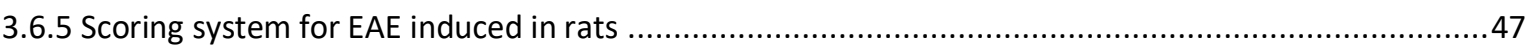

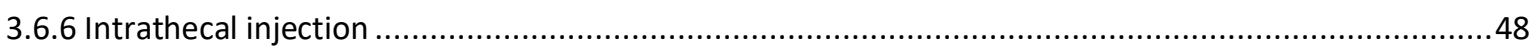

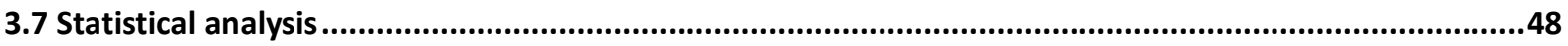

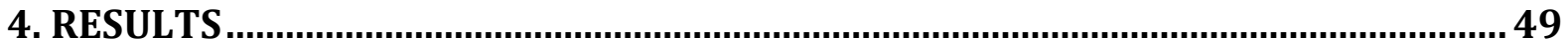

4.1 rMT-II rats do not develop any spontaneous EAE and do not show any aggravation of the adoptive

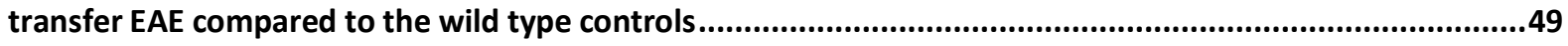

4.2 Primary rMT-II T cells are highly encephalopathogenic when undergoing peripheral activation in vivo...50

4.3 Effector T cell lines derived from rMT-II strain are highly sensitive to MBP stimulation in vitro...............54

4.4 Phenotype and CNS residence of rMT-II T cells under steady state condition ......................................57

4.5 Intrathecal transfer of primary rMT-II T cells is not sufficient for the induction of clinical disease ...........60

4.6 Recently activated effector T cells show a much higher level of activation in the CNS than naïve or resting

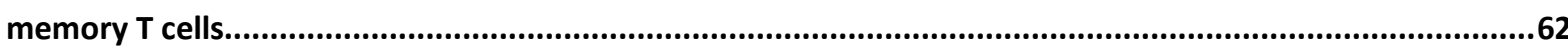

4.7 Antigenic stimulation of $\mathrm{T}$ cells is followed by the wave of glycolytic activation which subsides after time

4.8 Inhibition of glycolysis in vivo affects T-cell encephalogenicity ............................................................78

4.9 The inhibition of glycolysis in cultured T cells lowers their level of activation in vitro.............................83

4.10 The glucose uptake and expression of glycolytic enzymes in T cells before entry into the CNS is higher in recently activated effector $\mathrm{T}$ cells than in resting memory or naïve T cells

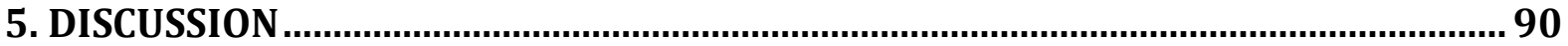

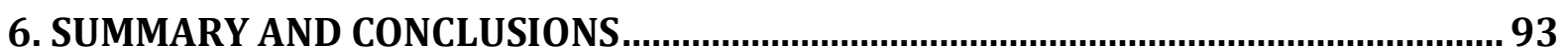

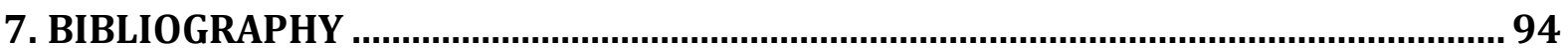

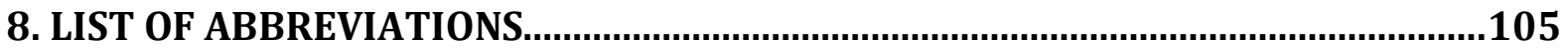




\section{LIST OF FIGURES}

- FIG I Two dominant competing models of T-cell differentiation.............................

- FIG II Metabolic differences between effector and memory T cells.................. 12

- FIG III Schematic view of the metabolism of glucose induced by the Warburg effect.

- FIG IV Transcriptional regulation of metabolism in effector T cells. ................. 15

- FIG V Life cycle of effector cell line used for transfer EAE in Lewis rats. .......... 24

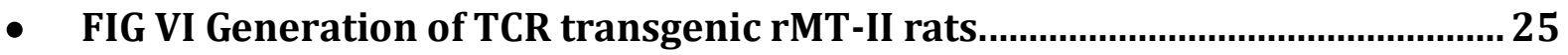

- FIG VII T cell specificity in rMT-II and rOT-II rats............................................ 27

- FIG VIII Active EAE induction in "memory" rats. ............................................... 28

- FIG 1 Clinical course of transfer EAE in rMT-II and WT rats...............................50

- FIG 2 Comparison of active EAE in rMT-II and WT Lewis rats. ..........................51

- FIG 3 Adoptive transfer of rMT-II T cells prior to immunization confers

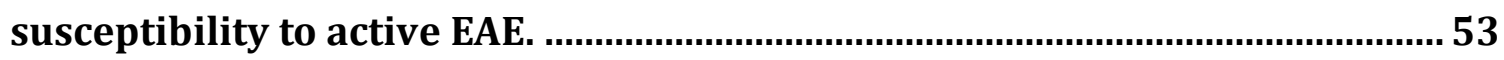

- FIG 4 In vitro activation kinetic of different $r$ MT-II T cell subsets......................55

- FIG 5 Activation of rMT-II T cells in vitro analyzed by flow cytometry. ............56

- FIG 6 Phenotype of rMT-II T cells in naïve animals. ...........................................59

- FIG 7 Intrathecal injection of freshly activated effector but not primary rMT-II

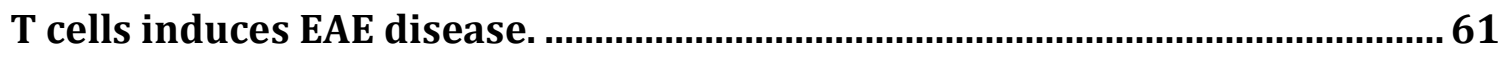

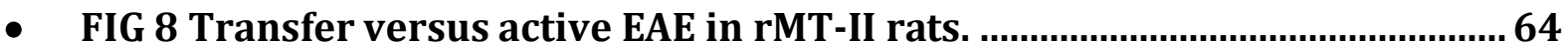

- FIG 9 Analysis of T cell activation in transfer and active EAE in TCR transgenic

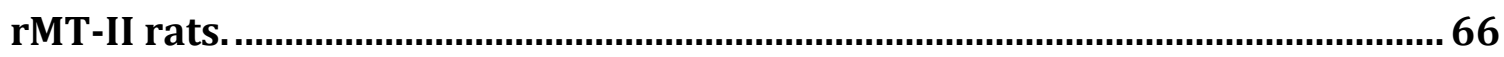

- FIG 10 Analysis of transfer and active EAE in T ${ }_{\text {MBP-memory rats. ........................68 }}$

- FIG 11 Activation of MBP-specific T cells in the target tissue during transfer and

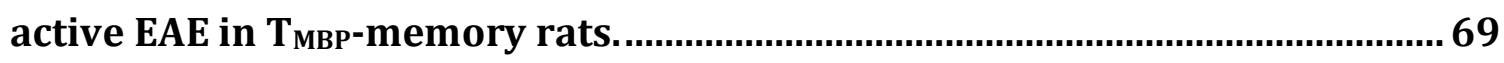

- FIG 12 Glucose uptake and glycolysis rate in the effector MBP-specific T cells during their re-stimulation cycle in vitro.............................................................. 71

- FIG 13 Expression of glycolytic enzymes and regulatory factors in $\mathbf{T}$ cells over

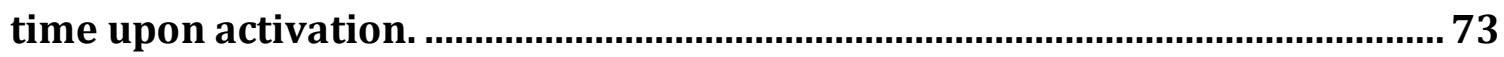


- FIG 14 Time course analysis of metabolic pathways in cultured effector $T_{M B P}$ cells.

- FIG 15 Time course analysis of metabolic pathways in transferred effector $\mathbf{T}_{\mathrm{MBP}}$ cells. 77

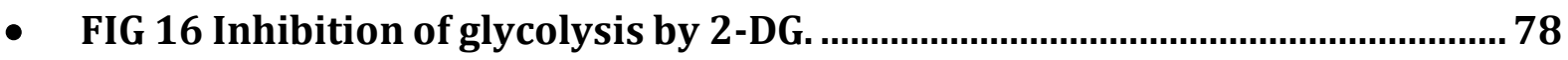

- FIG 17 Effects of 2-DG treatment on transfer EAE............................................ 80

- FIG 18 Effects of 2-DG treatment on the activation levels of MBP-specific

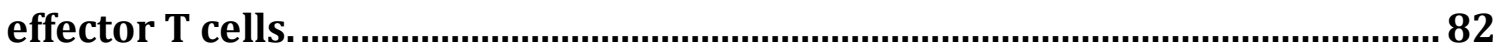

- FIG 19 Galactose metabolism: the Leloir pathway................................................... 83

- $\quad$ FIG 20 Effects of 2-DG treatment on the activation of effector T cells in vitro. 85

- FIG 21 State of glycolysis in different subsets of MBP-specific T cells analyzed

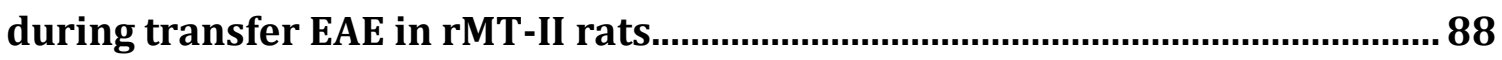




\section{LIST OF TABLES}

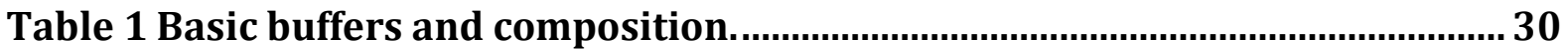

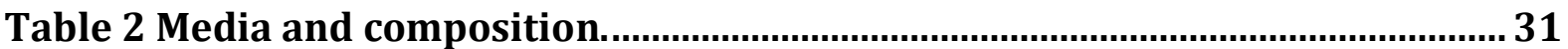

Table 3 Antibodies and counting beads used and their function. ............................. 38

Table 4 Primer and probe sequences for real time PCR. .........................................44 
Multiple sclerosis (MS) is an autoimmune disease of the central nervous system (CNS), where myelin-reactive $\mathrm{T}$ cells play a key role in the inflammatory events responsible for the formation of demyelinated lesions. Auto-reactive T cells are present in the immune repertoire of healthy people, but they only rarely cause autoimmunity. Exact mechanisms by which autoreactive $\mathrm{T}$ cells become pathogenic are still unclear.

In order to investigate these mechanisms, we used a transgenic Lewis rat model containing endogenous myelin basic protein (MBP)-reactive CD4 T cells and we analyzed these cells in naïve state or during experimental autoimmune encephalomyelitis (EAE) conditions. Further, we analyzed another experimental model, namely "memory" Lewis rats, which contain lifelong-persisting myelin-reactive memory CD4 T cells in their immune repertoire. Neither of these models develop spontaneous autoimmunity, however active immunization can readily induce disease with accelerated onset. We found that $\mathrm{T}$ cells of the memory but not of the naïve phenotype are capable of entering spinal cord tissue. Using intrathecal transfer of different T cells populations we were able to show that only freshly activated effector $\mathrm{T}$ cells are able to induce clinical disease after bypassing the blood brain barrier (BBB). After analysis of activation levels for different $\mathrm{T}$ cell subsets in active and transfer EAE, we hypothesized that the functional state of recently activated effector and not of resting memory MBP-specific T cells supports their pathogenicity and that such a state might be related to glycolytic activity. We studied glycolysis and factors regulating the metabolic switch after activation of MBP-specific T cells in vitro and after transfer in vivo during the course of transfer EAE. Of note, the inhibition of glycolysis by drug treatment in vivo delayed the onset of transfer EAE. This effect was associated with reduced inflammatory infiltration of the CNS tissue at the onset of disease. To confirm that the effect of in vivo glycolysis inhibition modulates the function of $\mathrm{T}$ cells, we tested a similar pharmacological approach in vitro and could show that inhibition of glycolysis in $\mathrm{T}$ cells prior to antigenic stimulation reduces the production of pro-inflammatory cytokines.

Our results suggest that a high glycolytic rate enables CD4 $\mathrm{T}$ cells to perceive weak antigenic signals in the immune privileged tissue of the CNS and to become re-activated, triggering inflammatory processes. A therapy lowering the glycolytic rate in auto- 
reactive $\mathrm{T}$ cells may be a relevant approach for the treatment of $\mathrm{T}$ cell mediated autoimmunity. 


\section{INTRODUCTION}

\subsection{T cell activation and self-tolerance}

The immune system is a network of cells communicating between each other by several mechanisms in order to protect the host organism from microbial pathogens. It can be divided into the innate and the adaptive immune system. Innate immunity represents the fast response system, comprising mainly phagocytic cells like macrophages, dendritic cells, and neutrophils as well as eosinophils, basophils, mast cells, cytotoxic cells like natural killer cells and the complement system. The cells belonging to the innate immune system recognize without fine specificity a broad range of pathogen-associated molecular patterns (PAMPs) by Toll-like receptors (TLR) and other pattern recognition receptors (PRRs) and initiate immune reactions. During the process of pathogen elimination the innate immune system tightly cooperates with the adaptive immune system. The latter consists mainly of lymphocytes, $\mathrm{T}$ cells and $\mathrm{B}$ cells which recognize pathogens by highly specific antigenic receptors (i.e. the $\mathrm{T}$ cell receptor (TCR) and $\mathrm{B}$ cell receptor, respectively) and carry out a delayed but much more precisely targeted response.

$\mathrm{T}$ cells can be divided into CD4+ or helper T cells and CD8+ or cytotoxic T cells. They recognize the antigen presented by antigen presenting cells (APCs) such as phagocytes of the innate immune system via a set of proteins on their surface known as major histocompatibility complex (MHC), (this being MHC-II for CD4+ cells and MHC-I for CD8+ cells). The antigen presentation to the $\mathrm{T}$ cell receptor, together with costimulatory inputs, triggers complex signal-transduction pathways that lead to the activation and differentiation of the T cells (Knosp and Johnston 2012; Ramana et al. 2002; Shaw et al. 1988). Both activation and differentiation can vary depending on several factors, including quality, duration and quantity of antigen presentation, ligand density, affinity, type of costimulatory signals and cytokine milieu. The activated state of $\mathrm{T}$ cells can be identified (and quantified) by proliferation and additionally by the production of inflammatory molecules such as the cytolytic enzymes granzyme B and perforin in CD8 T cells (Chávez-Galán et al. 2009). CD4 T helper cells produce cytokines (e.g. IFN $\gamma$, TNF $\alpha$, IL-2, IL-17 or GM-CSF) and upregulate expression of the surface membrane receptors (e.g. CD69, CD25 orOX40) upon activation (Bikker et al. 2014; Codarri et al. 2011; Knosp 
and Johnston 2012; Redmond, Ruby, and Weinberg 2009). By these and other molecules, CD4 T cells are able to fuel the activation of other immune cells and even of themselves. The tremendous variability of TCRs ensures that almost any pathogen can be targeted by adaptive immunity. However this wide range of specificities also implies that the $\mathrm{T}$ cell response can be directed against self-tissues which might ultimately result in the development of an autoimmune disease. The necessity of the immune system to discriminate between self and non-self gave rise to the development of self-tolerance mechanisms. In the case of T cells, the unresponsiveness to self can be obtained by central and peripheral mechanisms. The central tolerance is established during $\mathrm{T}$ cell development in the thymus where thymocytes expressing TCR with high affinity for selfantigen/MHC complexes are deleted (negative selection). The highly self-reactive T cells that escape the negative selection can be inactivated in the periphery by mechanisms of peripheral tolerance that include deletion, suppression by regulatory cells and induction of an imprinted cell-intrinsic program mediating a state of functional unresponsiveness, or anergy (Schietinger and Greenberg 2014).

The activation and differentiation of $\mathrm{T}$ cells are highly controlled and can change depending on the nature, context and duration of antigen presentation, potentially generating, as in the case of self-tolerance, various states of T-cell dysfunction and unresponsiveness. Anergy and ignorance, for example, are two described dysfunctional states. Anergic T cells are the result of sub-optimal stimulations like the absence of costimulatory signals and are characterized by the inability to produce an effective immune response even in the presence of an optimal antigenic stimulus (Jenkins and Schwartz 1987; Schietinger and Greenberg 2014; Schwartz 2003). Ignorance may occur when anatomical barriers sequester the (self-)antigen from immune surveillance or when the antigen is expressed or presented at too low concentrations to stimulate T cells. Hence, (self-)reactive $\mathrm{T}$ cells remain ignorant or unaware of the (self-)antigen. However, ignorant $\mathrm{T}$ cells are antigen-inexperienced and therefore persist as naïve but potentially functional cells. Thus, ignorance can be easily overcome (Kurts et al. 1999; Lang et al. 2005; Oldstone et al. 1991; Schietinger and Greenberg 2014).

The primary tasks of the immune system are the maintenance of tissue homeostasis and the defense of the organism against pathogens. The evolution towards a higher specificity of the immune response and hence the formation of the immunological memory has led on the one hand to a better performance of these tasks but on the other hand to the 
possibility of harmful and counterproductive events. Indeed, under certain circumstances, the dysregulation of some immune mechanisms can cause self-tolerance to break down and the adaptive immune responses to be directed against self-tissue, inducing acute or chronic organ-directed autoimmune diseases such as type I diabetes, rheumatoid arthritis or multiple sclerosis (Dendrou, Fugger, and Friese 2015).

\subsection{The immunological memory}

A hallmark of the immune system is its potential to generate a secondary response to an infectious agent generally faster and more effectively than the primary response. This can occur because the recall responses are carried out by long-living, antigen-specific lymphocytes generated from the first exposure of a pathogen and able to readily and vigorously react to a new infection of the same agent. For this reason, these lymphocytes are called memory cells and represent experienced and specialized sentinels of the organism, putting the body under continuous immune surveillance in a quiescent and non-activated state, but ready to quickly respond in the case of an infiltration of the cognate pathogen.

Currently there are two main models to explain the differentiation of T cells into memory cells, even if this concept is still debated (Restifo and Gattinoni 2013). The most known and accepted model (ON-OFF-ON / OFF-ON-OFF model) (FIG I) proposes naïve T cells to be stimulated by antigen, then proliferate and differentiate into effector cells producing cytokines and cytolytic molecules to clear the pathogen. After the peak of the response, once the antigen has been eliminated, most of the effector $\mathrm{T}$ cells enter the so-called contraction phase undergoing apoptosis, but a part of them survive and differentiate into memory cells that in turn can quickly become effector cells again and give rise to fast immune responses in occasion of a subsequent encounter with the cognate antigen. The second model (developmental model) (FIG I) opens up the possibility that effector T cells do not turn into memory cells but rather represent terminally differentiated cells. Hence, this model could involve asymmetric division of progenitor cells (Chang et al. 2007; Pollizzi et al. 2016) and the progressive differentiation of naïve T cells into memory and lastly effector T cells (Restifo and Gattinoni 2013). 


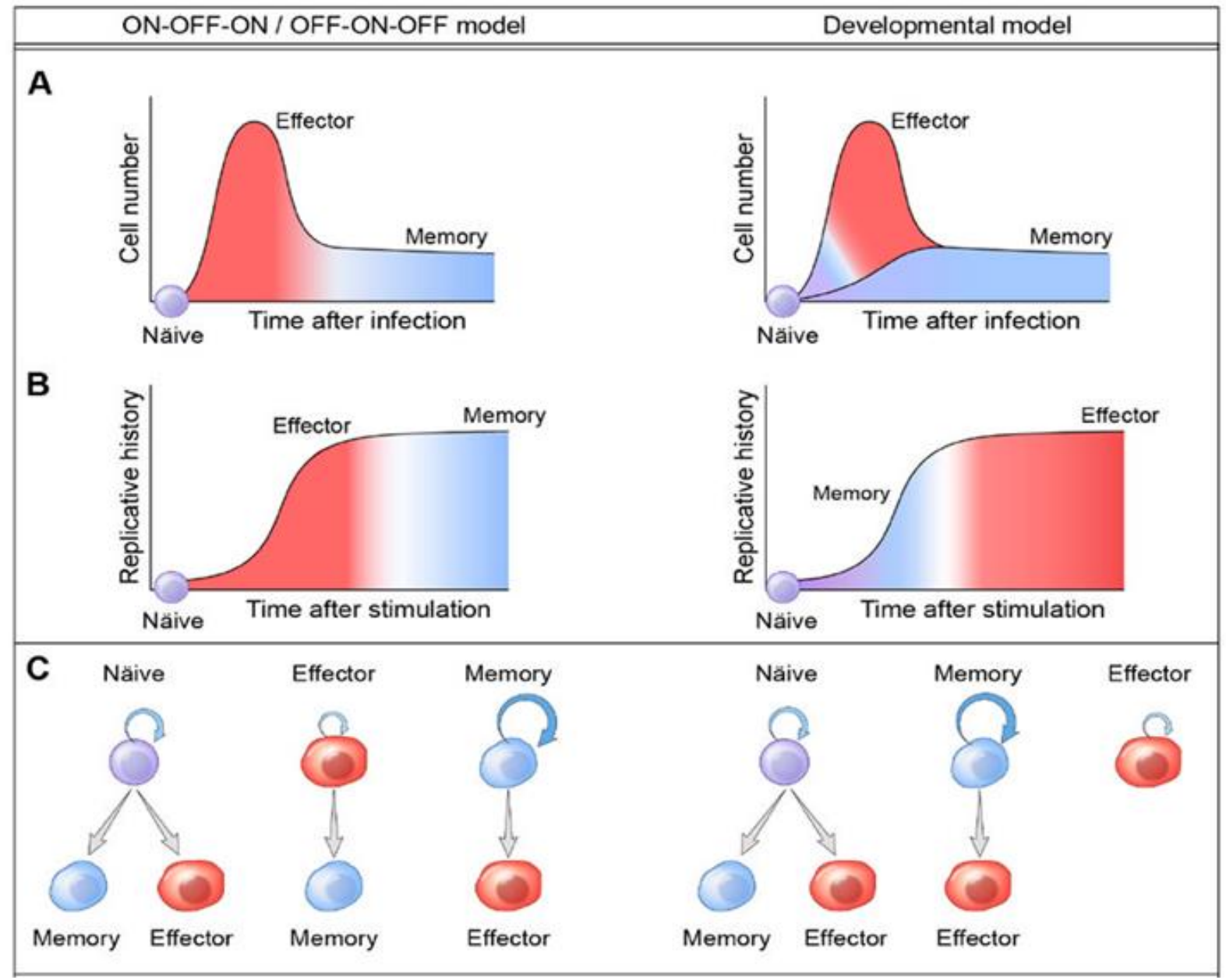

FIG I Two dominant competing models of T-cell differentiation (Restifo and Gattinoni 2013). 
Memory T cells are predominantly quiescent but able to intermittently self-renew and survive long-term in the absence of cognate antigen (Pepper and Jenkins 2011), probably also owing to periodical activation through cross-reactive environmental antigens or selfantigen (Sprent and Surh 2001). Memory T cells are heterogeneous, but the phenotype and function of the different subpopulations are still under discussion. In any case, among the CD4 memory T cells at least two classes have emerged, the central memory (Tcm) and the effector memory $\mathrm{T}$ cells (Tem). The latter express homing receptors that allow the migration to non-lymphoid organs, whereas $\mathrm{Tcm}$, as well as naïve cells, express CD62L and CCR7, involved in the migration through the lymphoid sites (Sprent and Surh 2001). Moreover, both the subsets appear to respond well to antigen stimulation, with the Tem assuming the effector phenotype faster than the Tcm (Restifo and Gattinoni 2013; Sallusto, Geginat, and Lanzavecchia 2004). Finally, there is reason to believe that central memory $\mathrm{T}$ cells can differentiate from suboptimal antigen stimulations during the primary response (Langenkamp et al. 2000; Sallusto et al. 2004).

\subsection{Metabolism and $T$ cell function: the role of glycolysis}

In order that naïve $\mathrm{T}$ cells can comply with the bioenergetic and biosynthetic demands occurring upon their activation due to rapid proliferation, differentiation and effector functions, these cells have to switch their metabolic program from a catabolic state relying mainly on fatty acid oxidation (FAO) and oxidative phosphorylation (OXPHOS) into an anabolic state. Indeed, the effector T-cell metabolism is based mostly on a superior uptake of nutrients such as amino acids, as suggested by evidence of increased glutaminolysis (Griffiths and Keast 1990), and mainly glucose. This sugar is then metabolized by aerobic glycolysis which represents the predominant metabolic pathway in effector cells (MacIver, Michalek, and Rathmell 2013), providing metabolic intermediates for de novo nucleotides and fatty acid synthesis and, however, to OXPHOS that is maintained engaged for a higher production of adenosine triphosphate (ATP) (Wang et al. 2011) (FIG II). In light of the above, T-cell activation and the metabolic reprogramming described above seem to be strictly correlated. One factor playing a major role in this correlation is the phosphoinositide 3-kinase (PI3K)-AKT1-mammalian 
target of rapamycin complex 1 (mTORC1) pathway, which integrates signals coming from TCR engagement, cytokine receptors, CD28 co-stimulation, amino acids and other nutrients with glycolysis up-regulation and metabolic reprogramming, nutrient uptake, biosynthesis, cell growth and cytokine production (Laky et al. 2015) (FIG II).

During memory $\mathrm{T}$ cell development, $\mathrm{T}$ cells revert back to a catabolic state, downregulating aerobic glycolysis and using again mainly FAO and OXPHOS (FIG II). However, differently from naïve $\mathrm{T}$ cells, the memory $\mathrm{T}$ cells present an increased mitochondrial mass (Buck et al. 2016) and therefore a higher spare respiratory capacity (SRC) (Van der Windt et al. 2012) that could promote their long-term survival (Pearce et al. 2009) or even a rapid ATP production upon antigen encounter, favoring in this way the formation of a quick secondary response (Van der Windt et al. 2013). The metabolic switch in memory T cells seems to be dependent on memory T-cell-promoting cytokines like IL15 and IL7 (Van der Windt et al. 2012) rather than on the absence of TCR signalling. An important role in this respect is also played by the function of the AMP-activated protein kinase (AMPK) which is able to inhibit the mTORC1 complex (FIG II) (Schackelford and Shaw 2009). Consistent with these findings are the observations that inhibiting glycolysis with 2-deoxy-D-glucose (2DG) (see below) and blocking mTORC1 with rapamycin enhanced the development of memory T cells (Sukumar et al. 2013; Rao et al. 2010). 


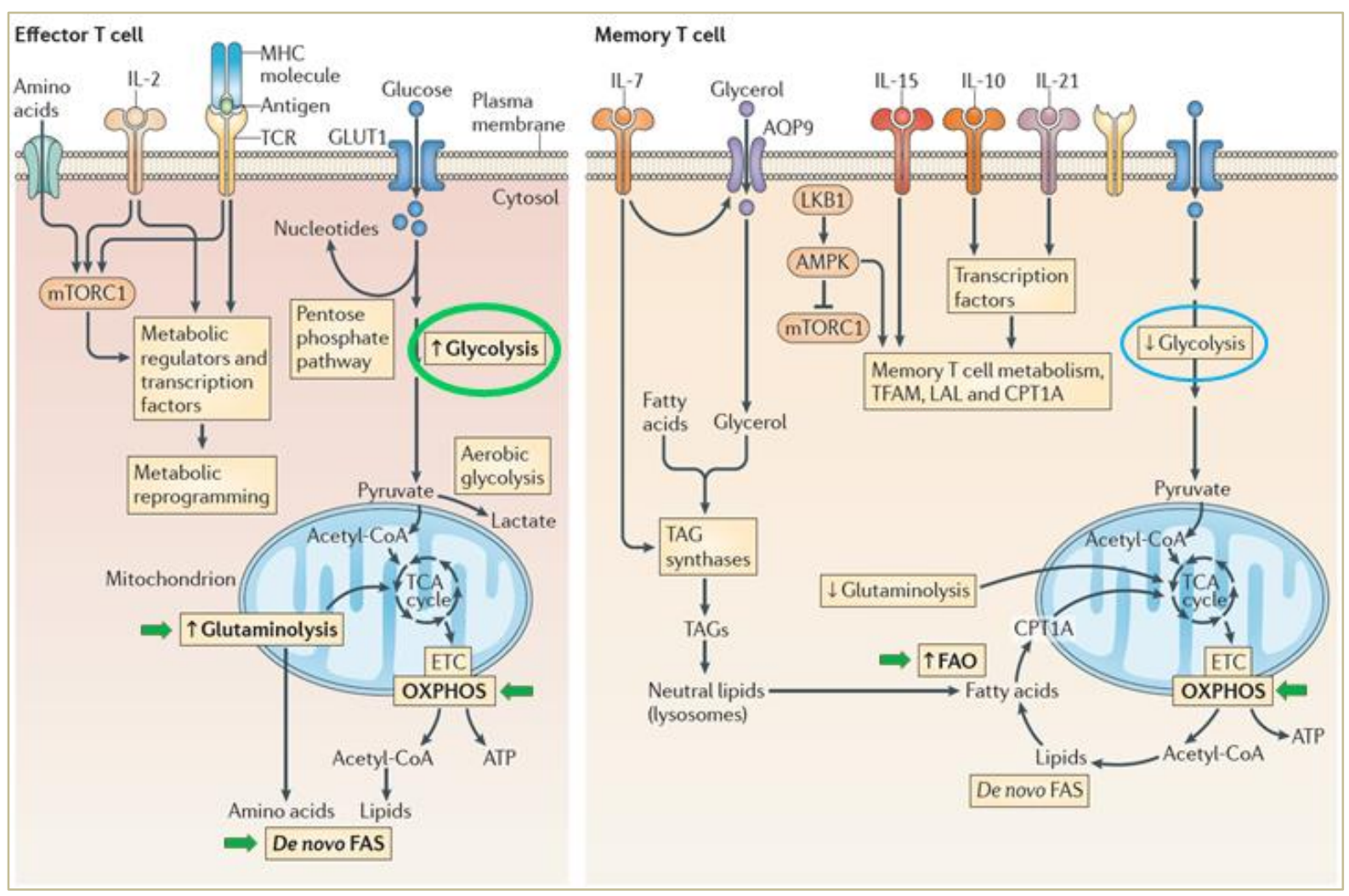

FIG II Metabolic differences between effector and memory T cells (Man and Kallies 2015).

During glycolysis, glucose is transformed into two molecules of pyruvate in a process which does not require oxygen and that generates two molecules of nicotinamide adenine dinucleotide (NADH) and two of ATP. Afterwards, pyruvate can be fully oxidized in the tricarboxylic acid (TCA) cycle. The TCA cycle generates NADH and reduces flavin adenine dinucleotide $\left(\mathrm{FADH}_{2}\right)$ that can be used by the electron transport chain (ETC) to fuel OXPHOS (FIG III), a process dependent upon oxygen that produces 36 ATP molecules per glucose molecule. Alternatively, in absence of oxygen, pyruvate can be transformed into lactate through the activity of the enzyme lactate dehydrogenase A (LdhA), producing $\mathrm{NAD}^{+}$for further use in glycolysis, thereby fueling this pathway (FIG III). From an energetic point of view, utilizing OXPHOS maximizes the quantity of ATP derived from glucose but, as described above, effector T cells engage aerobic glycolysis, characterized by the conversion of pyruvate into lactate despite the availability of oxygen for a complete oxidation via OXPHOS. This process, also called the Warburg effect, is a common feature of the actively proliferating cells (Pearce, Poffenberger, Chang, and Jones 2013).

The fast processing of glucose induced by the Warburg effect (FIG III) allows the effector T cells to generate ATP very quickly and, as described before, provides this type of cell 
with many metabolic intermediates important for proliferation and cell growth. In fact, the metabolism of glucose through the pentose phosphate pathway (PPP) is important for nucleotide synthesis. Moreover, the pyruvate can enter the mitochondria as acetylCoA, forming citrate in the first step of the TCA cycle, but then can be exported to the cytosol where is converted back to acetyl-CoA in order to start the free fatty acid synthesis (FAS). Interestingly, it was observed that inhibiting this pathway to FAS restrains the development of Th17 but favors the induction of regulatory T cells (Berod et al. 2014). Finally, the consequence of using glucose-derived citrate for lipid biosynthesis in the cytosol is the depletion of many metabolites from the TCA cycle. Therefore, in order to avoid mitochondrial dysfunction, the cells engage glutaminolysis that, inducing the formation of $\alpha$-ketoglutarate $(\alpha-K G)$, is able to provide the mitochondria with the TCA cycle intermediates (Pearce, Poffenberger, Chang, and Jones 2013) (FIG III).

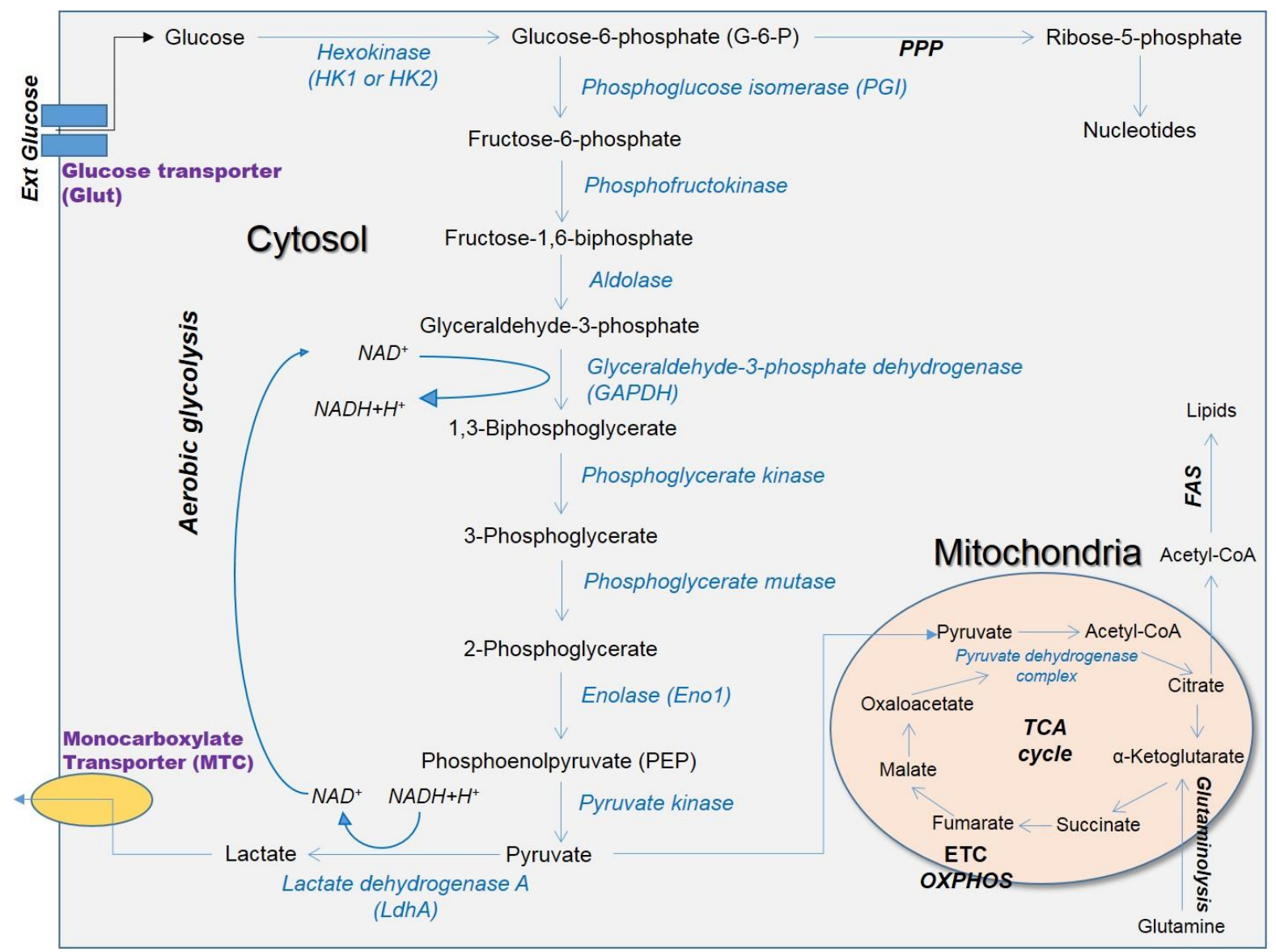

FIG III Schematic view of the metabolism of glucose induced by the Warburg effect. 
The metabolic programs associated with different $\mathrm{T}$ cell functions are regulated by signals coming from TCR engagement and cytokines. In the effector T cells, the signaling cascade of the PI3K-AKT1-mTORC1 pathway induces the expression of glycolysisassociated transcription factors such as Myc (Myc proto-oncogene, bHLH transcription factor), hypoxia-inducible factor $1 \alpha$ (Hif1 $\alpha)$ and interferon-regulatory factor 4 (Irf4) that positively regulate the transcription of glycolytic enzymes or molecules. At the same time, the mTORC1 pathway is responsible for the down-regulation of memory-cell-associated transcription factors like EOMES (eomesodermin) (Man and Kallies 2015) (FIG IV). Myc normally initiates cell division and is responsible for activation-associated glycolysis and glutaminolysis (Wang et al. 2011), Hif1 $\alpha$ sustains glycolysis during T cell proliferation (Dang et al. 2011) and generally is up-regulated in low oxygen conditions; Irf4 was found to be able to stimulate the expression of Hif1 $\alpha$, sustain the glycolysis program and promote the expansion and differentiation of effector $\mathrm{T}$ cells and the maintenance of their effector functions (Man et al. 2013). It could also inhibit the expression of EOMES and, through the induction of BLIMP1, favors the down-regulation of another memory cellassociated transcription factor as well as inhibitor of glycolysis, B cell lymphoma 6 (Bcl6) (Man and Kallies 2015) (FIG IV). 


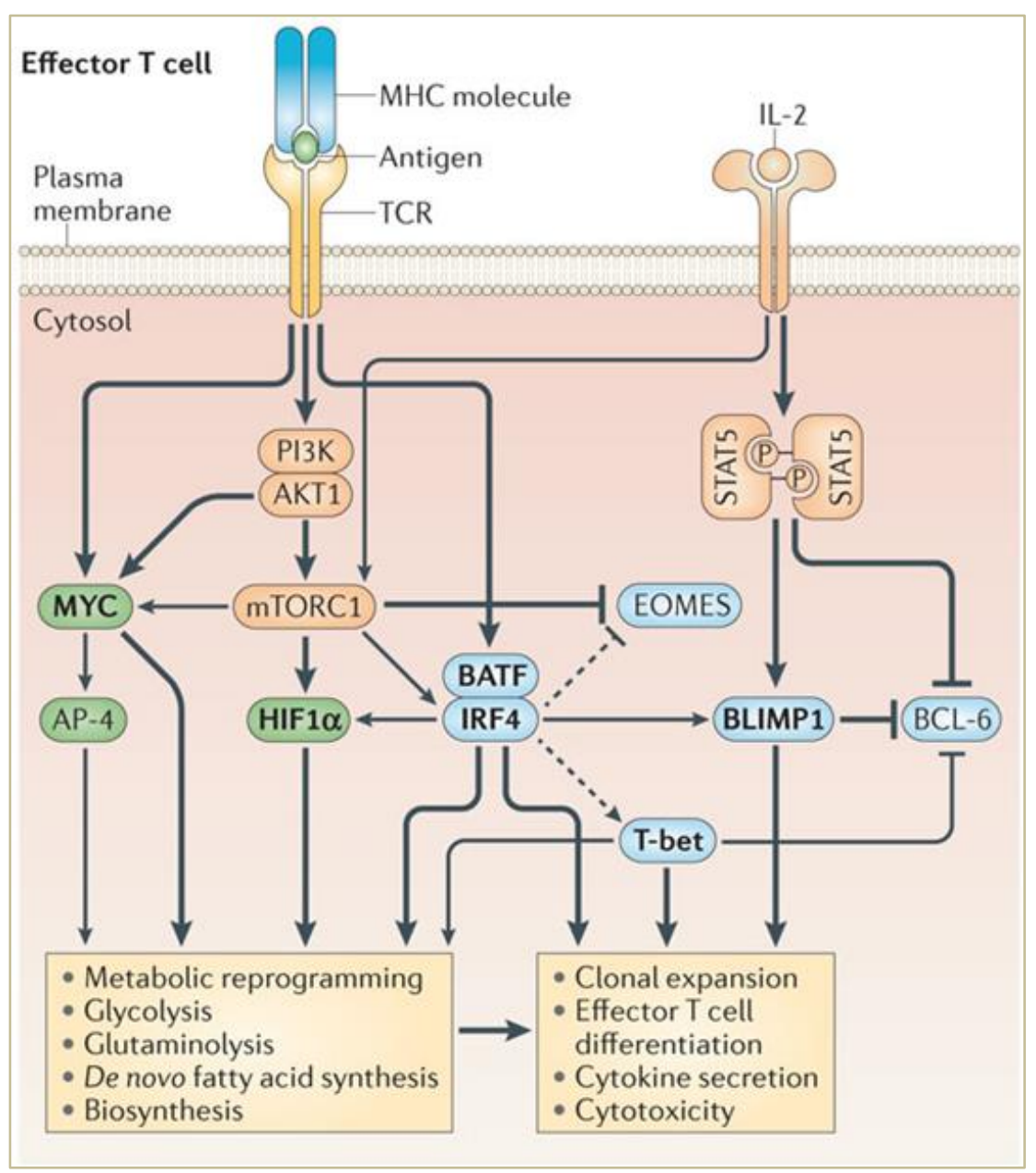

FIG IV Transcriptional regulation of metabolism in effector $\mathrm{T}$ cells.

Cooperation between TCR - IL2 receptor signaling and metabolic transcription factors in the induction of the glycolytic program and effector T cell differentiation (adapted from Man and Kallies 2015).

Recently the store-operated $\mathrm{Ca}^{2+}$ entry (SOCE) was emphasized to play a role in the regulation of aerobic glycolysis after TCR engagement, mainly through the action of the transcription factor NFAT (nuclear factor of activated T cells) on the expression of other transcription factors mentioned above (Vaeth et al. 2017). This regulation depends mainly on $\mathrm{Ca}^{2+}$ release-activated $\mathrm{Ca}^{2+}$ channels (CRAC) located in the plasma membrane. They represent the main source of intracellular of calcium influx upon TCR engagement and are critical for calcineurin activation. Upon TCR stimulation, the production of the second messenger inositol 1,4,5-trisphosphate (IP3) and the opening of IP3 receptor channels in the endoplasmic reticulum (ER) triggers the release of $\mathrm{Ca}^{2+}$ into the cytosol. The subsequent decrease in the $\mathrm{Ca}^{2+}$ concentration in the ER results in the dissociation of $\mathrm{Ca}^{2+}$ from stromal interaction molecules (STIMs) located in the ER membrane. In this way, STIMs bind to and activate CRAC channels in the plasma membrane, leading to a $\mathrm{Ca}^{2+}$ 
influx called store-operated $\mathrm{Ca}^{2+}$ entry because it is regulated by the $\mathrm{Ca}^{2+}$ concentration inside the ER. Afterward, calcineurin is activated by the free cytosolic $\mathrm{Ca}^{2+}$ and in turn induces the nuclear translocation and transcriptional activity of NFAT (Vaeth et al. 2017). Importantly, the metabolic activity can directly regulate the expression of effector molecules. In fact, high glycolytic flux maximizes cytokine production by recruiting glycolytic enzymes such as GAPDH and LdhA that, in conditions of low glycolysis rate, bind regions of mRNA, inhibiting the translation of inflammatory cytokines (Chang et al. 2013; Menk et al. 2018). Moreover, the higher presence of glycolytic metabolites such as phosphoenolpyruvate (PEP) favors the inhibition of sarco/endoplasmic reticulum $\mathrm{Ca}^{2+}$ ATPase (SERCA), responsible of the $\mathrm{Ca}^{2+}$ uptake into the ER. It results in an increase of $\mathrm{Ca}^{2+}$ cytosolic concentration that promotes NFAT nuclear translocation and thereby, elevated cytokine production and tumoricidal activities of T cells (Ho et al. 2015).

In conclusion, there is some evidence for glycolysis being correlated with the $\mathrm{T}$ cell functional state, and for a manipulation of glycolysis during antigen stimulation affecting the differentiation, activation and performance of T-cell effector functions. It was also observed that the nutritional milieu, for instance a low or high glucose concentration in the extracellular space of the area where $T$ cells encounter the antigen, can influence the $\mathrm{T}$ cell activation as a result of changes in the glycolysis rate (Ho et al. 2015).

However, it is still not clear if the cellular level of glycolysis prior to stimulation is able to influence the level of activation of T cells once they encounter the antigen, even in optimal environmental conditions. In other words, we still do not know if the level of glycolysis in $\mathrm{T}$ cells in homeostatic conditions can influence the immune potential of these cells.

\subsection{Multiple sclerosis, an autoimmune disease}

Multiple sclerosis (MS) is a chronic neuroinflammatory demyelinating disease of the central nervous system (CNS). It is a common cause of physical disability in young adults, especially women (Compston and Coles 2008). The average age of disease onset is 30 years and 25 years after diagnosis, approximately $50 \%$ of patients require permanent use of a wheelchair. The symptoms have a very heterogeneous presentation, including sensory and visual disturbances, motor impairments, fatigue, pain and cognitive deficits (Compston and Coles 2008). The variation in clinical manifestations correlates with the 
spatiotemporal dissemination of the lesions within the CNS (Kearney et al. 2015). These lesions are a hallmark of MS and are caused by immune cell infiltration across the bloodbrain barrier (BBB) that promotes inflammation, demyelination, gliosis and neuroaxonal degeneration, leading to disruption of neuronal signalling (Frischer et al. 2009). T cells appear early in lesion formation, therefore MS is classed as an autoimmune disease, initiated by autoreactive lymphocytes mounting aberrant responses against CNS autoantigens, the precise nature of which is still unclear. Three most common forms of disease progression have been defined: relapsing-remitting MS (RR-MS), secondary progressive MS (SP-MS) and primary progressive disease (PP-MS). RR-MS affects $85 \%$ of patients and is characterized by recurring bouts of relapse and remission where relapses coincide with focal CNS inflammation and demyelination. Later, about $80 \%$ of these patients develop SP-MS. During this stage, inflammatory lesions are no longer characteristic, and the progressive neurological decline is accompanied by CNS atrophy. Finally, approximately $10 \%$ of patients are diagnosed with PP-MS, which shows a progressive decline from the outset in absence of relapses (Dendrou, Fugger, and Friese 2015).

The etiology of MS is poorly understood. Several factors have been proposed to contribute to MS pathogenesis including genetic and environmental risk factors. Genetic variation accounts for approximately $30 \%$ of the overall disease risk, and genome-wide association studies identified more than 100 distinct genetic regions associated with multiple sclerosis (Beecham et al. 2013) the majority of which is thought to be immunological, i.e. HLA variants essential for antigen presentation and genes encoding molecules involved in T cell biology such as IL-2R $\alpha$, IL-7R $\alpha$ and CD6 (Gourraud et al. 2012). The environmental factors can possibly trigger the autoreactivity or modulate the activation of the auto-reactive immune cells (Dendrou, Fugger, and Friese 2015). Among them, viral factors like Epstein-Barr virus (Ascherio and Munger 2007; Serafini et al. 2010) and cytomegalovirus, or factors linked to the lifestyle, such as smoking, vitamin D (Belbasis et al. 2015), diet (Yatsunenko et al. 2012) and circadian disruption (Hedström et al. 2011) could contribute to MS by several mechanisms, including the induction of peripheral activation of CNS-reactive $\mathrm{T}$ cells by molecular mimicry and bystander activation, thus facilitating their infiltration into the CNS. Furthermore, the CNS-reactive $\mathrm{T}$ cells could be activated directly in the inflamed CNS by epitope spreading (Harkiolaki et al. 2009; Muenz et al. 2009; McMahon et al. 2005). 
Besides the immunological genetic association with multiple sclerosis, the autoimmune nature of the disease is strongly supported by the evidence of the infiltration of immune cells, including $\mathrm{T}$ lymphocytes, B lymphocytes and macrophages within CNS lesions (Lucchinetti et al. 2000; Serafini et al. 2004) of patients with different MS stages.

It has not been possible to identify a single CNS-protein as a universal target for the autoimmune response in MS. CD4+ T cells reactive to myelin-derived self-antigens such as myelin basic protein (MBP), myelin oligodendrocyte glycoprotein (MOG) and proteolipid protein (PLP) were found in the immune repertoires of both healthy individuals and MS patients (Hohlfeld, Dornmair, Meinl, and Wekerle 2016; Hellings et al. 2001). For those specificities, an increased frequency and activation of $\mathrm{T}$ cells was reported in MS patients (Ota et al. 1990; Pette et al. 1990; Bielekova et al. 2004; TejadaSimon et al. 2001). Aquaporin-4 (AQP4) has been identified as candidate antigen causing B cell responses and production of autoantibodies in neuromyelitis optica (NMO), an inflammatory and demyelinating disease affecting mainly the optic nerve but also the spinal cord (Lennon et al. 2005; Lennon et al. 2004). Interestingly, in NMO lesions a profound loss of $\mathrm{AQP}^{+}$astrocytes could be observed (Brück et al. 2012). An autoantibody response to the potassium channel KIR4.1 was also found in MS patients (Srivastava et al. 2012).

Finally, another convincing piece of evidence about the role played by $\mathrm{T}$ and other immune cells in the pathogenesis of MS is that therapies demonstrating efficacy in MS patients target mainly, or even exclusively, the immune system. Among these treatments, Alemtuzumab, for example, depletes lymphocytes, Teriflunomide inhibits their proliferation, IFN $\beta$ modulates lymphocyte activation and differentiation, Rituximab depletes the B cells and Natalizumab interferes with lymphocyte migration into the CNS.

\subsection{The CNS, an immune privileged organ}

The CNS is considered to be an immune-privileged site, i.e. an area in the body with a decreased immune response to foreign antigens, including tissue grafts (Dendrou, Fugger, and Friese 2015). Thus, the threshold for immune activation in the CNS is higher than in the periphery. This special "privileged" state evolved to provide a balance between the need for immune protection against microbial infections in the CNS and the 
possibility of an irreversible and fatal immune-mediated damage to this tissue. Indeed, the presence of post-mitotic neural cells not able to self-renew but controlling many vital physiologic functions must coexist with mechanisms that reduce dangerous inflammatory reactions threatening the life of the whole organism.

The immune-privileged status of the CNS has been attributed to the parenchymal antiinflammatory milieu, the lack of constitutive MHC class I and II expression, the lower efficiency of CNS-resident APCs in eliciting T cell immune responses (Wlodarczyk et al. 2014; Flügel et al. 1999b) and the presence of periendothelial barriers that prevent the free diffusion of molecules and restrict the leucocyte trafficking in the tissue, including the $\mathrm{BBB}$, the blood-cerebrospinal fluid (CSF) and the blood-leptomeningeal barriers. (Dendrou, Fugger, and Friese 2015; Engelhardt and Ransohoff 2005).

However, even in a healthy CNS, T cells traffic in perivascular, subarachnoid or meningeal spaces, indicating their capacity to take constitutively the CNS under immunesurveillance without disrupting the BBB (Shechter, London, and Schwartz 2013). Consistent with this, blood-derived antigen-presenting cells constitutively expressing MHC class II are localized in the meningeal, ventricular and perivascular spaces in order to present the antigen to the patrolling T cells, whereas microglial cells fulfill this function in the parenchyma and, as observed in MS animal models, can activate CNS-reactive T cells in high inflammatory conditions (McMahon et al. 2005; Lodygin et al. 2013).

Although there is much information about genetic and environmental factors involved in MS pathogenesis and speculation about their role in triggering the onset of the disease, the mechanisms, the circumstances and the elements crucial in the dysregulation of the central and peripheral tolerance and in the stimulation of immune cells to inducing and then maintaining inflammatory events against auto-antigens in the CNS are still to be elucidated. What triggers APCs to start presenting CNS-derived antigens or how a physiological immune-surveillance can turn into an auto-disruptive situation are still unanswered questions. Furthermore, the mechanisms which allow the immune cells to become able to pass through the BBB and induce the pathological autoinflammatory response inside the CNS, i.e. overcoming the high pathogenicity threshold of such immune-privileged organ, are still unclear but could represent potential targets for further therapies.

A possible way to elucidate at least some of these mechanisms and create new concepts is via the aid of animal models. 


\subsection{Experimental autoimmune encephalomyelitis (EAE)}

The limited amount of biological samples derived from MS patients and the impossibility to study the entire course of the disease already starting from the preclinical phase, together with the high heterogeneity of MS, are all factors complicating the study of this disease, in particular, its mechanistic aspects. For this reason, the creation of animal models that can mimic at least some of the pathological events and the symptoms of MS is indispensable.

The first evidence that an immune reaction against CNS components leads to brain inflammation was reported by Rivers in 1928 when he described an epidemics of paralysis among people vaccinated for rabies (Remlinger 1928; Baxter 2007). Afterward, it was observed that immunization with CNS tissue led to the formation of demyelinating lesions in monkeys (Rivers 1935; Schwentker and Rivers 1934). These findings, together with the establishment of an emulsion called complete Freund's adjuvant (CFA) containing lyophilized mycobacterium tuberculosis and paraffin oil, able to facilitate immune responses in host animals, favored the development of CNS inflammation model caused by autoimmune reactions. This animal model was called experimental autoimmune encephalomyelitis (EAE) (Freund and McDermott 1942) and was based on the generation of a peripheral immune reaction against a self-CNS-antigens favoring the formation of auto-reactive activated immune cells able to migrate to the CNS and lead demyelinating inflammatory events. Nowadays EAE represents the classical animal model with which to study autoimmune processes in the CNS. One of the main modalities to induce EAE is named active EAE (aEAE), characterized by the immunization of the experimental animal with myelin proteins in combination with CFA. Active EAE can be induced in several species including primates (Rivers et al. 1933), dogs (Thomas et al. 1950), mice (Olitsky and Yager, 1949) and rats (Lipton and Freund, 1952) Moreover, several antigens can be used for the induction of active EAE. Widely used antigens are myelin components such as MBP, MOG, myelin-associated glycoprotein (MAG) and PLP, but also non-myelin antigens like S-100 $\beta$ expressed primarily in astrocytes and the medium-sized neurofilament (NF-M) for instance (Linington et al. 1988; Piddlesden et al. 1993; Kojima et al. 1994; Kaye et al. 2000).

The genetic background of species and strains, or the nature of antigen can determine the course and the severity of active EAE. For example, commonly used active mouse EAE 
models are the chronic paralytic disease induced by $\mathrm{MOG}_{35-55}$ immunization in the C57BL/6 strain (Mendel et al. 1995) and the PLP139-151-induced relapsing-remitting EAE in the SJL/J strain (Tuohy et al. 1988), whereas the MBP immunization in Lewis rats generates a monophasic EAE course (Lipton and Freund 1953).

An alternative way to induce EAE consists of transferring myelin-specific $\mathrm{T}$ cells into healthy animals (Bell and Paterson 1960), and is called adoptive or passive, or transfer EAE (tEAE). This tEAE model was developed in Lewis rats, where lymphocytes from MBPimmunized animals cultured under CD4+ T cell-favoring conditions and subsequently transferred into syngeneic animals were able to induce a classical EAE course after a defined period of time (Ben-Nun et al. 1981). Today, both Th1 CD4 T cells producing IFN $\gamma$ and Th17 CD4 T cells producing IL-17 are recognized to be important for the EAE induction (Baron et al. 1993; Segal and Shevac 1996; Cua et al. 2003; Zepp, Wu, and Li 2011).

\subsection{Active EAE in Lewis rats}

In Lewis rats, active EAE comes in the form of an acute paralytic disease. It is induced via subcutaneous immunization of naïve rats with guinea pig MBP (or MBP peptide corresponding to aminoacids 68-88) emulsified in CFA. Circa ten days after immunization, Lewis rats develop clinical EAE characterized by loss of body weight as first appearing symptom, followed by paresis of the tail that then ascend to a complete paralysis of the hind limbs and in some cases to a partial paralysis of the front limbs at the peak of the disease. The active EAE course is monophasic so the Lewis rats recover completely a few days after reaching the EAE peak. In total, the whole EAE phase, from the onset to the complete recovery, lasts 8 - 9 days. The development of clinical symptoms is accompanied by CNS infiltration by T cells, phagocytes and other immune cells (Huitinga et al. 1995), primarily detected in the spinal cord. Lewis rats challenged with a second MBP immunization do not develop a second disease bout (Sun et al. 1999). 


\subsection{Transfer EAE in Lewis rats}

The tEAE in Lewis rats is commonly induced by injection of MBP-specific CD4+ effector T cells activated in vitro (FIG V) (Ben-Nun et al. 1981; Wekerle et al. 2008). The onset of disease occurs usually about 3 days (FIG V) after $\mathrm{T}$ cell transfer and the clinical signs and disease course resembles that of aEAE. To evoke inflammation and the development of the pathology, the transferred $\mathrm{T}$ cells transmigrate the $\mathrm{BBB}$ and become reactivated within the CNS, causing an inflammatory milieu and a dysfunction of the BBB (Flügel et al. 2001; Kawakami et al. 2004). These events favor the recruitment of other immune cells including lymphocytes and myeloid cells that together with the ones already inside the tissue contribute to creating an inflammatory environment and thus to demyelination and CNS damage.

One advantage of using the transfer of myelin-specific T cells to evoke EAE is the possibility to genetically engineer these $\mathrm{T}$ cells to express fluorescent markers or other genes (Flügel et al. 1999). Using green fluorescent protein (GFP)-tagged MBP-specific $T$ cell lines generated ex vivo, for instance, it is possible to identify them in vivo during all the phases of tEAE and analyze their behavior, their function and phenotype by combining in vivo imaging and ex vivo characterization (Kawakami et al. 2005b; Bartholomäus et al. 2009; Schläger et al. 2016).

Notably, the clinical signs of tEAE do not occur immediately after $\mathrm{T}$ cell transfer but rather only after a prodromal phase of about 3 days (Wekerle et al. 1994). Owing to the use of engineered fluorescent MBP-specific T cells in tEAE experiments, it was found that soon after transfer the $\mathrm{T}$ cells disappear from the circulation and home directly into the lung for about one day. Afterward, they move to the lung-draining mediastinal lymph nodes (med LNs) and subsequently, sometime between the second and the third day after transfer, re-enter the circulation, move to the spleen and then invade the CNS, mainly the spinal cord (SC) (FIG V) (Odoardi et al. 2012).

It is noteworthy that already in the lung the $\mathrm{T}$ cells switch on their migratory program, upregulating adhesion molecules such as LFA-1 and VLA-4 and chemokine receptors including CXCR3, CXCR4 and S1P1. However, on the other hand, they downregulate their activation factors such as IFN $\gamma$, TNF $\alpha$ and CD25. This reprogramming seems to facilitate the migration of these cells through the BBB and so their access into the SC where they scan environment for local APC-antigen (APC-Ag) complexes. Upon contact with APC-Ag 
the T cells get reactivated and produce inflammatory cytokines (IFN $\gamma, \mathrm{IL}-17, \mathrm{GM}-\mathrm{CSF}$ ) and membranous activation markers (CD25 and OX40) (Lodygin et al. 2013; Odoardi et al. 2012), thus setting up the precondition for the recruitment of other immune cells, the local cascade of inflammatory events and the onset of EAE.

Figure V presents a schematic view of different stages through which MBP-specific T cells proceed before they enter the spinal cord and induce disease. MBP-specific T cells are stimulated with thymocytes as APCs and MBP, in the course of which they switch on an activatory transcriptional response, then cluster and start to proliferate. On the day 2 , when the activatory transcription is completed, they reach the maximal activatory and effector phase that represents the suitable moment for these cells to be intravenously transferred into the animals to ensure induction of EAE. The non-transferred cells keep proliferating massively until the $3^{\text {rd }}$ day and a bit beyond, and then start to reduce proliferation and slowly become resting over time until the next re-stimulation, normally on day 6 or 7 .

After transfer in vivo, the T cells follow the pathway described above and, based on this, FIG V indicates in which organ and on what day it is possible to find the cells in order to analyze them. Finally, on day 3 after transfer, the T cells enter the SC, get reactivated and induce the disease in the Lewis rats (FIG V). 


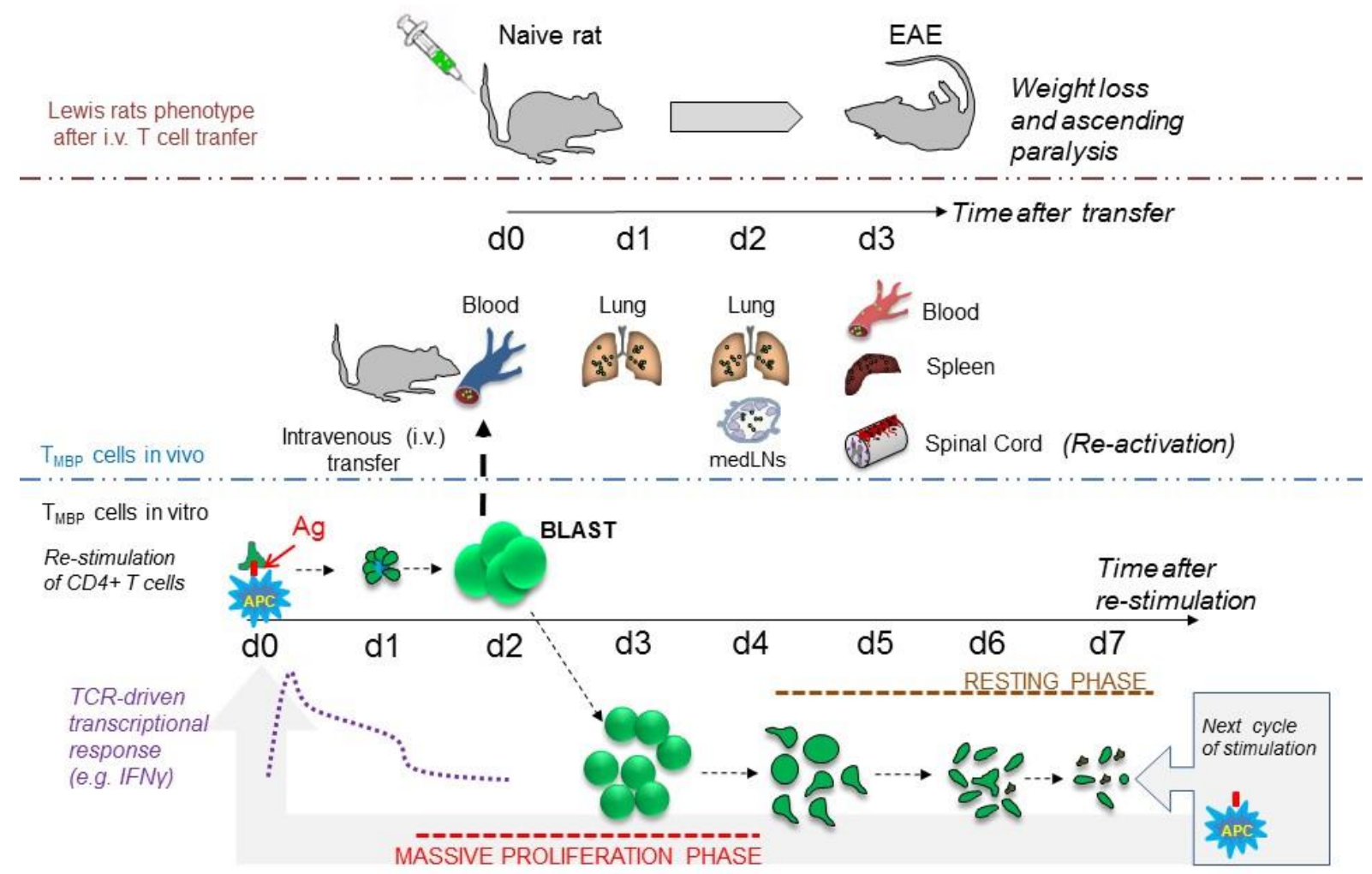

FIG V Life cycle of effector cell line used for transfer EAE in Lewis rats.

Schematic view of a time course of changes that MBP-specific T cells undergo in vitro and in vivo before induction of transfer EAE. SC, spinal cord; medLNs, mediastinal lymph nodes.

\subsection{Generation of TCR transgenic Lewis rats}

Active and transfer EAE in wild-type (WT) Lewis rats are very useful and reliable MS animal models. However, they rely on immune reactions induced by external inputs like MBP immunization with the use of adjuvant and the injection of MBP-specific CD4+ effector T cells activated in vitro, leaving all the endogenous MBP-specific T cells and their functions unavailable for analysis. The generation of transgenic rats in which the majority of T cells express a TCR specific for MBP provides the possibility of studying these autoreactive $\mathrm{T}$ cells in their natural environment, to characterize their phenotype and to analyze their activation and functionality either in the homeostatic condition or during induction of EAE. Furthermore, as observed in different TCR-transgenic mouse strains (Huseby et al. 2001; Bettelli et al. 2003; Pollinger et al. 2009), the fact that transgenic 
animals may develop a spontaneous disease can facilitate the unveiling of factors and mechanisms underlying or influencing the capacity of autoreactive $\mathrm{T}$ cells to differentiate into pathogenic subsets and induce EAE.

In our laboratory two novel TCR transgenic rat strains on Lewis genetic background were generated. One of these, known as rMT-II, standing for rat $\underline{\mathrm{MBP}}$-specific $\underline{\mathrm{T}}$ cell receptor

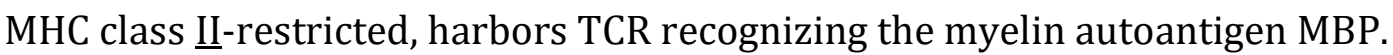

To obtain the DNA sequence for the reconstruction of the T cell receptor specific for MBP, the clonal T cell line Z85 where a variable segment of the $\beta$ chain is known to be V $\beta 8.2$ was used (Chluba et al. 1989). After identification of a matching alpha-chain sequence, a lentiviral construct was generated as shown in (FIG VIA).

The generation of rMT-II rats was achieved by injecting the concentrated lentiviral particles into the perivitelline space of fertilized oocytes. (FIG VIB). The founder animals positive for integration were identified, crossed to WT Lewis to check for germ line transmission and the F1 generation was inter-crossed). This yielded progenies with no, medium or high GFP expression in frequencies fitting to Mendelian laws. Breeding of rats with high GFP expression resulted in animals which were uniformly "high-GFP" suggesting that those rats were homozygous for the rMT-II allele (designated $\mathrm{Tg} / \mathrm{Tg}$ or rMT-II $^{++}$) (FIG VIC).

A

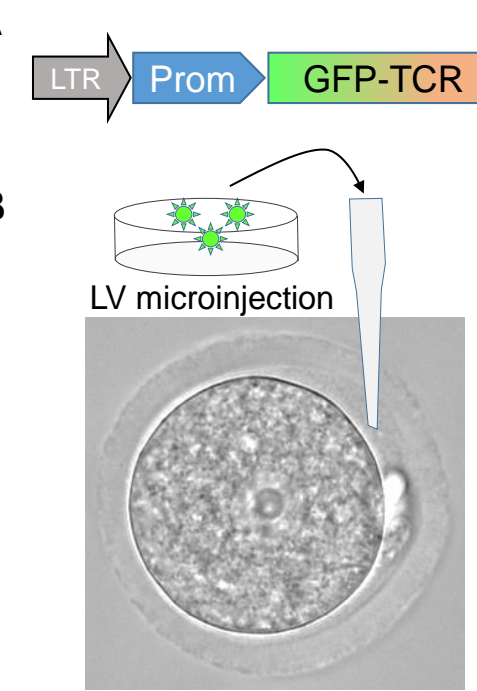

Lewis zygote
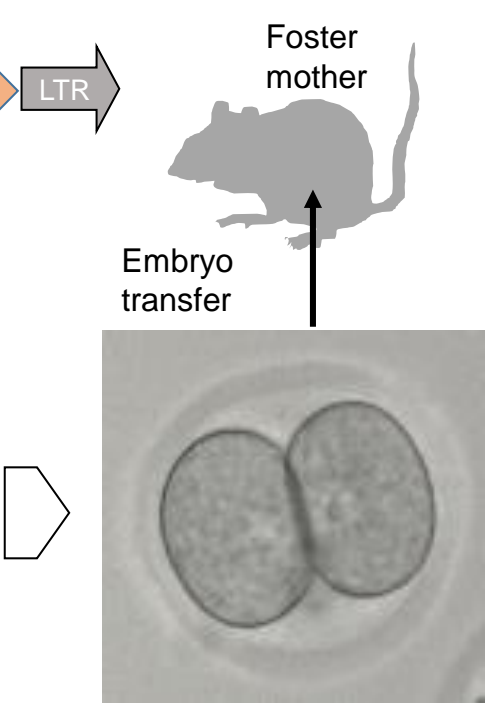

2-cell embryo

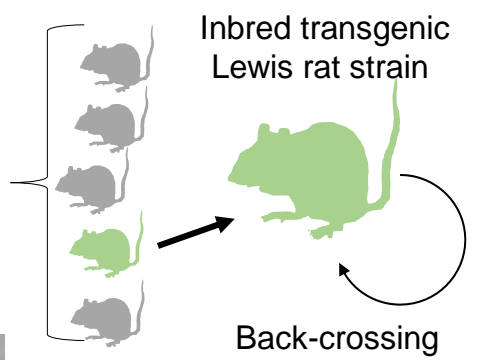

C

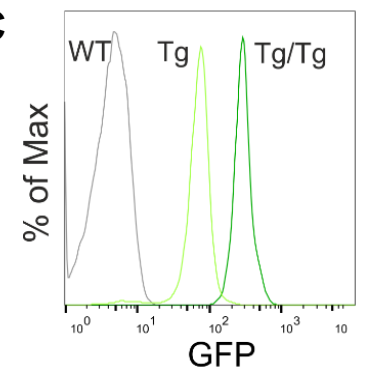

FIG VI Generation of TCR transgenic rMT-II rats (Lodygin, Kitz et al. unpublished).

(A) Schematic view of the lentiviral (LV) expression construct encoding fluorescent marker (GFP) and rat TCR specific for myelin basic protein. (B) Procedure for the formation of rMT-II rats. (C) GFP expression in T cells from homozygous ( $\mathrm{Tg} / \mathrm{Tg}$ ), hemizygous (Tg) rMT-II and non-transgenic (WT) littermates. 
In the secondary lymphoid organs and in the blood of homozygous transgenic rats (rMT$\mathrm{II}^{+/+}$), the CD8+ T cell population was reduced and the vast majority of T cells were CD4+. Moreover, in rMT-II rats were observed naïve and memory CD4 T cell populations, distinguished by the expression of CD62L (L-selectin), being expressed in naïve and down-regulated in memory cells. In fact, although in mice naïve T cells are defined as a CD62L $L^{\text {high }}$ CD44low (Sallusto et al. 1999), in rats CD44 is highly expressed in both naïve and effector/memory $\mathrm{T}$ cells and cannot be used to discriminate them. Instead, it was observed that both CD62L and CD45RC are expressed in naïve rat T cells and become down-regulated upon differentiation into effector or memory $\mathrm{T}$ cells (Bunce and Bell 1997). In contrast, there is some evidence showing that CD62L is expressed in naïve and in central memory T cells, but not in the effector memory ones (Sprent and Surh 2001). In summary, it is possible to conclude that the CD62L+ population could be composed of one portion of naïve cells and another of central memory cells, whereas the CD62Lpopulation is composed only of memory T cells.

Along with rMT-II rats, a control transgenic Lewis rat with a TCR specific for the non-selfantigen chicken egg ovalbumin (OVA) was generated using similar strategy. This strain

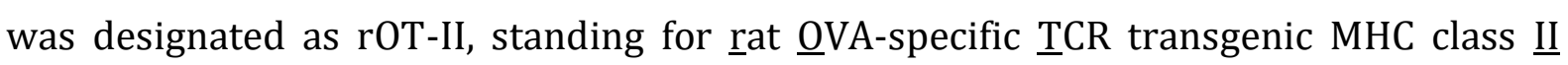
restricted. In the OVA-specific TCR, the variable region of the $\beta$ chain is V $\beta 16$ (FIG VIIA). T cells derived from $\mathrm{rMT}^{-\mathrm{II}^{+/+}}$and $\mathrm{rOT}^{-\mathrm{II}^{+/+}}$(homozygous) but not from WT rats proliferated in response to the respective specific antigen in a dose-dependent manner but did not do so upon stimulation with the non-specific protein. Only a minimal proliferative response was present in hemizygous T cells (bearing a single TCR transgenic allele) at the maximum concentration of antigen. It is noteworthy that $\mathrm{T}$ cell proliferation was abolished in cultures pretreated with OX-6 antibody blocking the rat MHCII complex (FIG VIIB).

Interestingly, only $50 \%$ of the $\mathrm{rOT}^{-\mathrm{II}^{+/-}}$and $12.5 \%$ of the rOT-II ${ }^{+/+}$rats developed $\mathrm{EAE}$ after immunization with MBP in CFA. Therefore, even if most of the T cells in rOT-II rats expressed the OVA-specific TCR, the residual non-transgenic repertoire still retained the capacity to induce EAE by MBP-immunization. However, this observation makes rOT-II rats a useful tool for testing the function of exogenous T cells in an EAE-resistant host. 

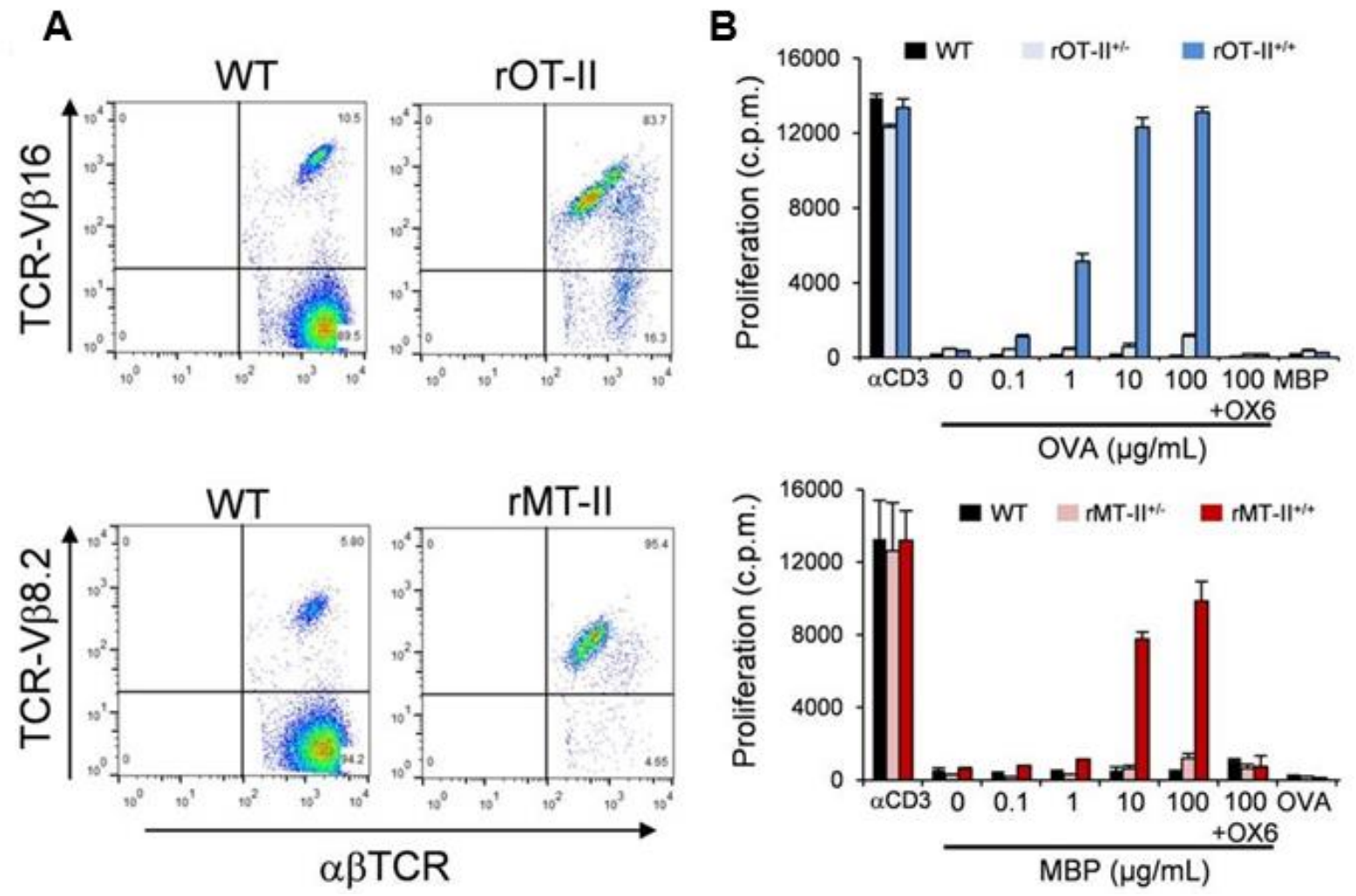

FIG VII T cell specificity in rMT-II and rOT-II rats (Lodygin, Kitz et al. unpublished).

(A) Expression of $\mathrm{V} \beta$-chains in peripheral blood T cells of WT and $\mathrm{rMT}^{-\mathrm{II}^{+/+}}$and $\mathrm{rOT}^{-\mathrm{II}^{+/+}}$rats. Flow cytometry data (gated on $\alpha \beta \mathrm{TCR}^{+}$population).

(B) Proliferation ([$\left.{ }^{3} \mathrm{H}\right]$-thymidine incorporation assay; c.p.m., counts per minute) of WT, $\mathrm{rMT}^{-}-\mathrm{II}^{+/+}, \mathrm{rMT}^{-}-\mathrm{II}^{+/-}$, rOT-II ${ }^{+/+}$, rOT$^{-} \mathrm{II}^{+/-}$lymph node $\mathrm{T}$ cells measured $48 \mathrm{~h}$ after indicated stimulations.

\subsection{Generation of "memory" Lewis rats}

In order to study the function of MBP-specific memory CD4 T cells in Lewis rats, Kawakami et al. generated so called "memory rats" characterized by the lifelong persistence of encephalitogenic $\mathrm{T}$ cell clones in healthy immune repertoires (Kawakami et al. 2005). To this end, effector CD4 T cells specific for MBP retrovirally engineered to express GFP were injected intraperitoneally (i.p.) into newborn syngeneic Lewis pups. The $\mathrm{T}$ cell lines were i.p. transferred $4-5$ days after antigen restimulation in vitro. Interestingly, these cells persisted lifelong in the host animals, even if in low numbers. They were found in all the lymphoid organs, in the blood and also in other non-immune organs and, noteworthy, maintained a memory phenotype with low levels of CD62L and CD45RC surface expression. Moreover, they did not affect the health of the hosts, i.e. they 
did not provoke any spontaneous clinical signs. However, "memory" rats exhibited an earlier onset of MBP/CFA-induced aEAE compared to the WT counterparts (FIG VIIIA), confirming the functionality of the memory T cells. Furthermore, "memory" rats showed a pathogenic reaction against an immunization with MBP/IFA (incomplete Freund's adjuvant), a regimen that failed to induce EAE in WT animals (FIG VIIIB) (Kawakami et al. 2005).

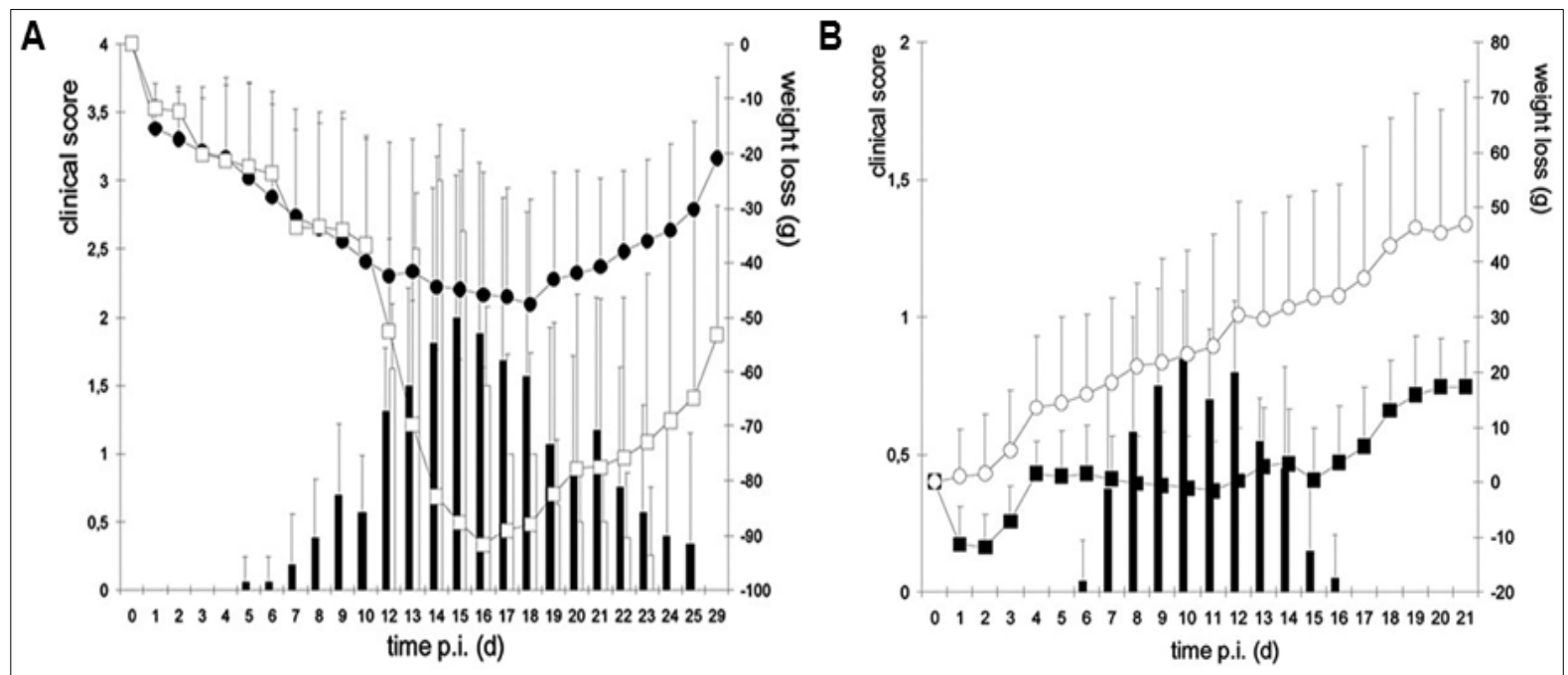

FIG VIII Active EAE induction in "memory" rats.

(A) EAE induction by MBP/CFA. (B) EAE induction by MBP/IFA. (A,B) Clinical score (left $y$-axis, bars) and weight changes (right $y$-axis, curves) of memory animals (black) and age-matched non-memory control rats (white) (Kawakami et al. 2005). 


\section{AIMS}

MBP-reactive T cells were detected in the blood of healthy humans yet had not caused autoimmune disease (Hohlfeld, Dornmair, Meinl, and Wekerle 2016). Presumably, these auto-reactive $\mathrm{T}$ cells need particular circumstances and the manifestation of extrinsic and/or intrinsic factors in order to trigger their activation and pathogenicity and contribute to the onset of autoimmune diseases. In order to investigate the factors and the mechanisms underpinning the activation of latent MBP-reactive T cells, we decided to exploit the properties of TCR transgenic rMT-II and "memory" Lewis rats. Interestingly, as previously indicated (Kavakami et al. 2005), EAE does not occur spontaneously in either of these two models, even though these animals are highly susceptible to EAE induced by active immunization. As shown in FIG 1, rMT-II rats did not show any further aggravation of the transfer EAE compared to WT rats. These findings prompted us to analyze in details the phenotype and encephalitogenic properties of $\mathrm{T}$ cells in different compartments and at different time points in rMT-II TCR transgenic and $\mathrm{T}_{\mathrm{MBP}}$-memory animals subjected to active or passive induction of neuroinflammatory disease. Furthermore, we decided to focus on the metabolic pathways, mainly on the glycolysis, which had been previously shown to distinguish various subsets of T cells (naïve versus effector, effector versus memory etc.) and to be important for modulating their functions. One of the central questions of the project was whether the glycolytic rate set by the preceding antigenic stimulation in the periphery (or in vitro) may directly affect the potential of $\mathrm{T}$ cells to become re-activated inside the CNS and thus contribute to the pathogenesis of EAE. 


\subsection{Buffers}

\begin{tabular}{|c|c|}
\hline Buffer & Composition \\
\hline 10X Phosphate buffered saline (PBS) & $\begin{array}{l}80 \mathrm{mM} \mathrm{Na}_{2} \mathrm{HPO}_{4} \\
1.5 \mathrm{M} \mathrm{NaCl} \\
20 \mathrm{mM} \mathrm{KH}_{2} \mathrm{PO}_{4} \\
30 \mathrm{mM} \mathrm{KCl} \\
\text { pH } 7.4\end{array}$ \\
\hline 1X PBS & $10 \times$ PBS diluted ten times in distilled water \\
\hline $\begin{array}{l}\text { ACK (Ammonium chloride } \\
\text { potassium) buffer }\end{array}$ & $\begin{array}{l}0.15 \mathrm{M} \mathrm{NH}_{4} \mathrm{Cl} \\
10 \mathrm{mM} \mathrm{KHCO}_{3} \\
0.1 \mathrm{mM} \text { Ethylenediaminetetraacetic acid } \\
\text { (EDTA) }\end{array}$ \\
\hline $\begin{array}{l}\text { Fluorescence-activated cell sorting } \\
\text { (FACS) buffer }\end{array}$ & $\begin{array}{l}0.5 \% \text { Bovine serum albumin (BSA) } \\
0.05 \% \text { Natrium acide } \\
\text { in PBS }\end{array}$ \\
\hline $\begin{array}{l}\text { Magnetic-activated cell sorting } \\
\text { (MACS) buffer }\end{array}$ & $\begin{array}{l}2 \mathrm{mM} \text { EDTA } \\
2 \% \text { Fetal calf serum (FCS) (Biochrom AG, } \\
\text { Berlin, Germany)) } \\
\text { in } 1 \mathrm{X} \text { PBS }\end{array}$ \\
\hline Washing buffer (for ELISA) & $0,05 \%$ Tween-20 in $1 \mathrm{X}$ PBS \\
\hline Blocking buffer (for ELISA) & $10 \%$ FCS in $1 \mathrm{X}$ PBS \\
\hline Isotonic Percoll & $\begin{array}{l}\text { 90\% Percoll (GE Healthcare) } \\
\text { 10\% 10X PBS }\end{array}$ \\
\hline
\end{tabular}

Table 1 Basic buffers and composition.

When not specified, all the components of the buffers were purchased from CARL ROTH Gmbh, Karlsruhe, Germany. 


\subsection{Primary T cell culture}

\subsubsection{Media composition}

\begin{tabular}{|c|c|}
\hline Media & Composition \\
\hline $\begin{array}{l}\text { Dulbecco's Modified } \quad \text { Eagle's } \\
\text { medium (DMEM) }\end{array}$ & $\begin{array}{l}\text { Gibco DMEM Powder (Invitrogen, Carlsbad, USA) } \\
1.2 \mathrm{~g} / \mathrm{l} \mathrm{NaHCO} 3 \text { (Carl Roth, Karlsruhe, Germany) }\end{array}$ \\
\hline Eagle's HEPES medium (EH) & $\begin{array}{l}\text { DMEM } \\
25 \text { mM Gibco Hepes (Invitrogen, Carlsbad, USA) }\end{array}$ \\
\hline T cell medium (TCM) & $\begin{array}{l}\text { DMEM } \\
1 \% \text { Gibco non-essential amino acids (Invitrogen, Carlsbad, USA) } \\
1 \% \text { Gibco sodium pyruvate (Invitrogen, Carlsbad, USA) } \\
1 \% \text { Gibco Penicillin/Streptomycin (Invitrogen, Carlsbad, USA) } \\
1 \% \text { L-glutamine (Pan Biotech GmbH, Aidenbach, Germany) } \\
1 \% \text { Asparagine Monohydrate (Sigma Aldrich, Munich, Germany) } \\
4 \mu \mathrm{l} / \mathrm{L} \beta \text {-mercaptoethanol (stock 13,6M, Invitrogen, Carlsbad, } \\
\text { USA) }\end{array}$ \\
\hline Restimulation medium (RM) & $\begin{array}{l}\text { TCM } \\
1 \% \text { rat serum }\end{array}$ \\
\hline T cell growth factor (TCGF) & $\begin{array}{l}\text { TCM } \\
10 \% \text { horse serum (Biochom Ag, Berlin, Germany) } \\
5 \% \text { Conditioned medium from mouse splenocytes treated with } \\
\text { the mitogen concanavalin A (Rosenberg et al. 1978) (Sigma } \\
\text { Aldrich, Munich, Germany) }\end{array}$ \\
\hline Freezing medium & $\begin{array}{l}\text { TCM } \\
50 \text { - } 80 \% \text { horse serum (Biochom Ag, Berlin, Germany) } \\
10 \% \text { DMSO (Carl Roth GmbH, Karlsruhe, Germany) }\end{array}$ \\
\hline Glucose-free DMEM & Gibco DMEM deprived of glucose (Life technologies) \\
\hline $\begin{array}{l}\text { Galactose + } 2 \text { Deoxy-D-glucose (2- } \\
\text { DG) TCM }\end{array}$ & $\begin{array}{l}\text { Glucose-free DMEM } \\
1 \% \text { Gibco non-essential amino acids } \\
1 \% \text { Gibco sodium pyruvate } \\
1 \% \text { Gibco Penicillin/Streptomycin } \\
1 \% \text { L-glutamine } \\
1 \% \text { Asparagine Monohydrate } \\
4 \mu \mathrm{l} / \mathrm{L} \beta \text {-mercaptoethanol } \\
\text { 22,7mM D-(+)-Galactose (Sigma Aldrich, Munich, Germany). The } \\
\text { concentration is equivalent to that of glucose in DMEM. } \\
5 \mathrm{mM} \text { 2-DG (Carbosynth, Compston, Berkshire, UK) }\end{array}$ \\
\hline Galactose + 2-DG RM & $\begin{array}{l}\text { Galactose }+2 \text {-DG TCM } \\
1 \% \text { rat serum }\end{array}$ \\
\hline Galactose + 2-DG TCGF & $\begin{array}{l}\text { Galactose + 2-DG TCM } \\
10 \% \text { horse serum (Biochom Ag, Berlin, Germany) } \\
5 \% \text { Conditioned medium from mouse splenocytes treated with } \\
\text { the mitogen concanavalin A (Sigma Aldrich, Munich, Germany) }\end{array}$ \\
\hline
\end{tabular}

Table 2 Media and composition. 


\subsubsection{Culture of packaging cells}

GP+E86 (mouse fibroblasts) packaging cells, producing a replication-deficient GFP or mCherry (red fluorescent protein) fluorescent protein retrovirus, were used to transduce $\mathrm{T}$ cells. The retroviral vector for the gene transfer promotes the transfer of a resistance to the neomycin derivative G418 (Invitrogen) or puromycin (Roth) (Flügel et al. 1999) All the processes described here and during all the primary $\mathrm{T}$ cell culture generation procedure were performed under a laminar flow (Laminar Flow Hera Safe, from Heraeus). Before co-culturing with primary T cells, packaging cells were cultured in TCM $+10 \%$ FCS and G418 $(0,4 \mathrm{mg} / \mathrm{ml})$ or puromycin $(2 \mu \mathrm{g} / \mathrm{ml})$ depending on the resistance of the cells in T75 flasks (Sarstedt). They were kept under $5 \%$ CO2 humidified atmosphere in an incubator (Thermo Scientific) at $37^{\circ} \mathrm{C}$.

Upon reaching a confluence of about $80 \%$ the packaging cell lines were split. To that end, the cells were washed with 1 X PBS and then incubated for 1 - 2 minutes with the endopeptidase trypsin (PAA) diluted 1:10 with PBS (from a 10X stock solution).

The digestion process by trypsin was stopped by TCM $+10 \%$ FCS. Afterwards, the cells were centrifuged for $6 \mathrm{~min}$ with $1200 \mathrm{rpm}$ at $4^{\circ} \mathrm{C}$ to remove trypsin residues. After centrifugation, the supernatant was discarded and the pellet resolved in TCM $+10 \%$ FCS and $2 \mu \mathrm{g} / \mathrm{ml}$ puromycin or $0.1 \mathrm{mg} / \mathrm{ml} \mathrm{G} 418$, depending on the cell line. Before co-culture with primary $\mathrm{T}$ cells, the packaging cells were cultured for about 2 days without any specific selection agent.

\subsubsection{Primary T cell cultures}

The process used to generate MBP-reactive CD4+ T cells retrovirally engineered to express fluorescent proteins (GFP or mCherry) is reported in the literature (Flügel et al. 1999).

As a first step, naïve female Lewis rats (8 to 10 weeks old) were immunized with MBP in CFA (see below). MBP was isolated from the brain of guinea pig as already described (Eylar et al. 1974).

Cells were harvested from the draining lymph nodes (LNs) of immunized animals (popliteal, inguinal and para-aortal LNs) on day 10 after immunization, corresponding to the preclinical phase of the disease. 
Briefly, the LNs were minced and separated through a metal mesh in EH medium. The cell suspension was spun down $\left(1200 \mathrm{rpm}, 8 \mathrm{~min}, 4^{\circ} \mathrm{C}\right)$ and the cell pellet was washed with EH medium.

On the same day, packaging cells were seeded into round-bottom 96-well plates (Nunc, Thermo Fischer Scientific Inc., Waltham, US) at a concentration of 15,000 cells/well in $100 \mu \mathrm{l} \mathrm{RM}$.

The LN cells were added to the 96-well plates containing GPE at a concentration of 200.000 cells/well, with the addition of $8 \mu \mathrm{g} / \mathrm{ml}$ MBP. Two days afterwards, $50 \mu \mathrm{l}$ of TCGF medium were added to the cells and, if necessary, supplemented with antibiotics for cell selection.

On day 3 or 4, $50 \mu \mathrm{l}$ of medium per well were removed and the cells were moved into flat bottom 96-well plates (Nunc, Thermo Fischer Scientific Inc., Waltham, US). Afterwards, $100 \mu \mathrm{l}$ of fresh TCGF containing G418 $(0.4 \mathrm{mg} / \mathrm{ml})$ or puromycin $(1 \mu \mathrm{g} / \mathrm{ml})$ were added into each well.

On day 7, the first stimulation of T cells was performed: As a first step, $100 \mu$ l of medium per well were removed and subsequently $1.4 \times 10^{6}$ irradiated syngeneic thymocytes (30 Gy irradiation), used as antigen presenting cells, were added into each well, diluted in $100 \mu \mathrm{RM}$ in the presence of $8 \mu \mathrm{g} / \mathrm{ml} \mathrm{MBP}$.

Two days after re-stimulation, TCGF $(50 \mu \mathrm{l})$ was added into each well together with antibiotics in order to support selection and T cell proliferation.

On day 3 after re-stimulation, the wells with the best viral transduced T cells (measured by fluorescence intensity and the best growth capacity) were chosen and pooled into 60 mm Petri dishes (Sarstedt) where they were kept until the next re-stimulation on day 7. To be restimulated, $3.5 \times 10^{6} \mathrm{~T}$ cells were mixed with $70 \times 10^{6}$ irradiated syngeneic thymocytes and $8 \mu \mathrm{g} / \mathrm{ml}$ antigen in $5 \mathrm{ml} \mathrm{RM}$ per $60 \mathrm{~mm}$ Petri dish. On day 2, TCGF medium (about $2 \mathrm{ml}$ per dish) was supplied to support the proliferation of the cells.

In order to maintain an optimal density, T cells were transferred into $100 \mathrm{~mm}$ culture Petri dishes on day 3 and split further when necessary.

Further cycles of re-stimulation were performed to increase the number of $\mathrm{T}$ cells for the maintenance of the cell line. The MBP-specific CD4+ T cell lines expressing GFP or mCherry were called respectively $\mathrm{T}_{\mathrm{MBP}}$ GFP and TMBP mCherry cells. 


\subsubsection{Cryo-conservation of the $\mathrm{T}$ cell line}

For cryo-conservation, $10-30 \times 10^{6} \mathrm{~T}$ cells were pelleted and then resuspended in $1.5 \mathrm{ml}$ freezing medium on days 2, 6 or 7 after restimulation and aliquoted in cryotubes (Nunc, Thermo Fischer Scientific Inc., Waltham, US). These tubes were placed in freezing containers for cryo-conservation (Nunc, Thermo Fischer Scientific Inc., Waltham, US) and frozen at $-80^{\circ} \mathrm{C}$. For long-term storage T cells were transferred into liquid nitrogen.

\subsubsection{Thawing of cryo-conserved T cells}

Cryo-conserved T cells were taken out of the liquid nitrogen and the cryotubes were kept for a few minutes at room temperature or incubated at $37^{\circ} \mathrm{C}$ in a water bath. Afterward, the cell suspension was diluted 1:10 in EH $+10 \%$ FCS, the $\mathrm{T}$ cells were counted, centrifuged and then used for further analyses or experiments.

\subsection{6 $\mathrm{T}$ cell counting}

The number of cells within a cell suspension was determined using a Neubauer hemocytometer (TH Geyer). The cell suspension was diluted in trypan blue (Sigma Aldrich, Munich, Germany) and then $10 \mu \mathrm{l}$ of the dilution were applied to the hemocytometer. The living cells were counted within the four quadrants of the grid and the total cell number was calculated using the following equation:

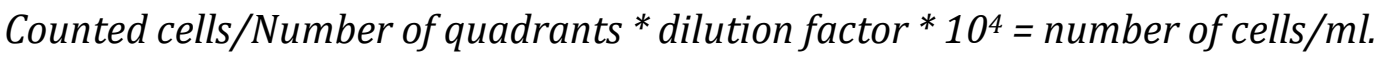

\subsection{Cell isolation from different Lewis rat organs}

Rats were sacrificed by $\mathrm{CO}_{2}$ inhalation. The animal abdomen and chest were cut open from the ventral side of the body. Blood was collected directly from the heart of the animal by a syringe (BBraun, Omnifix) prefilled with $250 \mu$ EDTA $80 \mathrm{mM}$ and kept at room temperature until further processing. Moreover, several lymph nodes (cervical, popliteal, inguinal, para-aortal, mediastinal), the small intestine from the gut, and the spleen were extracted. Afterward, the animal was cut open from the dorsal side of the body and the vertebral column was dissected and cut open in order to expose the spinal 
cord (SC) which was then removed. The meninges was stripped off the spinal cord and kept separately it.

The skull of the animal was cut from the occipital to the frontal bone in a rostral direction and then removed. The brain was then extracted and the meninges stripped off and kept separately.

All the dissected organs were kept on ice in EH medium. Finally, in order to measure the number of $\mathrm{T}$ cells inside the organs, the different tissues were weighed before being processed.

Blood. Isolation of lymphocytes from blood was obtained by a density gradient based on Ficoll and sodium diatrizoate (Lymphocyte Separation Medium, Lonza, Walkersville, US): the blood was diluted with PBS $1 \mathrm{X}$ up to $10 \mathrm{ml}$ and then gently placed above a layer of 5 $\mathrm{ml}$ lymphocyte separation medium (LSM 1077) in a $14 \mathrm{ml}$ tube (Greiner Bio-One). The sample was centrifuged for $30 \mathrm{~min}$ with $2000 \mathrm{rpm}$ at room temperature with minimal acceleration/deceleration. Afterwards, the lymphocyte interphase, visible as a ring in the clear fraction of the gradient, was collected and placed into a new tube. After washing with PBS $1 \mathrm{X}$ the cells were resuspended in $1 \mathrm{ml} \mathrm{EH}$ medium. When necessary, in order to better purify the lymphocyte population we performed erythrolysis. To this end, after the washing step, the cells were incubated in $1 \mathrm{ml} \mathrm{ACK}$ buffer on ice for 3 minutes, washed again with PBS $1 \mathrm{X}$ and resuspended in EH medium.

Spleen. A single cell suspension was prepared by smashing the spleen through a metal mesh (provided by UMG Göttingen, in-house machine shop) in EH medium. The homogenized organ was centrifuged for 6 minutes with $1200 \mathrm{rpm}$ at $4{ }^{\circ} \mathrm{C}$. Afterward, the cell pellet was incubated on ice for $3 \mathrm{~min}$ in $5 \mathrm{ml}$ of ACK buffer in order to lyse the erythrocytes, then washed with $50 \mathrm{ml}$ PBS $1 \mathrm{X}$ and resuspended in $10 \mathrm{ml}$ EH medium, filtered through a $70 \mu \mathrm{m}$ cell strainer (Greiner Bio-One), centrifuged and suspended again in $5 \mathrm{ml} \mathrm{EH}$ medium for further analyses.

Lymph nodes. The isolation of cells from the LNs was achieved by smashing them through the metal grid in EH medium, centrifuging the flow-through for 6 minutes with $1200 \mathrm{rpm}$ at $4{ }^{\circ} \mathrm{C}$ and resuspending the cell pellet in $1 \mathrm{ml} \mathrm{EH}$ medium.

CNS parenchyma and meninges. The isolation of cells from CNS (spinal cord or brain) parenchyma or meninges was achieved by a Percoll gradient. The organs were smashed 
through a metal grid, suspended in $12.5 \mathrm{ml}$ of cold EH medium and vigorously mixed with $5 \mathrm{ml}$ of isotonic Percoll (1.124 g/L density) in a $50 \mathrm{ml}$ tube (Greiner Bio-One). The cell suspension was centrifuged for 30 minutes with $2780 \mathrm{rpm}$ at room temperature with minimal acceleration/deceleration. After one washing step in $50 \mathrm{ml}$ PBS 1X, the cells were resuspended in $1 \mathrm{ml} \mathrm{EH}$ medium for further analyses.

In order to count the T cells present inside the CNS in naïve conditions, we needed to remove the blood to avoid interference with such a small number of cells. For this purpose, after euthanizing the rat with $\mathrm{CO}_{2}$, the heart was exposed and deprived of the pericard. We performed an incision in the left ventricle where a cannula connected to a pump via flexible tubes (ISM596B, Ismatec, Wertheim, Germany) was inserted and fixed with a clamp. Finally, we performed another incision in the right atrium to intercept the blood circulation and started to pump PBS $1 \mathrm{X}$ through the cannula at a flow-rate of $10.71 \mathrm{~m} / \mathrm{s}$ to flush out the blood.

Gut. The extraction of the small intestine and the isolation of intraepithelial lymphocytes (IEL) was performed as previously described (Reißig et al. 2014), through a procedure involving the combination of mechanical dissociation and enzymatic degradation of extracellular adhesion proteins.

\subsubsection{T cell magnetic activated cell sorting (MACS) isolation}

In the case of intrathecal injection or intravenous transfer of rMT-II T cells, or to improve the FACS sorting efficacy and velocity of fluorescent T cells, we performed MACS T cell isolation using two different kits: MACS Miltenyi Biotec for positive T cell selection, and EasySep Rat CD4+ T cell isolation kit (Stemcell technology) for negative selection.

MACS Miltenyi Biotec (positive selection). The cells just extracted from the organs and suspended in EH medium were counted to ensure they were in the range between $10^{7}$ and $10^{8}$ per organ. Afterwards, they were spun down and each cell pellet was incubated with $80 \mu \mathrm{l}$ Pan T cell (OX52) microbeads in $1100 \mu \mathrm{l}$ MACS buffer for 20 minutes at $4^{\circ} \mathrm{C}$. After centrifugation for 10 minutes with $300 \mathrm{xg}$ at $4^{\circ} \mathrm{C}$, the pellet was resuspended in $1 \mathrm{ml}$ MACS buffer and the suspension applied into a MACS LS column previously rinsed with buffer and placed on a magnetic separator. Subsequently, the column was washed 4 or 5 times with $1 \mathrm{ml}$ of MACS buffer and the flow-through discarded. In the end, the column was removed from the magnetic separator and $5 \mathrm{ml}$ of MACS buffer were pipetted onto it 
so that the magnetically labeled T cells could be flushed out by pushing a plunger into the column and then collected in a new collection tube.

EasySep Rat CD4+ T cell isolation kit (negative selection). Firstly, the cells extracted from blood, spleen and LNs were counted. After centrifugation, they were then resuspended in MACS buffer with a ratio of $5^{*} 10^{7}$ cells $/ \mathrm{ml}$ and collected into a $14 \mathrm{ml}$ tube. Afterwards, the supplied isolation cocktail for CD4 $\mathrm{T}$ cell negative isolation was added in a concentration of $25 \mu \mathrm{l} / \mathrm{ml}$. After 10 minutes of incubation at room temperature, the supplied Vortex RapidSpheres were added to the sample $(25 \mu \mathrm{l} / \mathrm{ml})$ which in turn was topped up with MACS buffer to 5 or $10 \mathrm{ml}$, depending on the initial volume (to $5 \mathrm{ml}$ for samples $\leq 2 \mathrm{ml}$; to $10 \mathrm{ml}$ for samples $>2 \mathrm{ml}$ ). Immediately after this the tube was placed right into a magnet (EasySep magnet, Stemcell Technologies Inc) for 3 minutes at room temperature. Finally, the enriched $\mathrm{T}$ cell suspension was poured into a new collection tube and used for further experiments or analyses.

\subsection{Characterization of $T$ cell phenotype and activation}

The cells were analyzed directly after isolation from organs or after being harvested from culture in Petri dishes, in order to ascertain their phenotype or their activation by antibody-staining for cell surface markers. In addition, T cells were also sorted by FACS and collected for gene expression and protein analyses.

Part of the cells was stimulated in vitro. 50.000 T cells were seeded into each well of a flat bottom 96-well plate and stimulated with $10^{6} 30$-Gy irradiated thymocytes and the indicated concentrations of antigen.

When stimulated by antibodies, the wells of a flat bottom 96-well plate were coated with $\alpha$-CD28 and $\alpha$-CD3 antibodies diluted in $30 \mu \mathrm{l}$ of PBS at concentrations indicated in the table 3. After one day, 200.000 T cells were added to each well.

In both the cases, the cells were kept under $10 \% \mathrm{CO} 2$ humidified atmosphere at $37^{\circ} \mathrm{C}$. For either stimulations, the cells were collected at different time points in order to analyze the level of their activation by staining for cell surface markers or intracellular staining for IFN $\gamma$ and, at the same time, some cells were collected and lysed with Qiazol lysis reagent (Qiagen) for gene expression analysis, and the supernatant stored at $-20^{\circ} \mathrm{C}$ 
for enzyme-linked immunosorbent assay (ELISA). For proliferation assay, $\mathrm{T}$ cells were labelled by eFluor $670(2,5 \mu \mathrm{M})$ prior to stimulation.

\subsubsection{Antibodies (Ab)s and counting beads}

\begin{tabular}{|c|c|c|c|c|c|c|}
\hline Primary target & Host & Clone & Label & Dilution & Company & Used as, for \\
\hline$\alpha$ rat $\alpha \beta \mathrm{TCR}$ & mouse & R73 & AlexaFluor 647 & $1: 300$ & Biolegend & $\begin{array}{l}\text { Primary Ab, FACS } \\
\text { staining and sorting }\end{array}$ \\
\hline$\alpha$ rat $\mathrm{CD} 62 \mathrm{~L}$ & mouse & 0X-85 & $\mathrm{PE}$ & $1: 200$ & Biolegend & $\begin{array}{l}\text { Primary Ab, FACS } \\
\text { staining and sorting }\end{array}$ \\
\hline$\alpha$ rat $\mathrm{CD} 25$ & mouse & oX-39 & $\mathrm{PE}$ & $1: 200$ & Biolegend & $\begin{array}{l}\text { Primary Ab, FACS } \\
\text { staining }\end{array}$ \\
\hline$\alpha$ rat $\mathrm{CD} 11 \mathrm{~b} / \mathrm{c}$ & mouse & $0 X-42$ & AlexaFluor 647 & $1: 200$ & $\begin{array}{l}\text { AbD } \\
\text { Serotec }\end{array}$ & $\begin{array}{l}\text { Primary Ab, FACS } \\
\text { staining }\end{array}$ \\
\hline$\alpha$ rat $\mathrm{CD} 25$ & mouse & - & biotinylated & $1: 100$ & $\begin{array}{l}\text { AbD } \\
\text { Serotec }\end{array}$ & $\begin{array}{l}\text { Primary Ab, FACS } \\
\text { staining }\end{array}$ \\
\hline$\alpha$ rat $\mathrm{CD} 134$ & mouse & $0 X-40$ & biotinylated & $1: 100$ & $\begin{array}{l}\text { AbD } \\
\text { Serotec }\end{array}$ & $\begin{array}{l}\text { Primary Ab, FACS } \\
\text { staining }\end{array}$ \\
\hline$\alpha$ rat IFN $\gamma$ & mouse & DB-1 & - & $1: 100$ & Biolegend & $\begin{array}{l}\text { Primary Ab, FACS } \\
\text { intracellular } \\
\text { staining }\end{array}$ \\
\hline$\alpha$ rat $\mathrm{CD} 3$ & mouse & G4.18 & - & $\begin{array}{l}\text { Conc: } \\
1 \mu \mathrm{g} / \mathrm{ml}\end{array}$ & $\begin{array}{l}\text { BD } \\
\text { Biosciences }\end{array}$ & $\begin{array}{l}\text { Primary Ab, } \\
\text { stimulation by Abs }\end{array}$ \\
\hline$\alpha$ rat $\mathrm{CD} 28$ & mouse & JJ316 & - & $\begin{array}{l}\text { Conc: } \\
5 \mu \mathrm{g} / \mathrm{ml}\end{array}$ & $\begin{array}{l}\text { BD } \\
\text { Biosciences }\end{array}$ & $\begin{array}{l}\text { Primary Ab, } \\
\text { stimulation by Abs }\end{array}$ \\
\hline$\alpha$ rat IFN $\gamma$ & goat & - & - & $1: 200$ & Peprotech & Capture Ab, ELISA \\
\hline$\alpha$ rat IL-2 & rabbit & - & - & $1: 200$ & Peprotech & Capture Ab, ELISA \\
\hline$\alpha$ rat IFN $\gamma$ & goat & - & biotinylated & $1: 100$ & Peprotech & Detection Ab, ELISA \\
\hline$\alpha$ rat IL-2 & rabbit & - & biotinylated & $1: 100$ & Peprotech & Detection Ab, ELISA \\
\hline$\alpha$ rat & $\begin{array}{l}\text { mouse } \\
\text { IgG1 }\end{array}$ & MOPC-21 & 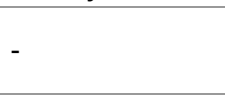 & $1: 100$ & Biolegend & $\begin{array}{l}\text { Isotype control, } \\
\text { FACS staining }\end{array}$ \\
\hline
\end{tabular}

Beads

\begin{tabular}{|l|l|l|l|l|l|l|}
\hline APC-beads & - & - & APC & - & $\begin{array}{l}\text { BD } \\
\text { Biosciences }\end{array}$ & $\begin{array}{l}\text { Beads, FACS } \\
\text { counting }\end{array}$ \\
\hline PerCP-beads & - & - & PerCP & - & $\begin{array}{l}\text { BD } \\
\text { Biosciences }\end{array}$ & $\begin{array}{l}\text { Beads, FACS } \\
\text { counting }\end{array}$ \\
\hline
\end{tabular}

\section{Secondary antibodies}

\begin{tabular}{|l|l|l|l|l|l|l|}
\hline$\alpha$-mouse & Goat & - & APC & $1: 200$ & $\begin{array}{l}\text { JacksonImm } \\
\text { Research }\end{array}$ & $\begin{array}{l}\text { Secondary Ab, FACS } \\
\text { staining }\end{array}$ \\
\hline Streptavidin-APC & - & - & APC & $1: 400$ & $\begin{array}{l}\text { BD } \\
\text { Biosciences }\end{array}$ & $\begin{array}{l}\text { Secondary Ab, FACS } \\
\text { staining }\end{array}$ \\
\hline Streptavidin-PECy5 & - & - & PE-Cy5 & $1: 400$ & Biolegend & $\begin{array}{l}\text { Secondary Ab, FACS } \\
\text { staining }\end{array}$ \\
\hline Streptavidin-HRP & - & - & HRP & $1: 250$ & $\begin{array}{l}\text { BD } \\
\text { Biosciences }\end{array}$ & $\begin{array}{l}\text { Secondary Ab, } \\
\text { ELISA }\end{array}$ \\
\hline
\end{tabular}

Table 3 Antibodies and counting beads used and their function. 


\subsubsection{FACS analysis of the antibody staining of cell surface markers and cell count}

In order to perform cell surface staining with fluorescently labeled antibodies, the cells were incubated on ice for 15 minutes with the required primary antibodies diluted as mentioned (Table 3) in $100 \mu \mathrm{l}$ FACS buffer. Afterward, the cells were centrifuged for 3 min with $1300 \mathrm{rpm}$ at $4^{\circ} \mathrm{C}$ and either incubated on ice with a secondary antibody diluted in $100 \mu \mathrm{l}$ FACS buffer for about $20 \mathrm{~min}$, or directly resuspended in $200-300 \mu \mathrm{l}$ FACS buffer and then transferred into $5 \mathrm{ml} \mathrm{FACS}$ tubes (BD Biosciences, San Jose, CA, US) for analysis. All the incubation steps were performed in the dark. In order to detect the number of cells, $50 \mu \mathrm{l}$ of FACS buffer with a precise number of fluorescent counting beads was added to the top of the $200 \mu \mathrm{l}$ suspension, and the number of the required cells was calculated in relation to the number of beads.

FACS analysis was performed using a flow cytometer FACS Calibur instrument (BD Biosciences, San Jose, CA, USA). This system consists of two lasers, a red diode laser (640 $\mathrm{nm}$ excitation) and an air-cooled argon laser (488 $\mathrm{nm}$ excitation) that make possible to measure four fluorescent parameters.

The flow cytometer BD FACS ArialII (BD Biosciences, San Jose, CA, USA) was also used FACS analysis.

\subsubsection{Intracellular staining}

48 hours after stimulation, the cells were treated for 3 hours at $37^{\circ} \mathrm{C}$ in incubator with 5 $\mu \mathrm{g} / \mathrm{ml}$ Brefeldin A (Sigma Aldrich, Munich, Germany) in RM to trap the intracellular cytokines in the Golgi apparatus.

After that, the cells were centrifuged and then fixed with 2\% PFA (Roth) for 20 minutes on ice. After a washing step with PBS 1X, and another with 1X BD Perm/Wash buffer (BD Biosciences, San Jose, CA, US), they have been resuspended in 1X BD Perm/Wash buffer plus 5\% rat serum and kept on ice for 30 minutes. Afterward, the cells were incubated with $\alpha$-rat IFN $\gamma$ Ab diluted as indicated (Table 3) in the same buffer, then washed one time and incubated again for 90 minutes on ice with the APC-conjugated secondary Ab. Subsequently, they were washed with 1X BD Perm/Wash buffer plus 5\% rat serum, centrifuged and resuspended in $200 \mu \mathrm{l}$ of FACS buffer for FACS analysis. 


\subsubsection{Proliferation assay}

To check the proliferation of the cells after stimulation, we used the cell proliferation dye eFluor 670 (eBioscience) and proceeded according to the supplied protocol:

Approximately $10 \times 10^{6}$ cells were washed two times with PBS $1 \mathrm{X}$ to remove any serum and then resuspended in $1 \mathrm{ml}$ PBS $1 \mathrm{X}$. Afterwards, an equal volume of a $10 \mu \mathrm{M}$ solution of cell proliferation dye eFluor 670 in PBS1X was added on the suspension in order to reach a 2,5 $\mu \mathrm{M}$ final concentration of the dye eFluor 670 . After that, the cells were kept for 10 minutes at $37^{\circ} \mathrm{C}$ in the dark and then the labelling was stopped by the addition of $10 \mathrm{ml}$ PBS $+10 \%$ FCS. Finally, the cells were washed 3 times with EH $+10 \%$ FCS and then resuspended in RM and stimulated as desired.

\subsubsection{Enzyme-like immunosorbent assay (ELISA)}

The supernatant of in vitro stimulated $\mathrm{T}$ cells was collected at different time points, and the concentration of produced cytokines was analyzed and measured by ELISA.

96-well plates with a polystyrene-based surface (Nunc, Thermo Fischer Scientific Inc., Waltham, US) were coated with cytokine-specific capture antibodies diluted in PBS overnight at room temperature. The next day, the plate was washed 4 times with ELISA washing buffer (Table 1) and then was incubated with $300 \mu \mathrm{l}$ of blocking buffer (Table 1) in each well for 1 hour at room temperature. After 4 washing steps with washing buffer, a volume of supernatant ( $40 \mu \mathrm{l}$ to measure IFN $\gamma$ and $100 \mu \mathrm{l}$ to measure IL-2) was loaded on each well. Also, a serial dilution of standard cytokines (Peprotech) was loaded on other wells in order to favor the measurement of the concentration of the cytokines inside the $\mathrm{T}$ cell supernatant. The incubation was kept for 2 hours at room temperature.

After 4 washing steps, the wells were incubated for 2 hours at room temperature with detection antibodies specific for the desired cytokines, diluted in $100 \mu \mathrm{l}$ of blocking buffer. Afterwards, the plate was washed again for 4 times and then incubated for $30 \mathrm{~min}$ at room temperature with the enzyme horseradish peroxidase (HRP)-conjugated streptavidin diluted in $100 \mu$ l.

After an extensive washing, the substrate tetramethylbenzidine (TMB) (BD Biosciences), coupled to $\mathrm{H}_{2} \mathrm{O}_{2}$, was added in each well $(100 \mu \mathrm{l})$ and allowed to react in the dark for maximum 30 minutes. HRP catalyzes the oxidation of TMB to benzidine blue. The reaction was stopped via the addition of $50 \mathrm{\mu l} \mathrm{H}_{2} \mathrm{SO}_{4}$ and the optical density of each sample-well 
was measured with a SUNRISE ELISA reader (TECAN) at $450 \mathrm{~nm}$ wavelength and the software Magellan 6.

In order to calculate the cytokine concentration in the supernatants, the optical density of each sample was correlated with that of each dilution of the standard cytokines.

\subsubsection{FACS sorting}

For cell sorting, we used a flow cytometer BD FACS AriaIII (BD Biosciences, San Jose, CA, USA), equipped with a four-laser system (488 nm, $561 \mathrm{~nm}, 633 \mathrm{~nm}$, and UV).

The cells were taken up in $500 \mu \mathrm{l}$ EH medium with $1 \mathrm{mM}$ EDTA and, when necessary, stained with $\alpha$-rat AlexaFluor 647- $\alpha \beta$ TCR Ab, together or not with $\alpha$-rat PE-CD62L Ab, and then sorted for the expression of GFP, mCherry and the stained surface molecules, alone or in combination. The sorting process was performed at minimum flow-rate of 1000-2000 events/second and at $4^{\circ} \mathrm{C}$. This made it possible to reach a purity of $90-95 \%$ for the selected populations. During the sorting process, the cells were collected in $5 \mathrm{ml}$ tubes containing fresh RM. When the required number of cells was reached, the collected cells were centrifuged and used for further analyses.

\subsubsection{Analysis of gene expression}

\subsubsection{RNA extraction}

In order to quantify the expression of the genes of interest, we performed an RNA extraction from collected cells.

The T cells collected directly from in vitro cultures or sorted by FACS were centrifuged and resuspended in $100 \mu \mathrm{l}$ Quiazol Lysis reagent (Qiagen) by repetitive pipetting to induce cell lysis. Afterwards, the samples were stored at $-80^{\circ} \mathrm{C}$.

After some days, the samples were shaken and left for 5 minutes at room temperature to permit the complete dissociation of the nucleoprotein complex. Subsequently, $20 \mu \mathrm{l}$ of chloroform (Roth) were added and after vigorous shaking for 15 seconds, the samples were incubated for 3 minutes at room temperature. Afterward, the samples were centrifuged at $12.000 \mathrm{xg}$ for $15 \mathrm{~min}$ at $4^{\circ} \mathrm{C}$. By centrifugation, the samples were separated into a lower phenol-chloroform phase, an interphase, and an upper aqueous phase containing the RNA. For this reason, the upper phase was transferred to a new tube, and mixed with $50 \mu$ l of $100 \%$ isopropanol (Roth) and $1 \mu$ l glycogen (Sigma). After 10 minutes 
of incubation at room temperature, the samples were centrifuged at $12000 \mathrm{xg}$ for 10 minutes at $4^{\circ} \mathrm{C}$. The precipitated RNA formed a gel-like pellet so that the supernatant could be easily removed.

In order to dissolve the RNA, the pellet was washed with $100 \mu \mathrm{l}$ of $75 \%$ ethanol (Roth). Afterward, the sample was mixed by brief vortexing and then centrifuged at $7.500 \mathrm{xg}$ for $5 \min$ at $4^{\circ} \mathrm{C}$.

Afterwards, the supernatant was removed and the pellet was dried until ethanol evaporation. Finally, the RNA pellet was dissolved in $11 \mu \mathrm{l}$ of RNase-free water (Qiagen) and stored at $-80^{\circ} \mathrm{C}$ or directly used for subsequent enzymatic reactions.

\subsubsection{Reverse transcription: complementary DNA (cDNA) synthesis}

The synthesis of cDNA from the extracted RNA was performed following the manufacturer's instructions for the Fermentas RevertAidTM First Strand cDNA Synthesis Kit (Thermo Fischer Scientific Inc., Waltham, US).

$1 \mu \mathrm{l}$ of random hexamer primers was pipetted and mixed in the $11 \mu \mathrm{l}$ RA sample. These primers bind to the RNA non-specifically and therefore can synthesize cDNA from all possible RNA templates.

Afterwards, the RNA-primer mix was incubated at $65^{\circ} \mathrm{C}$ for 5 minutes and then cooled on ice for a further 5 minutes.

In the meanwhile, the following components of the kit were combined and mixed to form a master mix:

Per each RNA sample, $4 \mu \mathrm{l}$ 5x Reaction Buffer, $2 \mu \mathrm{l}$ 10mM dNTP Mix, $1 \mu$ l RiboLockTM RNase Inhibitor and $1 \mu$ RevertAidTM MMuLV Reverse Transcriptase.

$8 \mu \mathrm{l}$ of the master mix were added to the RNA-primer mix and all the solution was transferred in new small tubes that in turn were loaded in thermal cycler (Eppendorf Mastercycler EP Gradient) in order to perform the following reactions leading to new cDNA synthesis:

Firstly, the samples were incubated at $25^{\circ} \mathrm{C}$ for $5 \mathrm{~min}$. The cDNA synthesis was promoted by a subsequent 60 -minute incubation at $42^{\circ} \mathrm{C}$.The cDNA synthesis was stopped through heat inactivation of the enzyme at $70^{\circ} \mathrm{C}$ for 5 minutes.

Finally, the cDNA was stored at $-20^{\circ} \mathrm{C}$ or directly used for real-time PCR. 


\subsubsection{Real time polymerase chain reaction (PCR)}

The gene expression analysis was achieved by real time (or quantitative) PCR (qPCR) using the StepOnePlus Real Time PCR System and the StepOne Software v2.0 (Applied Biosystems, Darmstadt, Germany).

Per each gene of interest, custom designed real time PCR primers and probes (Table 4) were purchased from Sigma Aldrich (Munich, Germany) or from Microsynth, with FAMTAMRA as fluorophore-quencher pairs. Beta-actin ( $\beta$-actin) was used as a constitutively expressed gene (housekeeping gene).

The single strand cDNA of interest was diluted 1:20 with RNase-free water and $7.5 \mu$ of the solution were mixed with $12.5 \mu \mathrm{l}$ of ready-to-use real time PCR Master Mix (including dNTPs/dUTPs, HotGoldStar DNA polymerase, $5 \mathrm{mM}$ final $\mathrm{MgCl} 2$ concentration; Eurogentec, Seraing, Belgium) and $5 \mu \mathrm{l}$ of Primer-Probe mixture and finally loaded into one well of a 96-well real time PCR plate (Sarstedt AG \& Co, Nümbrecht, Germany) for a 40 cycles real time PCR run.

In the end, the $2^{\wedge}-\Delta C$ t method was used for the quantification of the expression of the gene of interest in relation to the one of the housekeeping gene, $\beta$-actin.

\begin{tabular}{|c|c|}
\hline Gene & Oligonucleotide sequences \\
\hline$\beta$-actin & $\begin{array}{l}\text { Fw: 5'-GTA CAA CCT CCT TGC AGC TCC T -3' } \\
\text { Rev: 5'-TTG TCG ACG ACG AGC GC -3' } \\
\text { Probe: 5'-Fam-CGC CAC CAG TTC GCC ATG GAT -Tamra-3' }\end{array}$ \\
\hline $\mathrm{IFN} \gamma$ & $\begin{array}{l}\text { Fw: 5'-AAC AGT AAA GCA AAA AAG GAT GCA TT -3' } \\
\text { Rev: 5'-TTC ATT GAC AGC TTT GTG CTG G -3' } \\
\text { Probe: 5'-Fam-CGC CAA GTT CGA GGT GAA CAA CCC -Tamra-3' }\end{array}$ \\
\hline IL-17 & $\begin{array}{l}\text { Fw: 5'-GAG TCC CCG GAG AAT TCC AT -3' } \\
\text { Rev: 5'-GAG TAC CGC TGC CTT CAC TGT -3' } \\
\text { Probe: 5'-Fam-ATG TGC CTG ATG CTG TT -Tamra-3' }\end{array}$ \\
\hline IL-2 & $\begin{array}{l}\text { Fw: 5'-CTC CCC ATG ATG CTC ACG TT-3' } \\
\text { Rev: 5'-TCA TTT TCC AGG CAC TGA AGA TG-3' } \\
\text { Probe: 5'-Fam-CAA TTC TGT GGC CTG CTT GG -Tamra-3' }\end{array}$ \\
\hline GM-CSF & $\begin{array}{l}\text { Fw: 5'-TCC TAA ATG ACA TGC GTG CT-3' } \\
\text { Rev: 5'-CCC GTA GAC CCT GCT TGT AT-3' } \\
\text { Probe: 5'-Fam-TGT GCA GAC CCG CCT GAA GC-Tamra-3' }\end{array}$ \\
\hline CD25 & $\begin{array}{l}\text { Fw: 5'-CAC AGT CTG TGT ACC AGG AGA ACC T-3' } \\
\text { Rev: 5'-CCA CGA AGT GGT AGA TTC TCT TGG-3' } \\
\text { Probe: 5'-Fam-CAG GTC ACT GCA GGG AGC CCC C-Tamra-3' }\end{array}$ \\
\hline Hif1 $\alpha$ & $\begin{array}{l}\text { Fw: 5'-TCC TGCA CTGA ATC AAG AGG-3' } \\
\text { Rev: 5'-AGG ACT TGC TG GCT GA TCTT-3' } \\
\text { Probe: 5'-Fam-TCC CAG TGA CTC TGG GCT TGA CTC-Tamra-3' }\end{array}$ \\
\hline $\operatorname{Irf} 4$ & $\begin{array}{l}\text { Fw: 5'-CTC CGA CCC ATA CAA GGT CT-3' } \\
\text { Rev: 5'-CAA AG TGA GCT GCT TTG CTC-3' } \\
\text { Probe: 5'-Fam-GGC TCC CTC TGG AAC AAT CCT G-Tamra-3' }\end{array}$ \\
\hline
\end{tabular}




\begin{tabular}{|c|c|}
\hline Bcl6 & $\begin{array}{l}\text { Fw: 5'-ACC CTC TTC AGA GGA CGA GA-3' } \\
\text { Rev: 5'-GGA GGA CTC TGT GGG TGA GT-3' } \\
\text { Probe: 5'-Fam-CCG CAG AAA TCC GAC TGC CA-Tamra-3' }\end{array}$ \\
\hline HK-1 & $\begin{array}{l}\text { Fw: 5'-ACG CTG ATG GAG GTG AAG AA-3' } \\
\text { Rev: 5'-TAC CAG CAG AAC CCG GAA AT-3' } \\
\text { Probe: 5'-Fam-TCC CAT CCG GGA TGC TCC GGA-Tamra-3' }\end{array}$ \\
\hline LdhA & $\begin{array}{l}\text { Fw: 5'-ACG GAT GCA GAC AAG GAG CA-3' } \\
\text { Rev: 5'-AAT GGG ATG CAC CCG CCT AA-3' } \\
\text { Probe: 5'-Fam-TGG GCC ATT GGC CTC TCC GTG GCA-Tamra-3' }\end{array}$ \\
\hline Eno 1 & $\begin{array}{l}\text { Fw: 5'-ACC CAG TGG TGT CCA TTG AA-3' } \\
\text { Rev: 5'-TGG TCA CTG TGA GGT CAT CC-3' } \\
\text { Probe: 5'-Fam-CCC ACC ACC TGG ATG CCT GCA-Tamra-3' }\end{array}$ \\
\hline cМyc & $\begin{array}{l}\text { Fw: 5'-CCC CTA GTG CTG CAT GAA GAG-3' } \\
\text { Rev: 5'-TCC ACA GAC ACC ACA TCA ATT TC-3' } \\
\text { Probe: 5'-Fam-CAC CAC CAG CAG CGA CTC TGA AGA AG-Tamra-3' }\end{array}$ \\
\hline
\end{tabular}

Table 4 Primer and probe sequences for real time PCR.

\subsection{Characterization of the glycolysis phenotype}

\subsubsection{Extracellular acidification rate (ECAR) assay}

We used the Agilent Seahorse XF Glycolysis stress test kit in order to assess the glycolytic flux in the cells.

The glycolytic conversion of glucose to pyruvate, and subsequently lactate, results in a net extrusion of protons into the extracellular medium. This results in the acidification of the medium surrounding the cells. The XF instrument measures the acidification rate and reports this as ECAR. The stimulation of glycolysis by glucose administration and its subsequent inhibition by 2-DG allows to measure the acidification caused by the glycolytic release of lactate thereby reporting the rate of glycolysis.

We proceeded as recommended in the manufacturer's kit. In the day prior to assay, the Seahorse XF Analyzer was turned on to let it warm up and stabilize; the Seahorse XF Microplate was coated with collagen $10 \mu \mathrm{g} / \mathrm{ml}$ diluted in PBS overnight at $4^{\circ} \mathrm{C}$; finally, the sensor cartridge was hydrated in Seahorse XF Calibrant at $37^{\circ} \mathrm{C}$ in a non- $\mathrm{CO}_{2}$ incubator overnight.

On the day of the assay, the Seahorse XF Base Medium (without glucose) was supplemented with $1 \mathrm{mM}$ glutamine, warmed up to $37^{\circ} \mathrm{C}$ and adjusted to $\mathrm{pH} 7.4$ (assay medium). Afterwards, $300000 \mathrm{~T}$ cells diluted in $180 \mu \mathrm{l}$ of prepared assay medium were plated in each well of the coated Seahorse XF Microplate. This was incubated in a $37^{\circ} \mathrm{C}$ non- $\mathrm{CO}_{2}$ incubator for 45 minutes to 1 hour prior to the assay. In the meantime, the 
supplied glucose and 2-DG were diluted in the assay medium at the desired concentrations and then loaded into the injection ports of the sensor cartridge in such a way as to achieve the final concentrations of $10 \mathrm{mM}$ glucose and $100 \mathrm{mM} 2-\mathrm{DG}$ per well. Afterwards, a utility plate with the loaded sensor cartridge was placed on the XF analyzer tray for 15-30 minutes calibration. Finally, the utility plate was replaced with the cell culture Seahorse XF Microplate and the glycolysis stress test was started by the XF software. All the measurements of ECAR over time and after glucose (acidification due to glycolysis) or 2-DG (non-glycolytic acidification) treatments were stored in an Excel spreadsheet and then all the data analyzed in order to assess the glycolysis rate (ECAR after glucose - ECAR after 2-DG) of each cell population under analysis.

\subsubsection{Glucose uptake assay}

The measurement of the glucose uptake level of T cells was achieved by the use of the Glucose Uptake Cell-Based Assay Kit reagents purchased from Cayman Chemical.

After in vitro cultured T cells were harvested, they were washed once in glucose-free DMEM. Afterwards, 250000 cells per well were plated in a V96 well plate (Thermo Fisher Scientific), and incubated with $150 \mu \mathrm{g} / \mathrm{ml}$ of the fluorescently-tagged glucose derivative (2-NBDG) diluted in $100 \mu$ glucose-free DMEM. The non-stained T cells used as control were kept in $100 \mu \mathrm{l}$ of their culture medium. After 3 hours of incubation in a $10 \% \mathrm{CO}_{2}$ incubator at $37^{\circ} \mathrm{C}$, the cells were centrifuged at room temperature at $1400 \mathrm{rpm}$ for 4 minutes and then washed with $200 \mu \mathrm{l}$ of the supplied cell-based assay buffer. After a new centrifugation, they were resuspended in $200 \mu \mathrm{l}$ of FACS buffer and analyzed by a cytometers FACS AriaIII or CytoFLEX (Beckman Coulter Life Sciences). 2-NBDG is detectable at excitation and emission wavelengths of 485 and $535 \mathrm{~nm}$ respectively.

The cells stained ex vivo were incubated for only 50 minutes in EH medium. After centrifugation and a washing step in Cell-Based Assay buffer, they were further stained with AlexaFluor 647-conjugated $\alpha$-rat $\alpha \beta$ TCR Ab in $100 \mu$ FACS buffer (1:300). After 15 minutes of incubation on ice, the cells were centrifuged, washed and then resuspended in $200 \mu \mathrm{l}$ of FACS buffer for flow cytometer analysis by a FACS ArialII. 


\subsubsection{Western blot analysis}

The quantification of the protein expression of glycolytic enzymes was achieved by western blot conducted in the lab of Prof. Giuseppe Matarese at the Department of Molecular Medicine and Medical Biotechnology of the University of Napoli, "Federico II". At least $200000 \mathrm{~T}$ cells per sample were sorted and immediately centrifuged. The supernatant was removed and the pellet frozen at $-80^{\circ} \mathrm{C}$. Afterward, every pellet was shipped to Prof Matarese's laboratory for western blot analysis.

Briefly, total cell lysates were obtained incubating cells at $4^{\circ} \mathrm{C}$ for 20 minutes in Ripa Buffer (R0278; Sigma Aldrich), plus SigmaFast protease inhibitor (S8820; Sigma Aldrich) and Sigma phosphatase inhibitor (P5726; Sigma Aldrich). Immunoblot analysis was performed as previously described (De Rosa et al. 2007). The antibodies used were the following: anti-enolase, anti-hexokinase, anti-PKM1/2 (pyruvate kinase isozymes M1/M2), anti-FAsyn (fatty acid synthase), anti-apoA4 (apolipoprotein A-IV), anti-ACAT2 (Acetyl-CoA C-acetyltransferase 2) (1:500 dilution from Abcam), anti-pS6 (phospho-S6 ribosomal protein), anti-DLAT (dihydrolipoamide S-Acetyltransferase) and anti-SDHA (Succinate dehydrogenase complex flavoprotein subunit) (1:1000 dilution and from Cell Signaling Technology). Anti- $\beta$-actin (1:1000 dilution from Santa Cruz Biotechnology) and anti-S6 (S6 ribosomal protein) antibodies were used to normalize the amount of loaded protein. All filters were quantified by densitometric analysis.

\subsection{Animal experiments}

\subsubsection{Animals, caretaking and maintenance}

All the experimental animals used for this study were rats with the Lewis rats genetic background,. namely, wild-type (WT), rMT-II and rOT-II rats. They were all obtained from the animal facility of the University Medical Center Göttingen (UMG) and kept under standardized conditions. The animal experiments were performed according to the local regulations for animal welfare of Lower Saxony. 


\subsubsection{Generation of "memory" Lewis rats}

The creation of "memory" Lewis rats was achieved as previously described (Kawakami et al. 2005). Intraperitoneal transfer of T $\mathrm{MBP}_{\text {GFP }}$ cells $\left(2 \times 10^{6}\right.$ cells, in $0.5 \mathrm{ml} /$ animal in $\mathrm{EH}$ medium) into newborns was performed under hypothermia within 48 hours after birth. After $\mathrm{T}$ cell transfer, the pups were kept under a $30^{\circ} \mathrm{C}$ humid atmosphere and returned to the mother only when fully recovered. The T cells were transferred 5 or 6 days after in vitro restimulation.

\subsubsection{Active EAE induction}

Active EAE was induced by subcutaneous immunization of rats with guinea pig MBP protein (1 mg/ml in PBS) emulsified in an equal volume of complete Freund's adjuvant (CFA) containing Mycobacterium tuberculosis H37Ra (Difco, Becton Dickinson, Franklin Lakes, NJ, USA) (2 mg/ml in mineral oil). This emulsion was prepared with two tuberculin glass syringes (POULTEN \& GRAF GmbH, Wertheim, Germany) joint via a custom-made connector.

$150 \mu \mathrm{l}$ of the emulsion were injected subcutaneously into the tail base ( $50 \mu \mathrm{l}$ on each side) and into the hind limb popliteal cavity ( $25 \mu \mathrm{l}$ on each side) of rats anesthetized by diethyl ether (Roth).

\subsubsection{Induction of transfer EAE}

To induce transfer EAE, fully activated MBP-reactive CD4 T cell blasts of a $\mathrm{T}$ cell line, collected on the day 2 after in vitro restimulation (from 2 to $5 \times 10^{6}$ cells in $1 \mathrm{ml}$ of EH medium per rat) were injected by a $1 \mathrm{ml}$ syringe (Omnifix) into the tail vein of Lewis rats anesthetized with diethyl ether.

\subsubsection{Scoring system for EAE induced in rats}

After transfer or active EAE induction, the rats were weighed and scored daily (or several times in a day around the onset of the disease) for clinical symptoms, using the following scoring system: 
- 0: No symptoms.

- 0.5: Partial loss of tail tonus.

- 1: Flaccid tail (complete loss of tail tonus).

- 1.5: Flaccid tail and subtle gait disturbance.

- 2: Pronounced weakness of hind limbs, progressed gait disturbance.

- 2.5: Pronounced weakness of hind limbs, impaired adduction of hind limbs, paralysis of a single hind limb.

- 3: Paraplegia (complete hind limb paresis); animals are able to actively move forward using their forelimbs.

- 3.5: Weakness of forelimbs leading to impaired forward movement.

- 4: Tetraplegia.

- 5: Moribund or dead.

For animal welfare reasons animals with a score of 3.5 or higher were euthanized.

\subsubsection{Intrathecal injection}

In order to perform an intrathecal injection of $\mathrm{T}$ cells, rats were anesthetized by subcutaneous injection of xylazine $(10 \mathrm{mg} / \mathrm{kg})$ and ketamine $(50 \mathrm{mg} / \mathrm{kg})$. Вy a stereotactic device the head of the rat was fixed by ear bars and secured by the tooth holder. The T cells, diluted in $30 \mu \mathrm{EH}$ medium were injected between the cervical vertebrae C1 and C2. After disinfection of the injection site with ethanol, a $0.5 \mathrm{ml}$ tuberculin syringe (Becton Dickinson, Franklin River, NJ, USA) was fixed to the manipulator's arm and the needle was slowly inserted until the cerebrospinal fluid was reached. Afterward, the total volume of $30 \mu \mathrm{l}$ was injected over a time period of 10 minutes.

\subsection{Statistical analysis}

Statistical analyses were performed using GraphPad Prism 7 software (GraphPad Software Inc., San Diego, CA, US). For all analyses, the student's t-test was used and the pvalue was shown as follows:

p-value $>0.05$ : ns; p-value $\leq 0.05:{ }^{*}$; p-value $\leq 0.01{ }^{* *}$; p-value $\leq 0.001{ }^{* * *}$; -value $\leq$ $0.0001:^{* * * *}$. 


\section{RESULTS}

\section{1 rMT-II rats do not develop any spontaneous EAE and do not show any aggravation of the adoptive transfer EAE compared to the wild type}

controls

We followed more than 1000 homozygous rMT-II rats ranging in age from two months up to one year, however none of those animals spontaneously developed neurologic symptoms. This could not be explained by the loss of transgene expression, as this strain has maintained GFP expression in all blood cells, dominance of TCR-Vß8.2 in T cell repertoire and responsiveness to MBP ex vivo over many generations (data not shown). It is known that during transfer EAE the injected auto-reactive $\mathrm{T}$ cells are able to break the BBB, infiltrate the CNS and get re-activated locally by encountering APCs presenting autoantigen (Lodygin et al. 2013). The activation of T and APC cells inside the CNS guides the recruitment of the endogenous immune cells to the CNS. Among them, the recruited T cells can be either not auto-reactive or be specific for another auto-antigen. In the first case, they will either not be activated (Owens et al. 1998; Krakowski and Owens 2000) or, possibly, will undergo a bystander activation (Nogai et al. 2005), whereas in the second case, they can be activated by antigen due to determinant spreading (Owens et al. 1998; McLaughlin et al. 2015) Therefore, the recruited T cells could to some extent contribute to the inflammation pulse and the expansion of the tissue damage seen in EAE. In rMT-II rats most of the CD4+ T cells are MBP-reactive, and once recruited into the CNS they are expected to strongly contribute to the inflammation pulse via antigen-specific activation (Busch et al. 2000; Owens et al. 1998), leading to a higher and/or faster expansion of the tissue damage and aggravated clinical picture.

Surprisingly, we did not observe any aggravation of transfer EAE in rMT-II compared to WT rats during entire course of the disease induced by injection of MBP-reactive CD4+ blast T cells (FIG 1A and B). 
A

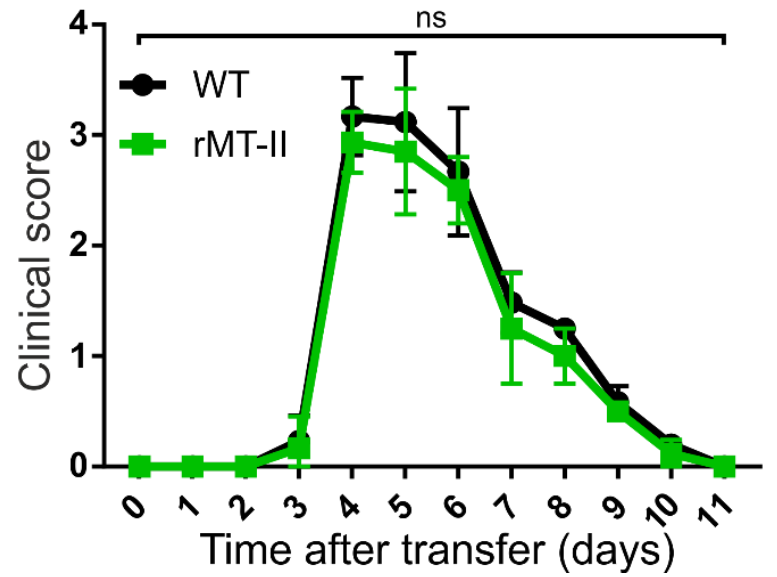

B

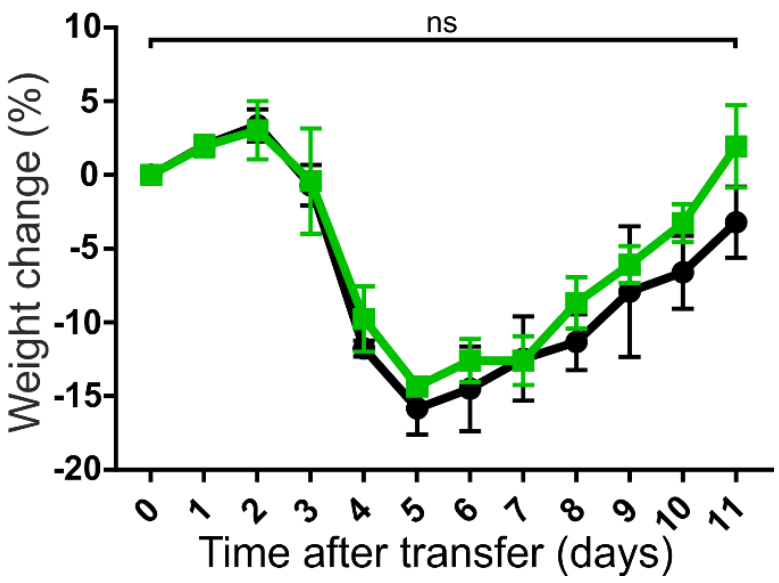

FIG 1 Clinical course of transfer EAE in rMT-II and WT rats.

Transfer EAE in rMT-II or WT rats ( $\mathrm{n}=3$ ) was induced by injection of $2 \times 10^{6} \mathrm{~T}_{\mathrm{MBP}}$ cells. (A) Clinical score and (B) percentage of weight variation in each rat were measured daily after transfer, until complete recovery. This is a representative experiment of $n=3$ experiments with different $\mathrm{T}_{\text {мвр }}$ cell lines (including rMT-II derived) and dose of transferred cells. Data are presented as mean \pm SD; Statistical analysis was performed by student's t test.

\subsection{Primary rMT-II T cells are highly encephalopathogenic when undergoing peripheral activation in vivo}

In order to explain this passivity of the MBP-specific $\mathrm{T}$ cells within the immune repertoire of rMT-II rats we next tested whether rMT-II $\mathrm{T}$ cells can be activated in vivo by immunization with guinea pig MBP and induce clinical disease. To this end, rMT-II rats and age-matching WT controls were subcutaneously (s.c.) immunized with MBP emulsified in CFA. In WT animals this protocol as expected evoked monophasic paralytic disease with onset 10 days after immunization (FIG 2A and B). Immunization of rMT-II animals also induced clinical EAE with 100\% incidence as with in WT controls, however with a clearly accelerated onset (day 6), higher severity and more protracted recovery phase (FIG 2A-C).

These in vivo data exclude an anergic state of rMT-II T cells. Moreover, here we have demonstrated that rMT-II T cells get primed much earlier than WT T cells after MBP immunization, are able to migrate into the CNS and represent the main drivers of a highly potent cascade of pathogenic events in the tissue. 
A

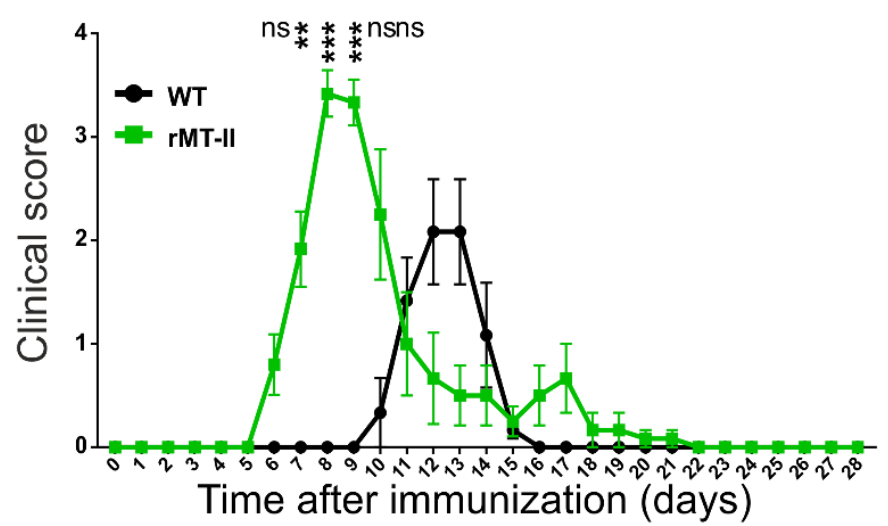

B

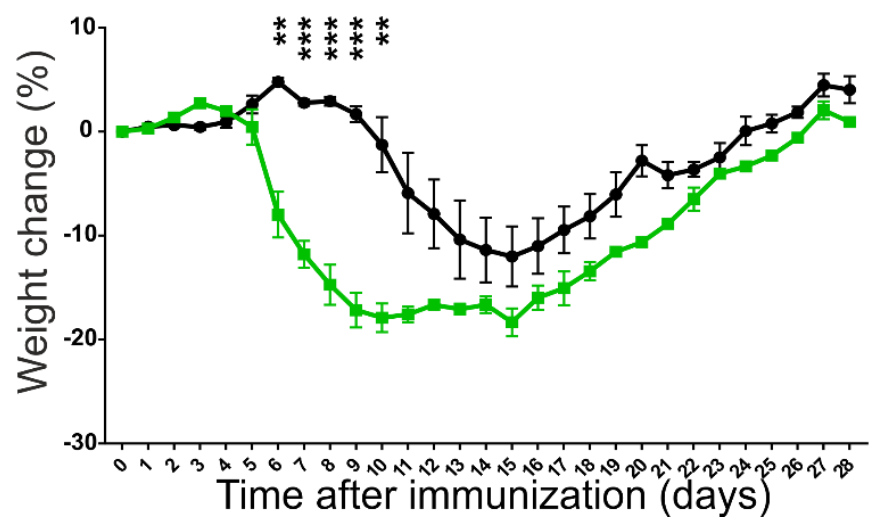

C

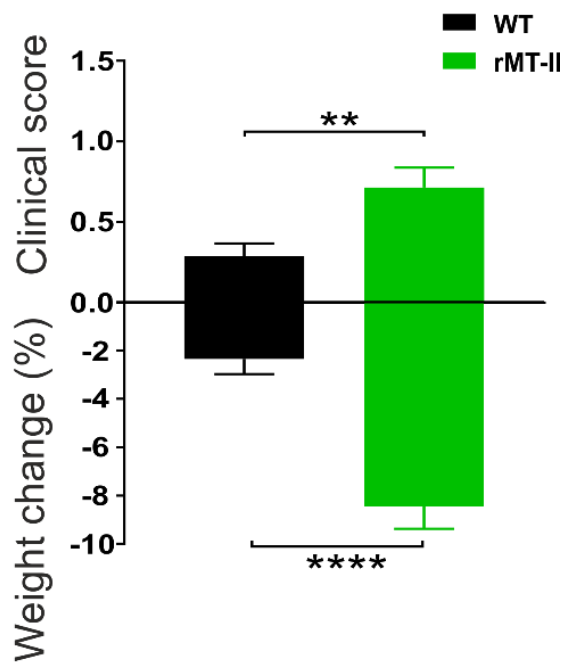

FIG 2 Comparison of active EAE in rMT-II and WT Lewis rats.

$(\mathbf{A}, \mathbf{B})$ WT and homozygous rMT-II rats were immunized in parallel with the same dose of MBP in CFA. The clinical score (scale 1-5; see METHODS for details) and body weight were measured daily ( $\mathrm{n}=3$ per group). (C) Averaged clinical score (mean \pm SEM; upper $Y$ axis) and weight change (lower $Y$ axis) measured over entire period (from 0 to 28 days after MBP immunization) shown in (A) and (B). ** $-\mathrm{P} \leq 0.01$; ${ }^{* * *}$ - $\mathrm{P} \leq 0.001$ by student's t test; ns - not significant ( $\mathrm{p}$ values and corresponding asterisks are listed in the paragraph "3.7 statistical analysis" of materials and methods).

Further we asked whether enhanced active EAE disease in rMT-II rats was mostly attributed to the transgenic MBP-reactive $\mathrm{T}$ cells. We transferred $\mathrm{T}$ cells isolated from a pool of lymph nodes (LNs), spleens and blood of naïve rMT-II rats into WT animals. One day after transfer, the animals were immunized with MBP in CFA. Also in this case, WT animals receiving transgenic rMT-II T cells showed the first symptoms about three days earlier than the non-transferred control rats (FIG 3A-C). Therefore, the T cell repertoire of naïve rMT-II rats obviously contains a component able to accelerate active EAE, but would this cellular population suffice to induce disease in a host resistant to active EAE? To address this question we used ovalbumin-specific TCR-transgenic Lewis strain rOT-II as a host for adoptive transfer and subsequent MBP-immunization (FIG 3D). Because $T$ cell repertoire of homozygous rOT-II rats is depleted of antigenic specificities other than 
ovalbumin, upon active immunization with MBP this strain is virtually disease resistant (Lodygin, Kitz et al. unpublished). We transferred isolated rMT-II or rOT-II T cells into rOT-II recipient rats and immunized them with MBP in CFA (FIG 3D). The transfer of rMT-II, but not rOT-II T cells fully restored susceptibility of the rOT-II strain to active EAE (FIG 3E and F). Moreover, the onset of clinical disease mediated by the transfer of rMTII T cells was accelerated relative to the onset of active EAE in WT controls (FIG 3E and F) resembling the earlier manifestation of disease observed in former experiments (FIG 2A and $B$, FIG 3B and C).

Thus, we have demonstrated that TCR transgenic rMT-II T cells become efficiently primed after immunization and can more rapidly acquire pathogenic properties allowing for migration into the CNS and initiation of inflammatory process than MBP-reactive WT T cells. 
A

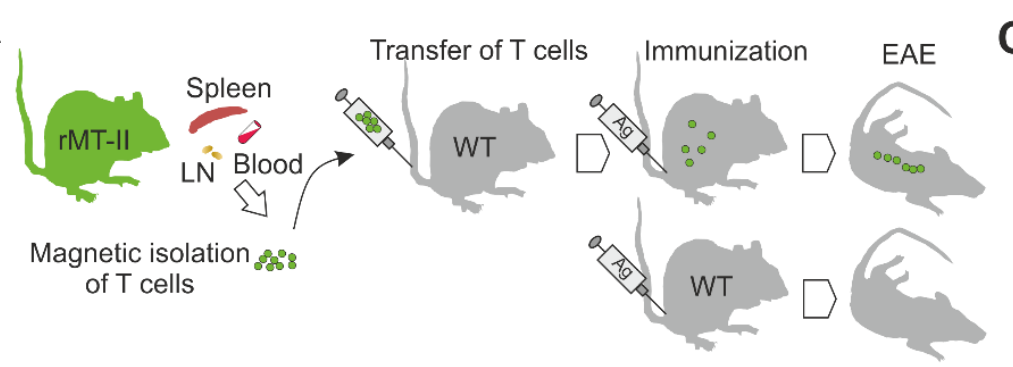

B
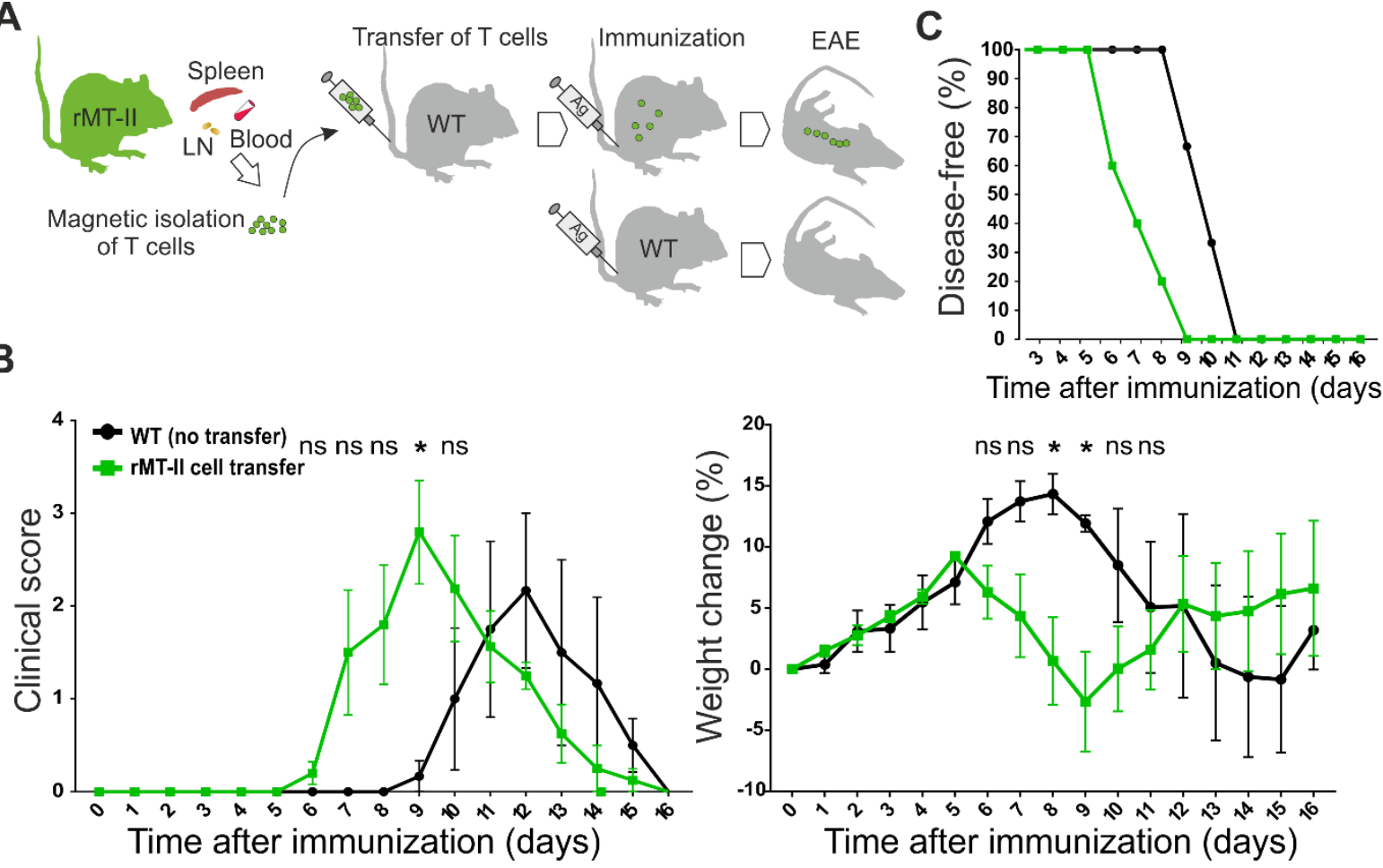

D

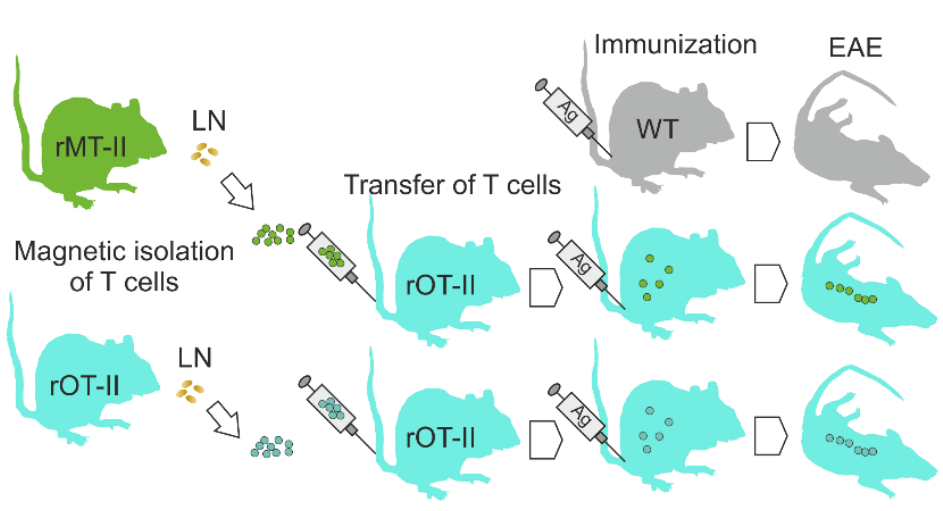

$\mathbf{F}$

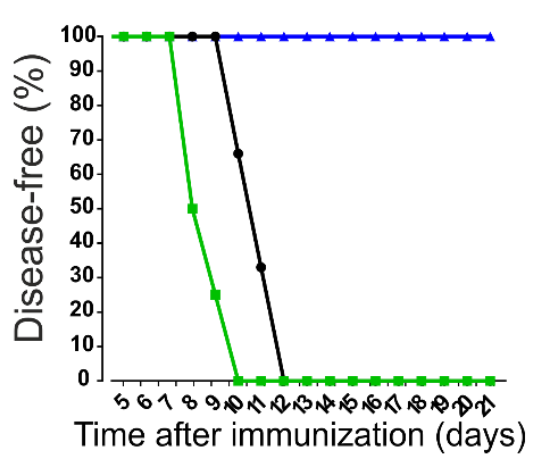

E
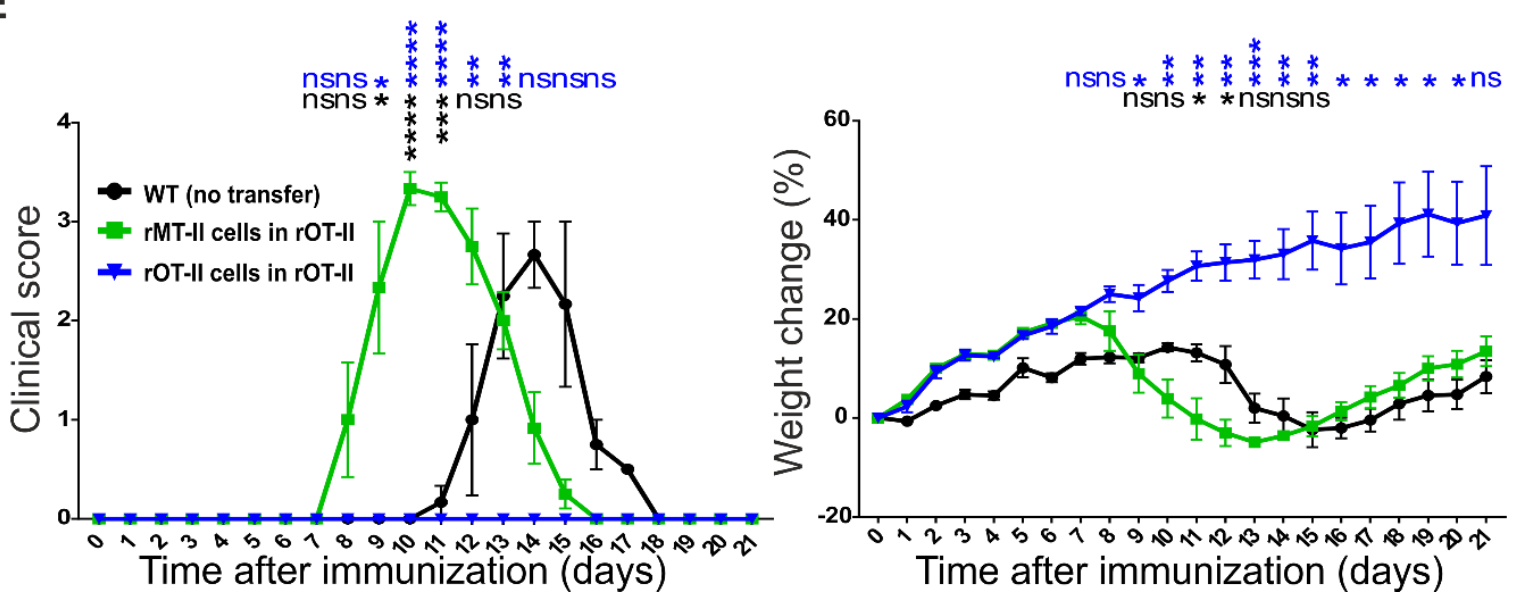

FIG 3 Adoptive transfer of rMT-II T cells prior to immunization confers susceptibility to active EAE.

(A) Outline of the experimental approach in transfer/immunization experiment using WT host. T cells were magnetically isolated from indicated organs and transferred i.v. into WT recipient Lewis rats. On the next day, these recipients and control naïve animals were s.c. immunized with MBP (Ag, antigen) in CFA. Clinical 
course (B) and the incidence of EAE $(\mathbf{C})$ are shown. Data are mean \pm SEM ( $\mathrm{n}=5$ for rMT-II transfer group and $n=3$ for $\mathrm{WT}$ group without $\mathrm{T}$ cell transfer). (D) Outline of the experimental approach in transfer/immunization experiment using TCR transgenic rOT-II host. T cells were magnetically isolated from lymph nodes of rMT-II or rOT-II background and transferred i.v. into rOT-II recipient rats. On the next day, rOT-II rats that received indicated type of T cells along with control naïve animals were s.c. immunized with MBP in CFA. (E) Clinical course of EAE (mean \pm SEM, $n=3$ per group). Statistical significance determined by t-test (blue: rMT-II cells in rOT-II versus rOT-II cells in rOT-II. black: rMT-II cells in rOT-II versus WT (NO transfer)) (F) EAE incidence (same legend as in E).

\subsection{Effector T cell lines derived from rMT-II strain are highly sensitive to MBP stimulation in vitro}

MBP-reactive CD4 effector T cell line can be established from immunized Lewis rats and are widely used for the induction of tEAE (Ben-Nun et al. 1981). Effector T cell lines can be readily established from rMT-II rats. Upon exposure to MBP-presenting APCs these cell lines vigorously proliferate and they are strongly pathogenic after transfer to healthy recipient rats (Lodygin, Kitz et al. unpublished). During generation and propagation of such lines, $\mathrm{T}$ cells are subjected to multiple rounds of antigenic stimulation and become terminally differentiated. We asked how the in vitro antigenic response of effector rMTII T cell lines differs from the response of primary rMT-II T cells isolated ex vivo from naïve donors.

To measure the antigenic response, equal numbers of resting effector T cells and primary T cells isolated from blood or lymph nodes were co-cultured with thymic APCs loaded with MBP at different concentrations. Then we performed a time course analysis of cytokine production by ELISA and qPCR over $48 \mathrm{~h}$ time period (FIG 4A-C). At each tested concentration of antigen, rMT-II effector T cells rapidly (from $6 \mathrm{~h}$ after stimulation on) increased secretion of IFN $\gamma$ and the concentration of this cytokine remained high until the end of experiment. Primary rMT-II LN T cells showed only transient and very small peak of IFN $\gamma$ production around $12 \mathrm{~h}$ time point. A similar discrepancy between effector T cell line and primary LN T cells was observed for the IL-2 cytokine release (FIG 4B).

The transcriptional response to MBP stimulation was much higher in the effector cell line than in blood or LN derived T cells (FIG 4C). It reached its peak after around $6 \mathrm{~h}$, and lasted until $24 \mathrm{~h}$ for IFN $\gamma$ and $12 \mathrm{~h}$ post stimulation for IL-2 mRNA (FIG 4C). The 
transcriptional response in blood and LNs T cells, even if much lower, was detected much later, at around $36 \mathrm{~h}$ after stimulation (FIG 4C).

The activation of LNs and blood rMT-II T cells by thymic APCs resulted in a very limited proliferation $72 \mathrm{~h}$ after stimulation, whereas these $\mathrm{T}$ cells vigorously proliferated in response to anti-CD3 and anti-CD28 antibody stimulation (FIG5 A). Additionally the CD25 expression in these cells increased after 48 hours and reached its peak in 72 hours with at all the antigen concentrations used. The maximal TCR stimulation by antibodies resulted, as expected, in a uniform increase of CD25 expression (FIG 5B).

A
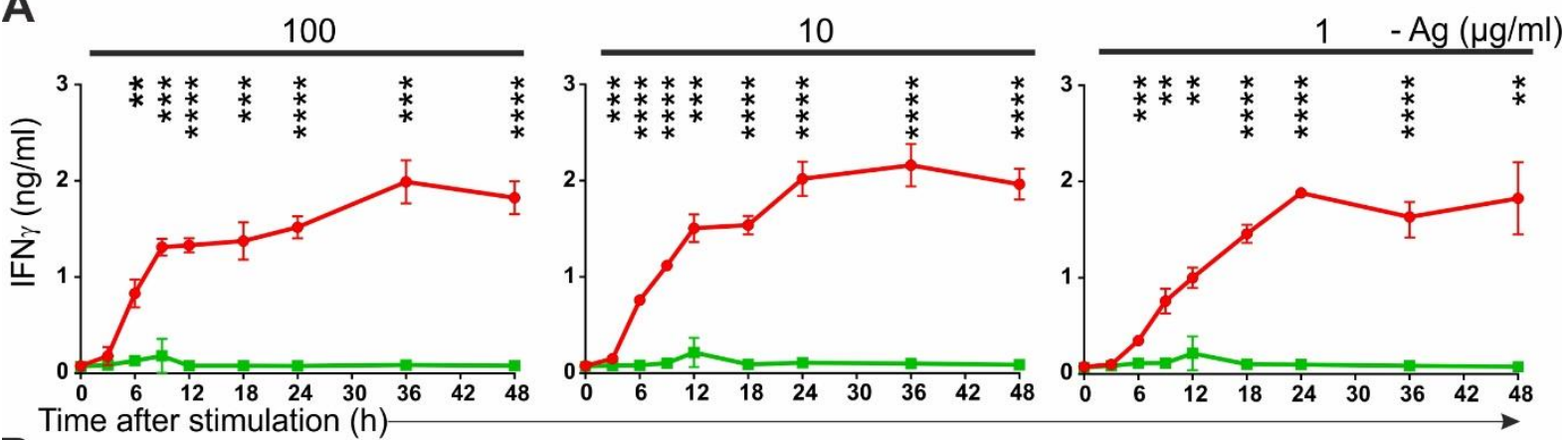

B

Time after stimulation $(\mathrm{h})$
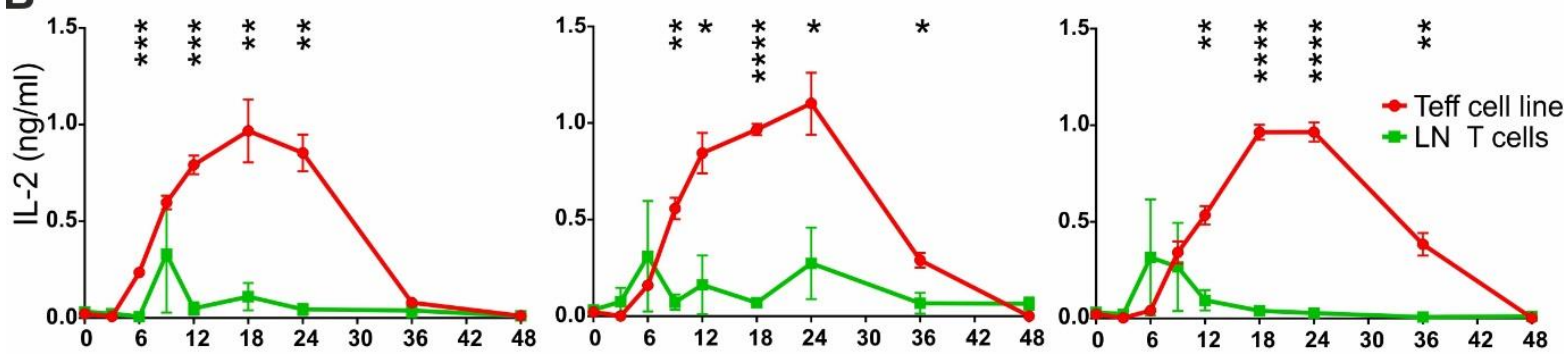

Time after stimulation $(\mathrm{h})$

C

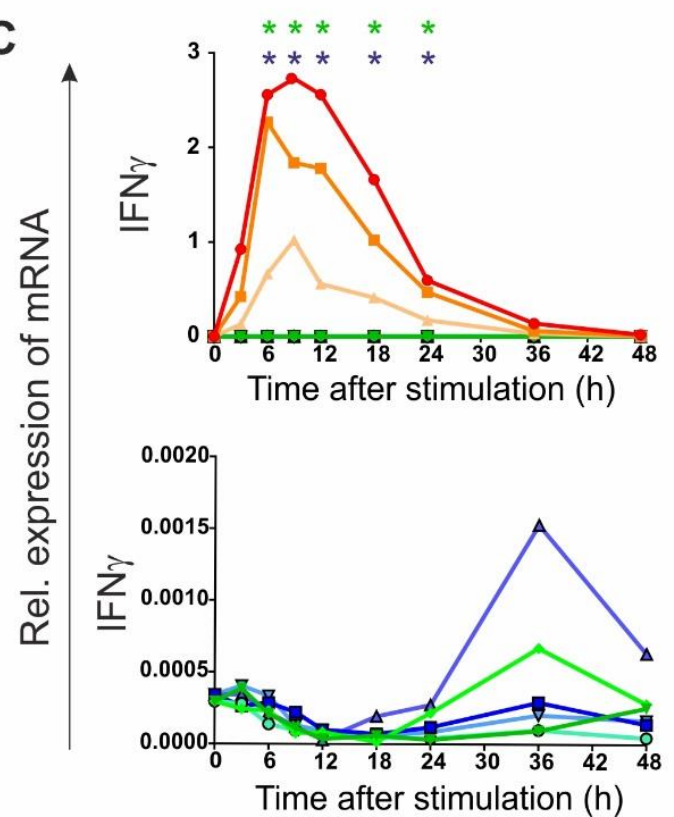

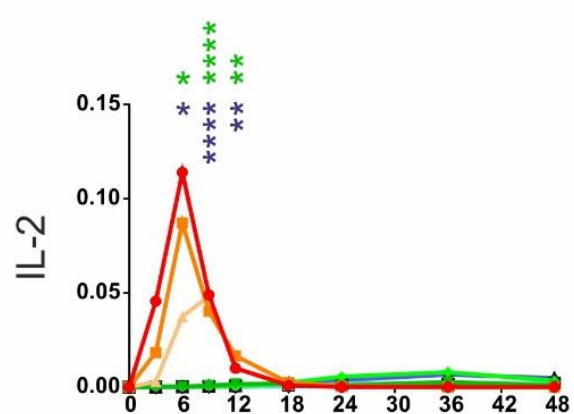

Time after stimulation $(\mathrm{h})$

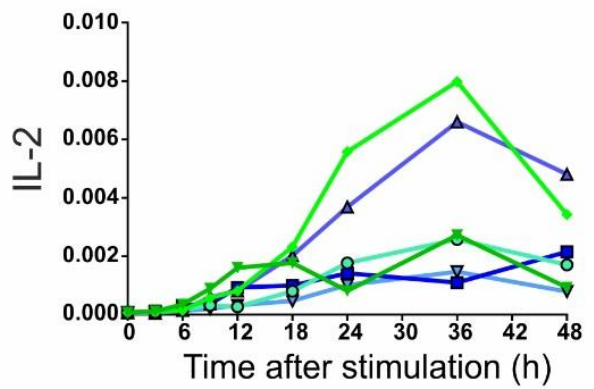

- Cell line 100

- Cell line 10

- Cell line 1

- LNs 100

- LNs 10

- LNs 1

- Blood 100

$\triangle$ Blood 10

$\nabla$-Blood 1

FIG 4 In vitro activation kinetic of different rMT-II T cell subsets. 


\section{FIG 4 In vitro activation kinetic of different rMT-II T cell subsets.}

Time course of cytokine production determined by $\operatorname{ELISA}(\mathbf{A}, \mathbf{B})$ and cytokine gene expression determined by quantitative reverse transcription polymerase chain reaction (RT-qPCR) (C). Concentration of IFN $\gamma$ (A) and IL-2 (B) in supernatants collected at the indicated time after addition of antigen loaded APC was measured over $48 \mathrm{~h}$ period. MBP-specific effector line established from rMT-II (Teff cell line, in red) and primary T cells isolated from naïve rMT-II LNs (LN T cells, in green). The stimulation was performed in vitro with irradiated thymocytes in the presence of $100 \mu \mathrm{g} / \mathrm{ml}, 10 \mu \mathrm{g} / \mathrm{ml}$ and $1 \mu \mathrm{g} / \mathrm{ml} \mathrm{MBP}$. Data are mean \pm SD. (C) RNA isolated from stimulated cells at the indicated time point after stimulation was converted to cDNA and analyzed by TaqMan PCR with primers and probes specific for IFN $\gamma$ and IL-2 gene transcripts. Shown is relative expression (mean \pm SEM) normalized to the level of beta-actin gene expression. On the bottom plots the expression values for the cell line are not shown in order to reveal small scale changes in the gene expression detected in primary $\mathrm{T}$ cells. The number on the plot legend indicates concentration of antigen $(\mu \mathrm{g} / \mathrm{ml})$.

\section{A}

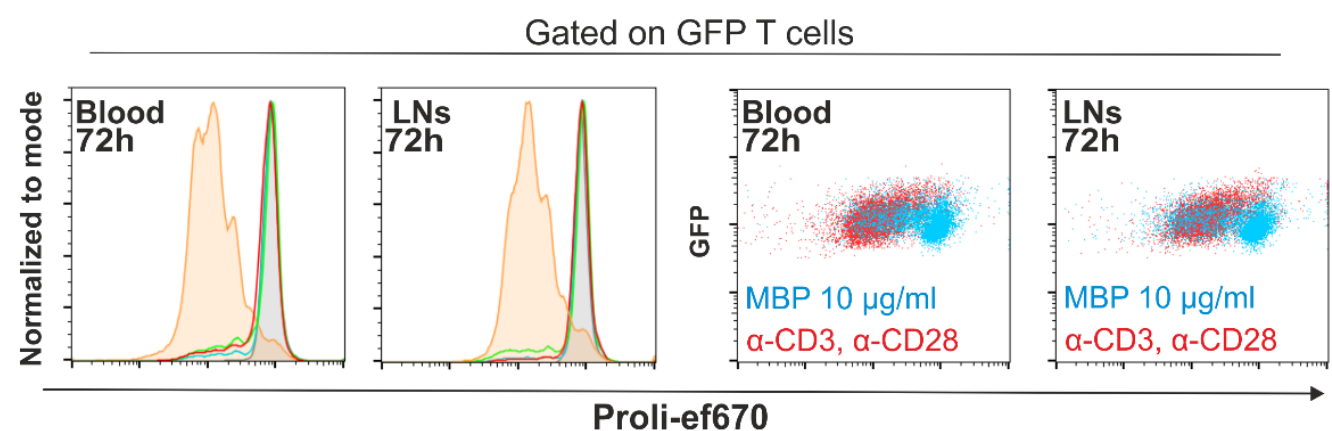

B

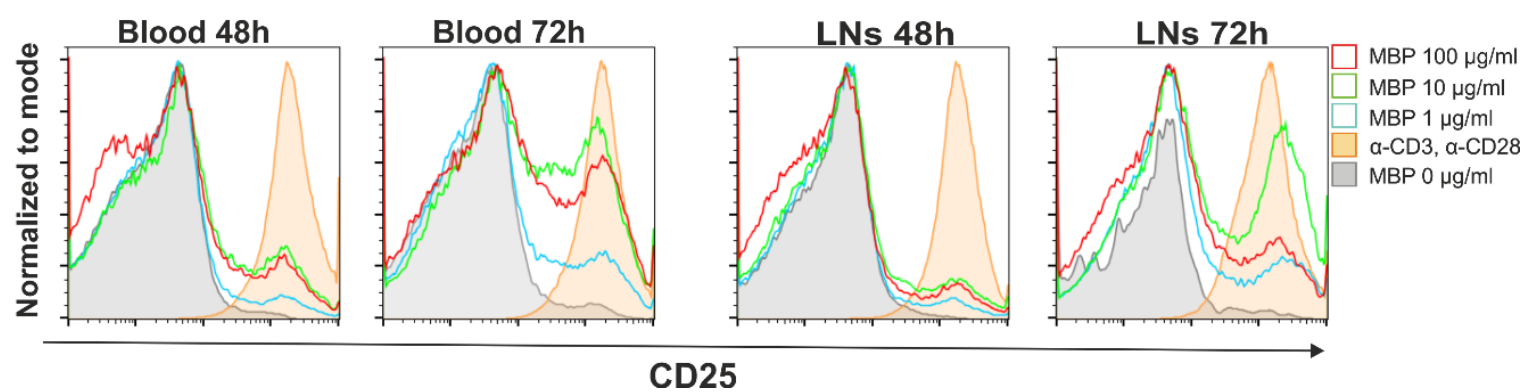

FIG 5 Activation of rMT-II T cells in vitro analyzed by flow cytometry.

(A) Proliferation-dependent dilution of fluorescent dye eFluor670 measured by flow cytometry. Primary rMT-II T cells isolated from blood and LN were stimulated with antigen loaded thymic APCs or with monoclonal antibodies specific for CD3 and CD28 (color code shown in panel B) and analyzed on day 3 after stimulation. (B) Expression of CD25 activation marker on blood and LN derived rMT-II T cells determined by immunostaining at the indicated time point after stimulation. 


\subsection{Phenotype and CNS residence of rMT-II T cells under steady state condition}

The inability of rMT-II T cells to enter the tissue expressing the myelin target antigen in rMT-II rats might be a reason why these animals do not develop spontaneous autoimmunity. It is however known that the central nervous system, in spite being an immune-privileged organ, undergoes continues surveillance by immune cells (Deli et al. 2005). We therefore asked whether MBP-specific rMT-II T cells can be detected in the CNS of healthy rats. We analyzed T cell frequency in the spinal cord (SC) of healthy rMTII rats (perfused with cold PBS to remove contaminating blood) and analyzed their immune phenotype. For comparison, we also analyzed T cells derived from immune organs such as blood, LN and non-immune organ, the gut.

In fact, we observed in the SC the presence of T cells. Expectedly, compared to blood, LNs or a preparation of intraepithelial lymphocytes (IELs) from the small intestine the numbers of these CNS-derived T cells were very low. However, we could counted an average of $1136.7 \pm 245.6 \mathrm{~T}$ cells per $\mathrm{g}$ of the total SC tissue including the meninges, of which an average of $327.6 \pm 59.2 \mathrm{~T}$ cells per g were present in the SC parenchyma (separated from meninges) (FIG 6A). This result indicates that T cells in rMT-II rats contribute, albeit at low rate, to CNS immune-surveillance. CD62L (L-selectin) expression can distinguish naïve T cells from memory T cells. Staining of T cells recovered from the SC revealed that the vast majority of them were CD62L negative $(96.7 \pm 1.5 \%)$ and therefore likely to be memory T cells (FIG 6B). In contrast, CD62L+ naïve rMT-II T cells were abundantly present in the blood and LN, where this population is known to circulate and home, respectively. Interestingly, among gut IELs 95\% of T cells were also CD62L negative, which confirms the concept that $\mathrm{T}$ cells residing in peripheral organs have a memory phenotype (Gebhardt et al. 2013). Further, we found that CD25 expression was increased in T cells recovered from SC relative to the levels detected in blood and LN T cells (FIG 6C), consistent with the assumption that SC-derived $\mathrm{T}$ cells belong to the memory subset. This findings can be interpreted in two ways. First, memory T cells preferentially (if not exclusively) gain access to and maintain residency in the healthy CNS. Second, naïve rMT-II T cells enter CNS tissue, recognize locally presented antigen and differentiate into memory type, thereby ceasing expression of CD62L and upregulating CD25 expression. The second scenario is unlikely as the following data 
suggest. As evident from TCR staining of rMT-II cells in different organs, there are two distinct populations of $\mathrm{T}$ cells with high and intermediate expression level of $\alpha \beta T C R$ (FIG 6A, see also FIG VII). TCR ${ }^{\text {int }}$ cells uniformly express the TCR-V $\beta 8.2$ chain whereas TCR high present with dispersed levels of V $\beta 8.2$ expression and some of them express endogenous (non-transgenic) TCR $\beta$ chains at the levels equivalent to TCR expression in WT rats. Thus, $\mathrm{TCR}^{\text {high }} \mathrm{T}$ cells in $\mathrm{rMT}$-II rats most likely represent those cells that during development have escaped allelic exclusion and express a second TCR from the endogenous promoter that is somewhat stronger than the promoter driving transgene expression. Because MBP-specific effector T cell lines established from rMT-II rats become uniformly TCR int (data not shown), T cells with high TCR expression seem to be less reactive to MBP and therefore are lost during repeated cycles of stimulation in vitro. Furthermore, when $\mathrm{T}$ cells isolated from naïve rMT-II rats are transferred into WT recipients, only the TCR ${ }^{\text {int }}$ fraction responds to the injection of cognate antigen by proliferation (FIG 6D), indicating that TCR high cells react poorly to MBP. Since T cells recovered from the CNS are predominately $\mathrm{TCR}^{\text {high, }}$, it is unlikely that local recognition of MBP accounts for their CD62L-CD25+ phenotype. 
A

Gated on living cells

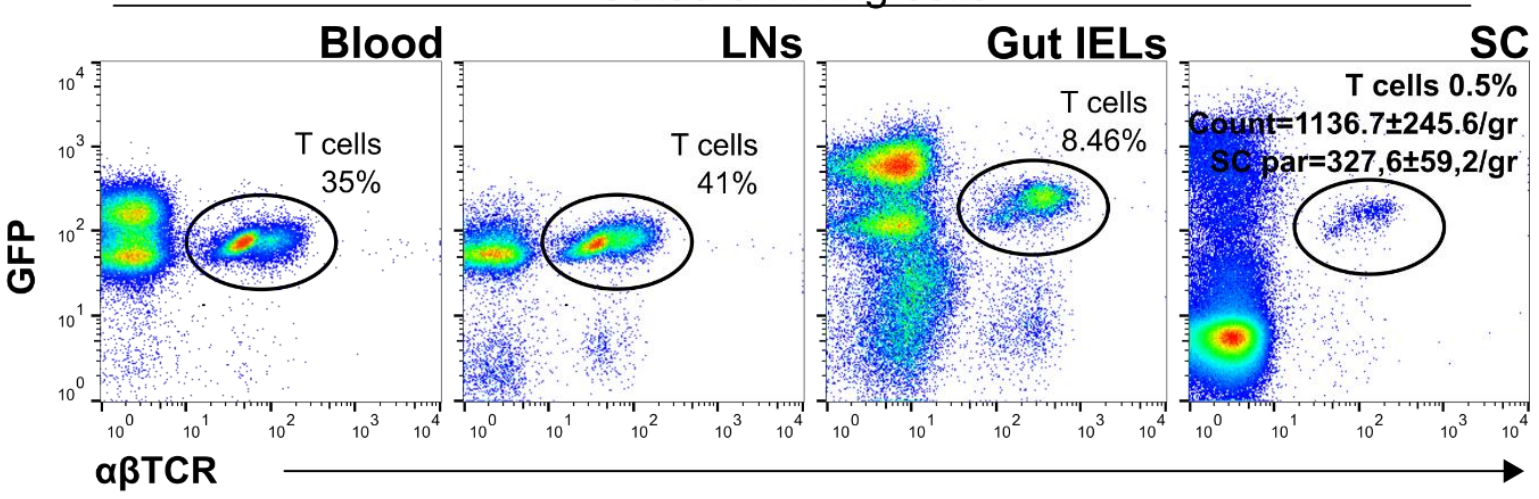

B

Gated on T cells

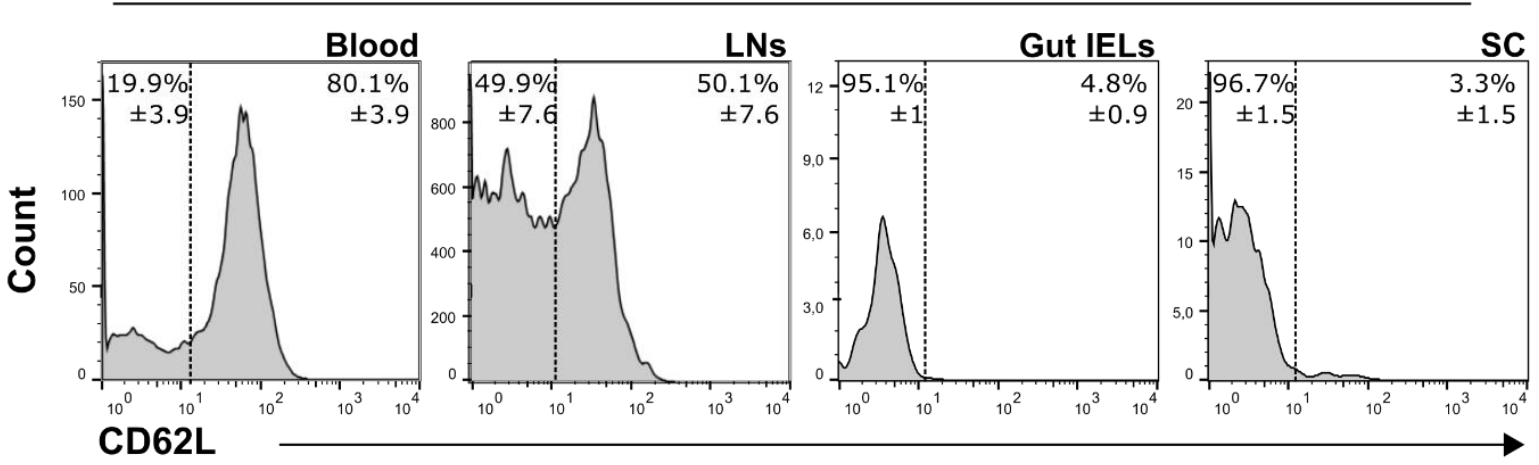

C

Gated on T cells
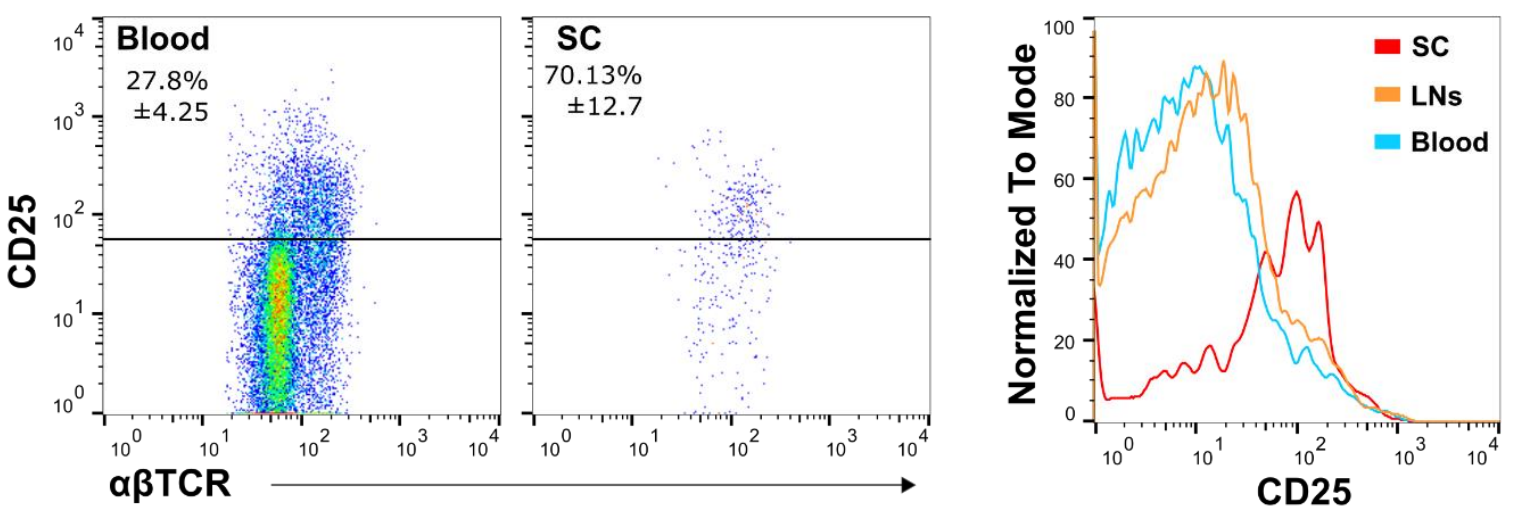

D
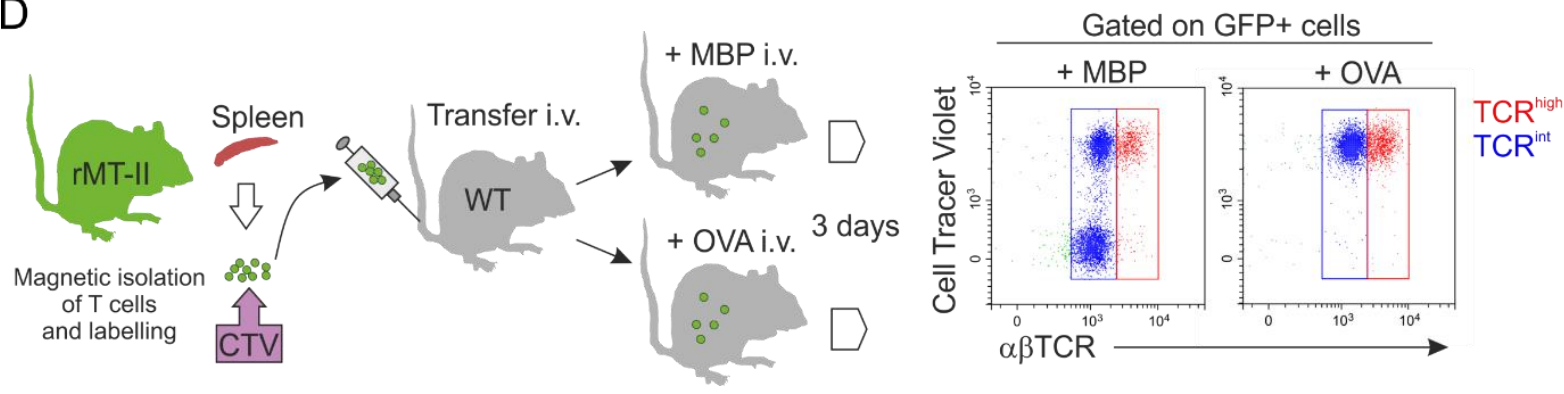

FIG 6 Phenotype of rMT-II T cells in naïve animals. 
FIG 6 Phenotype of rMT-II T cells in naïve animals.

Cells from blood, cervical lymph nodes (LNs), spinal cord (SC) and intraepithelial lymphocyte (IEL) preparation from the gut of rMT-II rats were isolated as described in METHODS, stained and analyzed by FACS to analyze T cell numbers and the expression of CD62L and CD25 surface markers.

(A) The frequency of $\alpha \beta T C R+$ GFP+ T cells among gated living cells is representative of $n>10$ samples in blood and LNs, $n=3$ samples in the gut IELs and $n=6$ samples in SC. The number of T cells infiltrating the SC and the SC parenchyma (SC par) is expressed as mean \pm SD of $n=3$ samples.

(B) The frequency of CD62L + and - $\mathrm{T}$ cells is presented as mean $\pm \mathrm{SD}$ of $\mathrm{n}=5$ samples in blood, LNs and SC and of $\mathrm{n}=3$ in gut IELs.

(C) The frequency of CD25+ T cells in blood and SC is expressed as mean $\pm \mathrm{SD}$ of $\mathrm{n}=3$ samples. The histogram is representative of $n=6$ experiments.

(D) The outline of experimental approach for in vivo testing antigen response of rMT-II T cells and representative flow cytometry results of measuring antigen-dependent proliferation in vivo $(\mathrm{n}=6)$. CTV, Cell Tracer Violet; OVA, ovalbumin.

\subsection{Intrathecal transfer of primary rMT-II T cells is not sufficient for the induction of clinical disease}

Very low numbers of rMT-II T cells in the CNS and the prevalence of $\mathrm{TCR}^{\text {high }}$ fraction among them (presumably having no or very little MBP reactivity) may suggest that there are not enough self-reactive $T$ cells entering the target organ to trigger the cascade of pathogenic events leading to EAE. To test this assumption, we decided to increase the number of T cells entering the CNS by performing an intrathecal injection of about 5 million rMT-II T cells isolated from a pool of LNs, blood and spleen into rMT-II rats. In another group of rMT-II rats we injected the same number of pathogenic effector T cell blasts of an rMT-II $\mathrm{T}$ cell line, harvested two days after MBP stimulation in vitro. Interestingly, none of the rats injected with primary $\mathrm{T}$ cells developed EAE. In contrast, the rMT-II effector T cell blasts were able to induce a typical monophasic EAE course, starting on the third day after transfer, in all the injected animals (FIG 7A and B). In order to verify the presence of the transferred T cells in the CNS, rMT-II LNs-blood-spleen T cells were intrathecally injected in WT rats. As shown in FIG 7C, the transgenic green cells were found one day later both in the spinal cord and in the brain of these rats. Therefore, these results indicate that the functional state rather than the number of MBP-specific $T$ cells crossing the BBB is crucial for the disease development. 

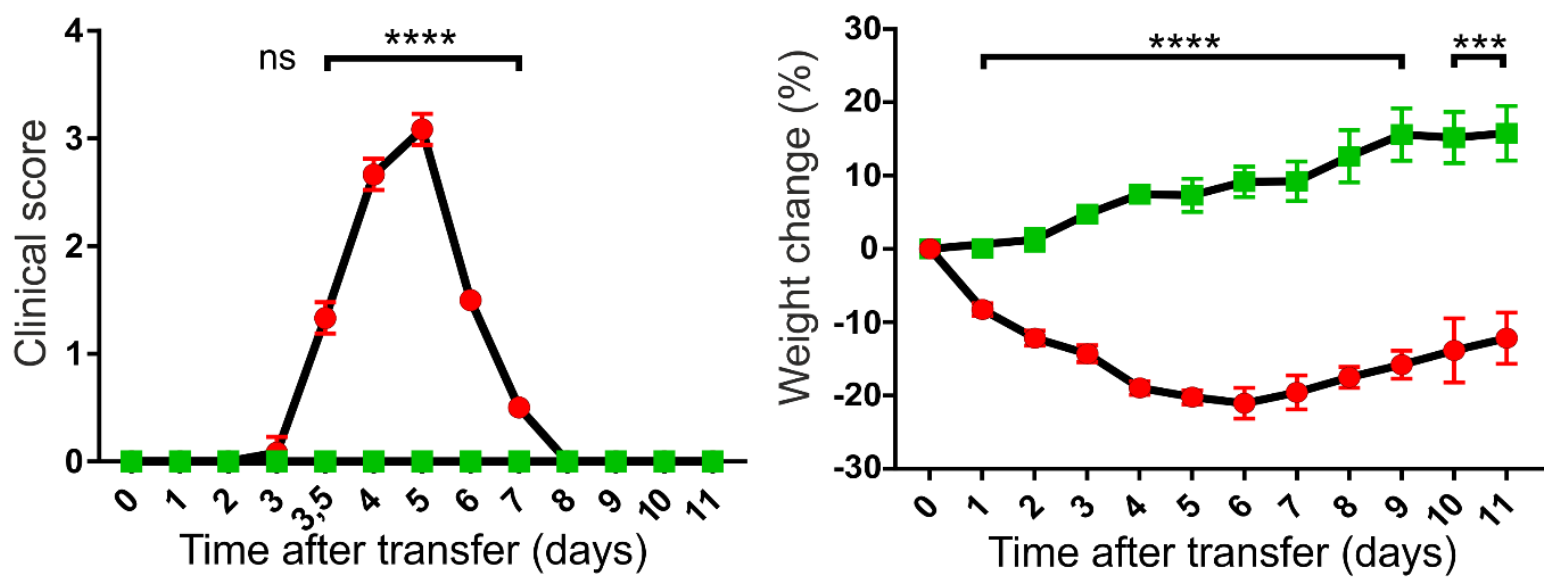

C

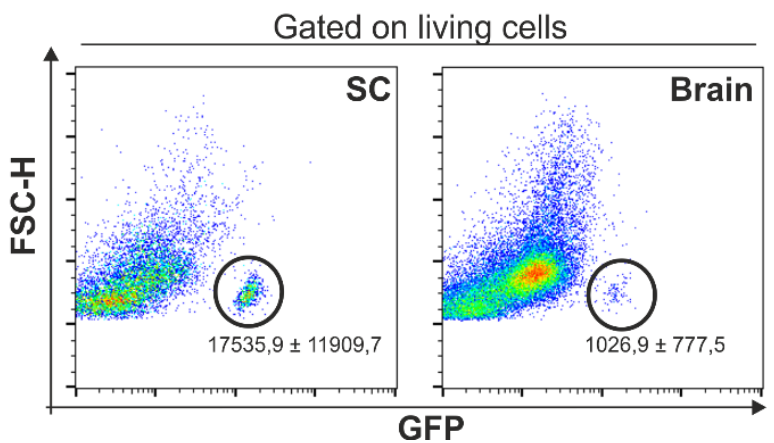

FIG 7 Intrathecal injection of freshly activated effector but not primary rMT-II T cells induces EAE disease.

(A,B) rMT-II rats were injected intrathecally with $5 \times 10^{6} \mathrm{rMT}$-II T cells. The clinical score and the percentage of weight variation were measured daily in each rat.

One group of rMT-II rats ( $\mathrm{n}=3$ ) was injected with T cells of a rMT-II T cell line (in red). Another group was injected with rMT-II T cells magnetically isolated from a pool of LNs, spleen and blood (transferred rats $n$ = 6) of naïve rats (in green). (C) WT rats $(n=2)$ were injected intrathecally with 5 million rMT-II T cells isolated by MACS from a pool of LNs, spleen and blood of naïve rats. One day after transfer, the brain and the SC were extracted after perfusion, in order to quantify by FACS the GFP rMT-II T cells inside the central nervous system.

All data are presented as mean \pm SD. In $(C)$ is shown the mean $\pm S D(n=2)$ of the GFP T cells number per total organ. Student's $t$ test was performed for all statistical analyses: In $(A, B)$ is shown the statistical difference between the two groups in each highlighted time point. 


\subsection{Recently activated effector $T$ cells show a much higher level of activation in the CNS than naïve or resting memory $\mathrm{T}$ cells}

Our hypothesis that the functional state of the $\mathrm{T}$ cells dictates encephalitogenicity was further tested in a following set of experiments. We performed transfer or active EAE induction in rMT-II rats and analyzed the activation status of different T-cell subsets (FIG 8A). In the case of EAE induced by the transfer of $\mathrm{T}_{\mathrm{MBP} \text {-mCherry }}$ cells, we isolated $\mathrm{T}$ cells from the blood and inflamed CNS at the onset of disease. Under this condition we could distinguish three populations of T cells, namely effector T cells (Cherry+, GFP-, CD62L-), naïve rMT-II T cells (Cherry-, GFP+, CD62 $\mathrm{L}^{+}$) and memory rMT-II (Cherry-, GFP+, CD62L-). In the case of active EAE induced by immunization, we also isolated $\mathrm{T}$ cells from the blood and inflamed CNS at the onset of disease. Under this condition we could distinguish two populations of T cells, these being effector/memory T cells (GFP+, CD62L-) and naïve rMTII T cells $\left(\mathrm{GFP}^{+}, \mathrm{CD} 6 \mathrm{~L}^{+}\right)$(FIG 8B).

In the transfer EAE experiments, effector $\mathrm{T}_{\mathrm{MBP}}$ cells were found in the blood and in the SC tissue at disease onset. As expected, the numbers of effector $\mathrm{T}_{\mathrm{MBP}}$ cells in this early clinical phase predominated over those of the recruited rMT-II T cells (FIG 8B). Recruited rMTII T cells isolated from SC were almost exclusively CD62L negative, whereas in the blood about $80 \%$ were naïve (GFP+, CD62L+; FIG 8B). Similarly to transfer EAE, under condition of immunization nearly all rMT-II T cells entering the SC were CD62L negative (FIG 8B). Therefore, naïve T cells are largely not capable of entering the CNS either in healthy condition or in the early stage of EAE disease.

In the transfer EAE experiment, the effector $\mathrm{T}_{\mathrm{MBP}}$ cells expressed higher levels of CD25 than rMT-II T cells both in the blood and in the SC (FIG 8C). The upregulation of CD25 expression in the SC relative to blood, which is indicative of antigenic stimulation, was stronger in effector $\mathrm{T}_{\mathrm{MBP}}$ cells than in rMT-II T cells (FIG 8C). However, in active EAE experiments, recently rMT-II T cells activated in the periphery also markedly upregulated CD25 upon entry into CNS (FIG 8D), very much like effector $\mathrm{T}_{\mathrm{MBP}}$ cells in the transfer $\mathrm{EAE}$ settings.

Further, we analyzed gene expression in T cells sorted by flow cytometry from blood and SC tissue in both types of EAE. As expected, effector $\mathrm{T}_{\mathrm{MBP}}$ cells isolated from SC tissue strongly upregulated the expression of pro-inflammatory cytokines IFN $\gamma$, IL-17 and GMCSF (FIG 9). We could also confirm upregulation of mRNA of the IL-2 receptor alpha chain 
gene (encoding CD25 protein, detected earlier by immunostaining). In contrast, rMT-II T cells recovered from SC tissue in transfer EAE showed only marginal increase of IFN $\gamma$, IL17 and GM-CSF mRNA levels relative to levels in blood derived rMT-II T cells (FIG 9). In active EAE, rMT-II T cells in the SC tissue induced expression of pro-inflammatory cytokines much more strongly than did rMT-II T cells passively recruited in transfer EAE settings (FIG 9). 


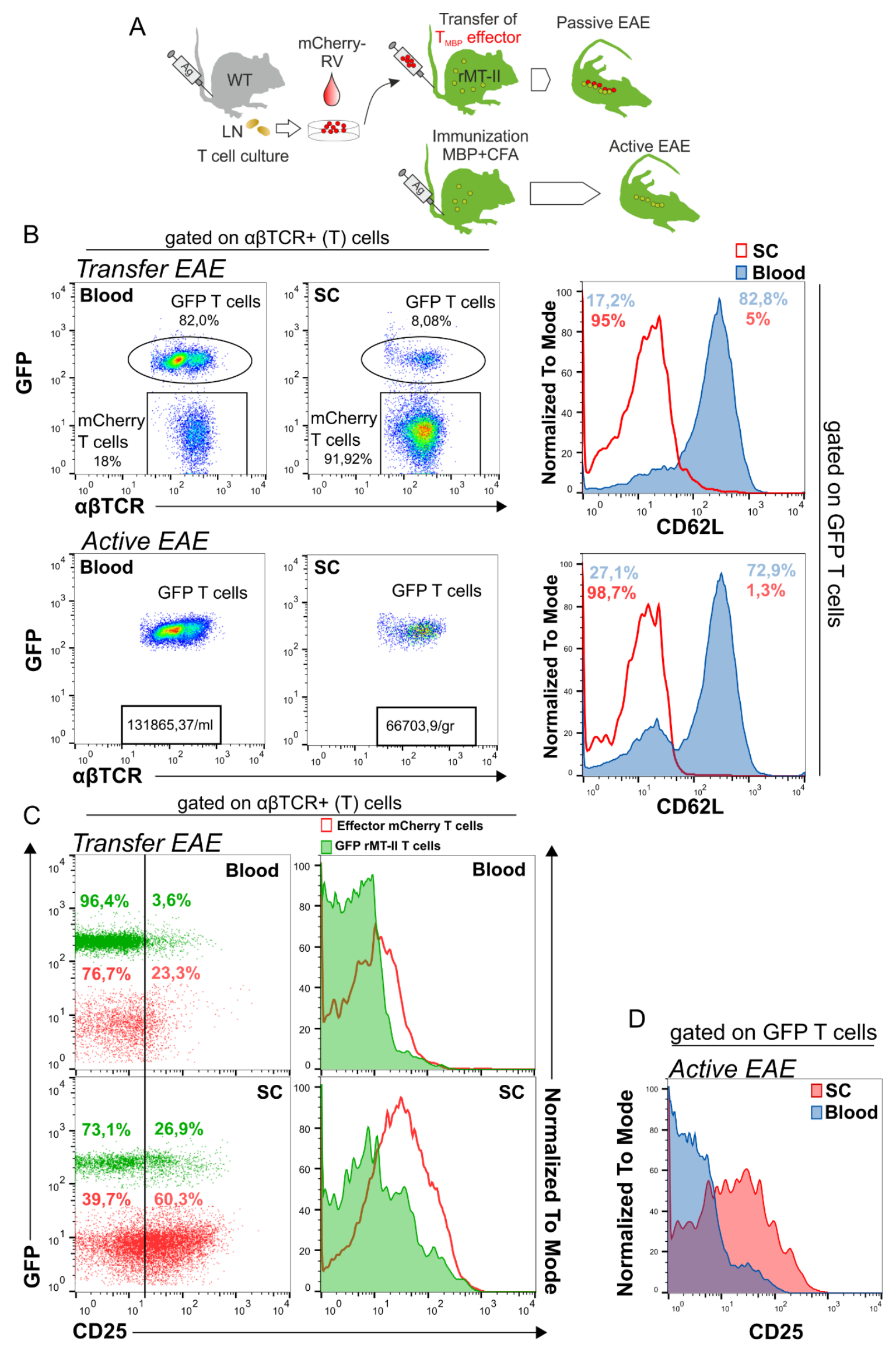

FIG 8 Transfer versus active EAE in rMT-II rats. 


\section{FIG 8 Transfer versus active EAE in rMT-II rats.}

(A) In the first group EAE was induced in rMT-II rats by transfer of $4 \times 10^{6}$ effector $\mathrm{T}_{\mathrm{MBP}}$ cells transduced in culture with retrovirus encoding mCherry red fluorescent protein (transfer EAE). The second group of rMTII animals was immunized with MBP in CFA (Active EAE). When animals developed clinical EAE (day 3 for transfer EAE and day 6 for active EAE) spinal cord tissue and blood were analyzed by flow cytometry. In (B) is shown the frequency of $\alpha \beta \mathrm{TCR}^{+} \mathrm{GFP}^{+}$(GFP T cells) and $\alpha \beta \mathrm{TCR}^{+}$mCherry+ GFP- (effector mCherry T cells) $\mathrm{T}$ cells in blood and SC after transfer EAE (top panels) and the number of GFP $\mathrm{T}$ cells in both the compartments in active EAE (bottom panels). Histogram shows the difference in CD62L expression of GFP $\mathrm{T}$ cells in the blood (blue) and in the SC, (red) both after transfer and after active EAE induction. In the overlay dot plots in (C) are compared the frequencies of $\mathrm{CD} 25^{+}$cells among the effector mCherry $\mathrm{T}$ cells (red) and the rMT-II GFP T cells (green) both in the blood and in the SC, after transfer EAE induction. The histograms in (C) show the difference in CD25 expression between the two groups of cells in the blood and in the SC, after transfer EAE induction. In (D) is shown the difference in CD25 expression between the rMTII $\mathrm{T}$ cells in the blood and in the SC after active EAE induction. All the shown data are representative of $n=$ 3 experiments. 


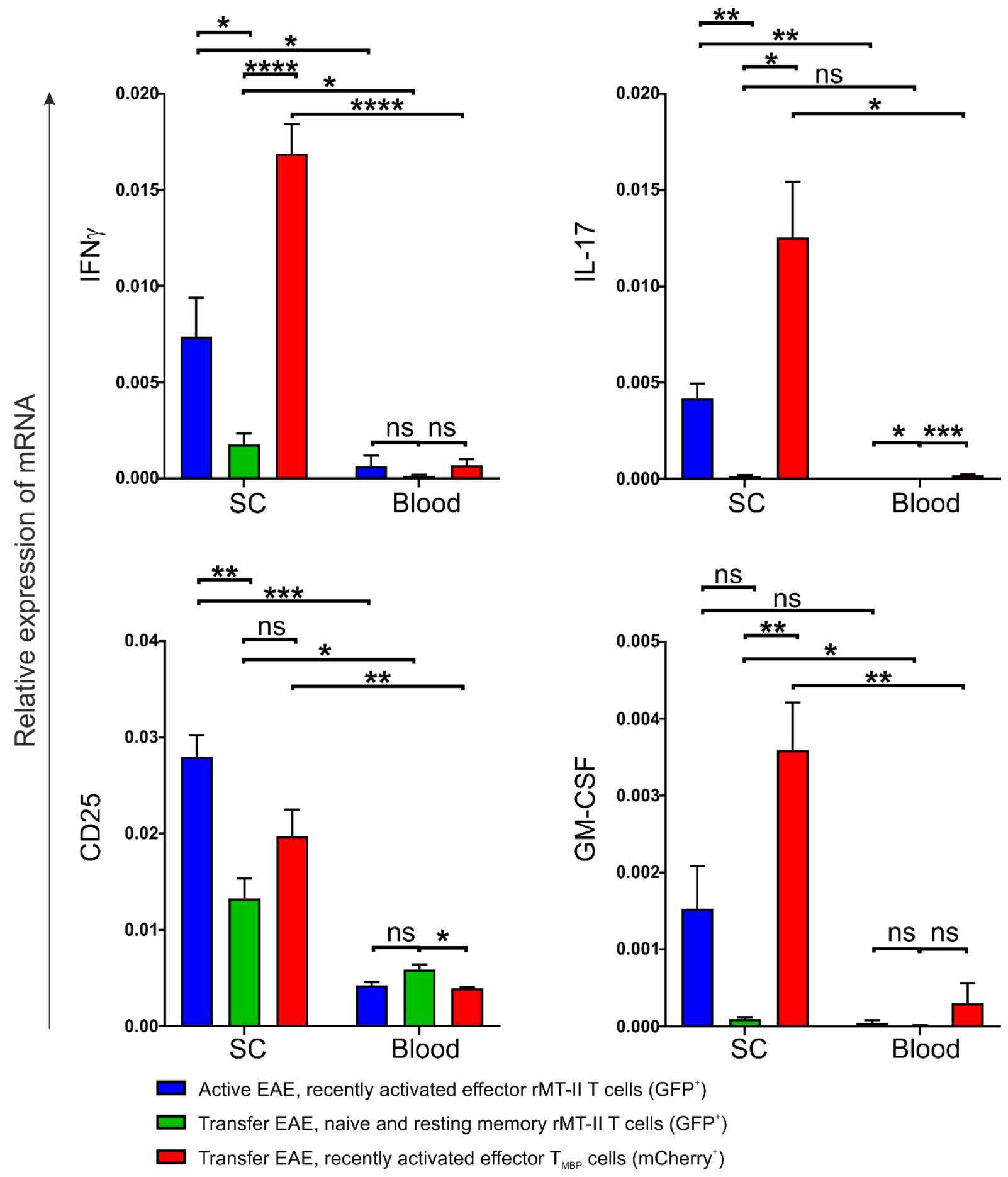

FIG 9 Analysis of T cell activation in transfer and active EAE in TCR transgenic rMT-II rats.

Experimental setup is outlined in FIG 8A. The rats were sacrificed around day 3 after transfer, or day 6 after immunization. The cells were isolated from blood and spinal cord (SC), stained for $\alpha \beta T C R$ and sorted by FACS as $\alpha \beta T C R+G F P+T$ cells (in blue for Active EAE; in green for Transfer EAE) and as $\alpha \beta T C R+$ mCherry+ GFP- T cells (in red). The graphs show the expression level of IFN $\gamma$, IL-17, CD25 and GM-CSF normalized to $\beta$-actin gene expression. All data are presented as mean \pm SEM of $n=3$ for active EAE and $n=3$ and 6 for transfer EAE. The statistical analysis was performed by student's $t$ test. In the graphs are shown the statistical differences per each indicated pair of groups. 
The entire population of rMT-II T cells in TCR transgenic rats is functionally heterogenic, i.e. it contains naïve and memory subsets and the memory subset itself may consist of central memory, effector memory and resident memory T cells. Moreover, the presence of TCR ${ }^{\text {high }}$ population with uncertain antigenic specificity complicates the interpretation of our results. Therefore, we decided to perform similar experiments in CD4 $\mathrm{T}_{\mathrm{MBP}}$ "memory" rats, as this system allows an analysis of a more uniform population of $\mathrm{T}$ cells with well-defined antigenic specificity and differentiation history. To this end, we generated "memory" rats using GFP-tagged $\mathrm{T}_{\mathrm{MBP}}$ cells established in culture and neonatally transferred into WT Lewis recipients. These "memory" animals were used as a host for transfer of effector $\mathrm{T}_{\mathrm{MBP}-C h e r r y}$ cells to induce transfer $\mathrm{EAE}$, or were subjected to immunization with MBP in CFA (FIG 10A). In transfer EAE settings, both recently activated effectors (Cherry ${ }^{+}$) and resting memory (GFP+) T cells were readily identified in blood at the day of onset of clinical symptoms, and both cell types entered SC tissue showing similar proportional enrichment ( $\sim 5$ fold) among all T cells detected (FIG 10B). The CD25 expression of the two T cell subsets was similar in the blood and evidently increased in the SC in both T cell groups. Instead, the OX40 expression was different in the blood, but only the one in recently activated effector T cells increased in the SC (FIG 10B). Immunization of "memory" rats resulted in a prominent increase of GFP+ $\mathrm{T}$ cells frequency in the blood (from 0.7 to $5.9 \%$ of all T cells) and in the SC tissue (from 3.6 to $58.7 \%$ of all T cells) (FIG 10C). Furthermore, ex-memory $\mathrm{T}_{\mathrm{MBP}}$ cells recently activated in the peripheral lymph nodes by immunization, upon entry into SC tissue upregulated CD25 and OX40 surface activation markers relative to the levels in blood (FIG 10C). 
A

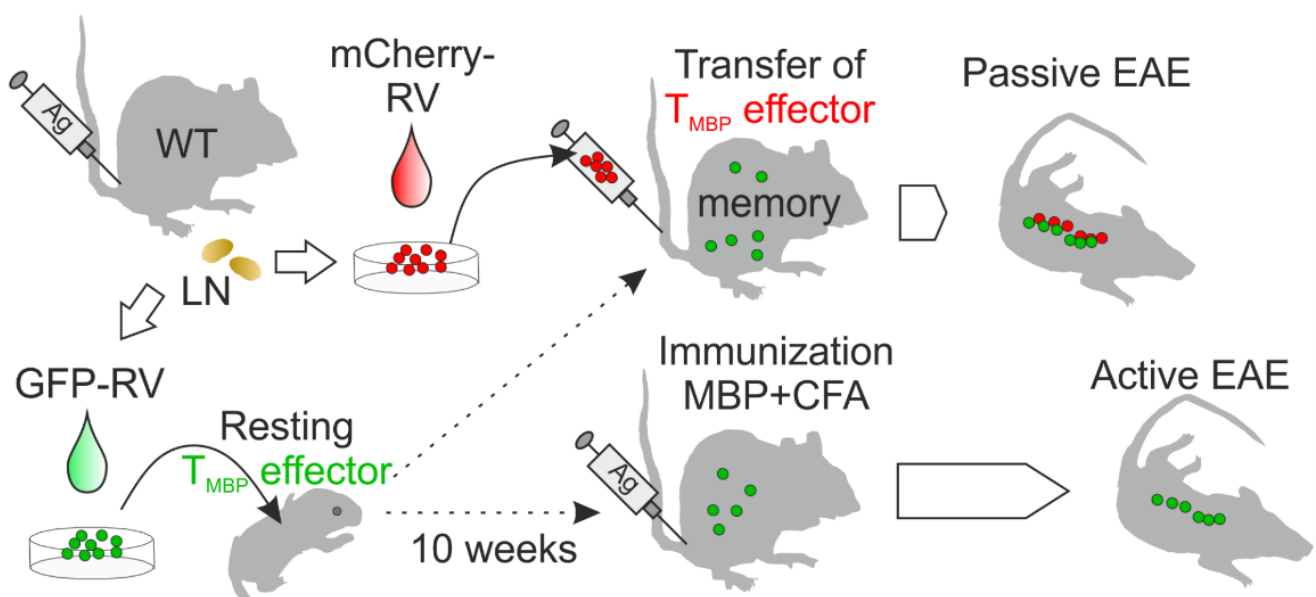

B
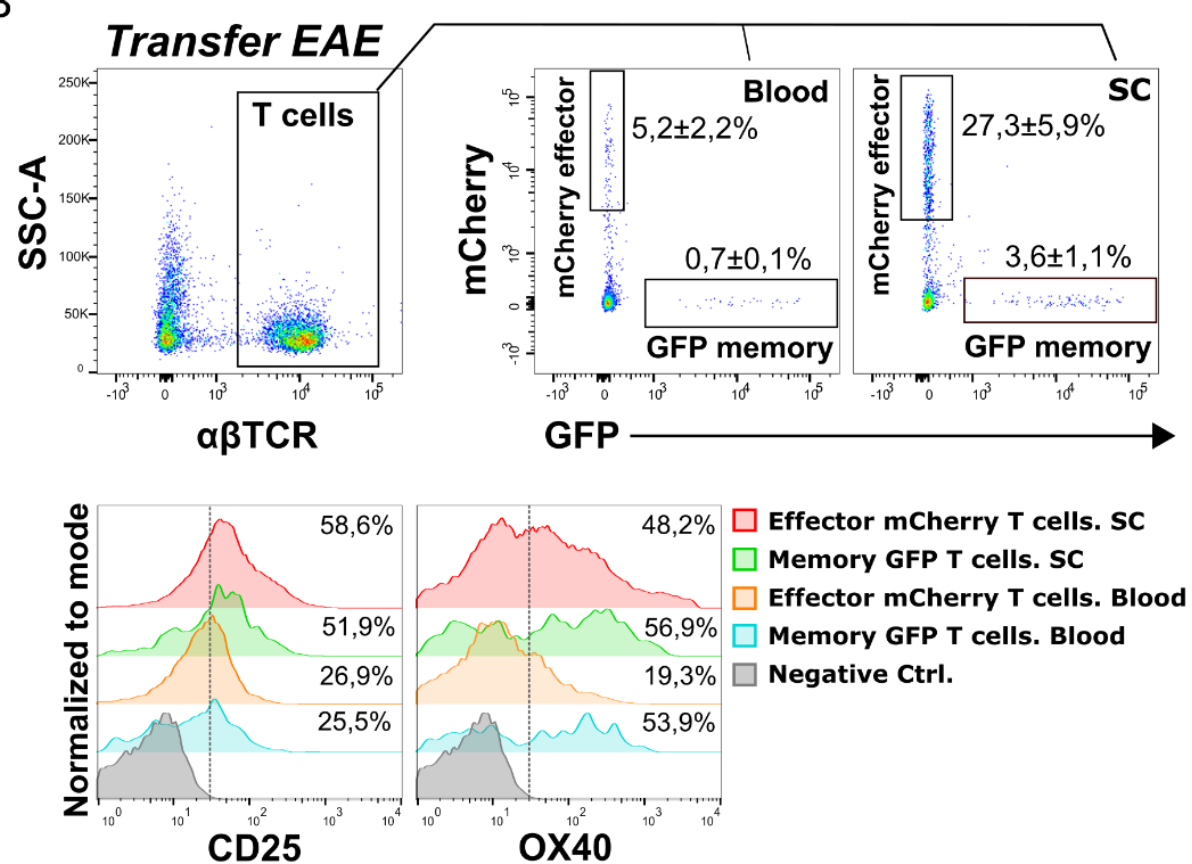

C
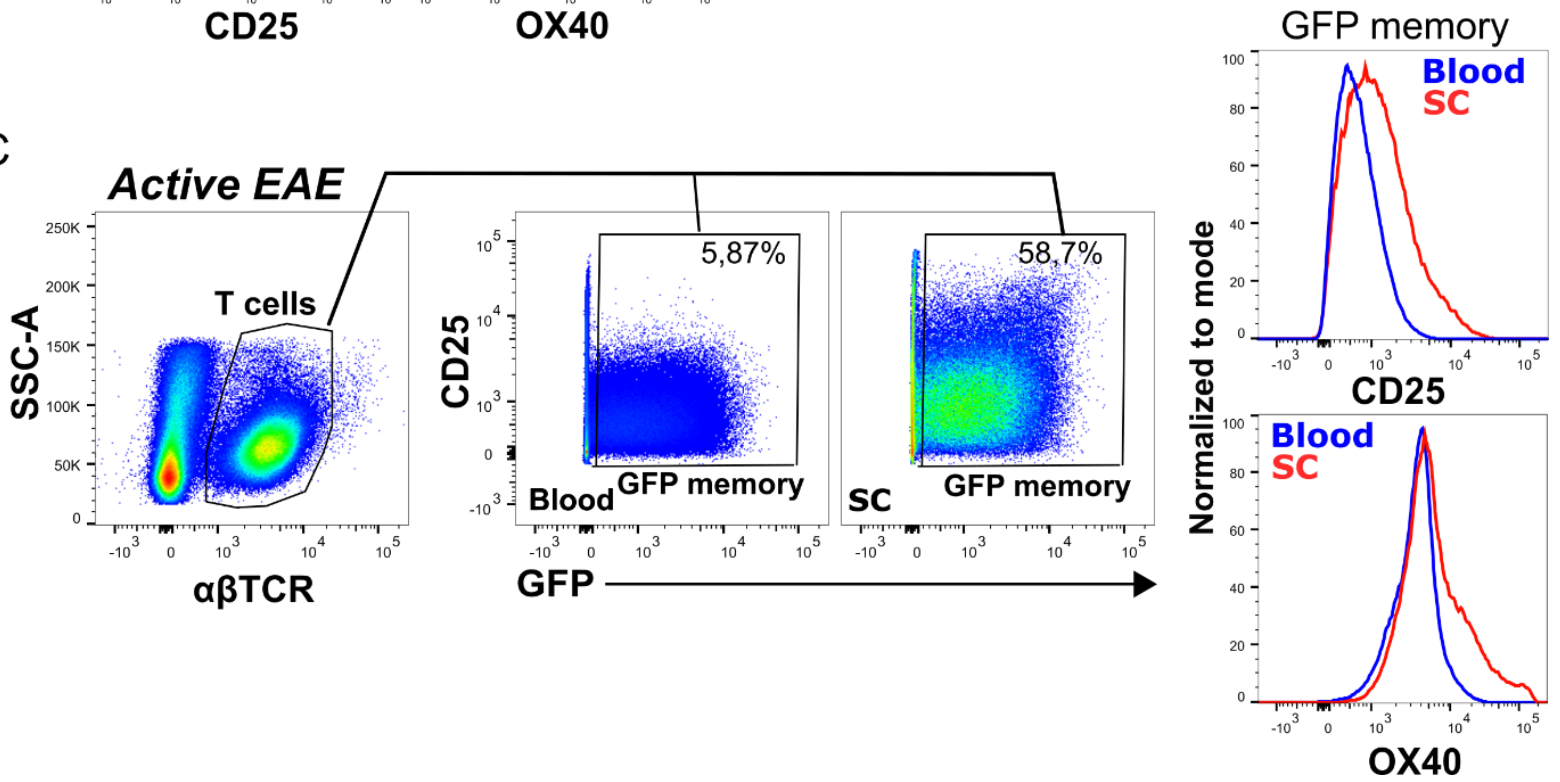

FIG 10 Analysis of transfer and active EAE in $\mathrm{T}_{\mathrm{MBP}}$-memory rats. 
FIG 10 Analysis of transfer and active EAE in $\mathrm{T}_{\mathrm{MBP}}$-memory rats.

(A) Memory rats were prepared by i.p. injection of $2 \times 10^{6}$ resting effector TMBP-GFP cells into newborn Lewis rats and 8 weeks later the engraftment was confirmed by flow cytometry analysis of peripheral blood samples. EAE was induced in the first group of "memory" rats by transfer of $4 \times 10^{6} \mathrm{~T}_{\mathrm{MBP}-\mathrm{mChery}}$ effector $\mathrm{T}$ cell blasts (transfer EAE) and in the second group by immunization with MBP in CFA (active EAE). The rats with clinical signs of disease were sacrificed 3 days after transfer (B) or 6 days after immunization (C). The cells were isolated from blood and spinal cord (SC) and analyzed by flow cytometry (B,C). (B) Shown is the frequency of GFP memory and mCherry effector T cells among the whole T cell population in blood and SC in transfer EAE. Numbers in the dot plots are frequencies of indicated T cell types (mean \pm SEM of $n=5$ ). (C) Shown is the frequency of GFP memory T cells in active EAE. The dot plots are representative of $n=4$.

Analysis of gene expression in T cells sorted from the CNS of memory rats at the onset of transfer or active EAE revealed substantial upregulation of IFN $\gamma$, IL-17 and CD25 transcripts in both transferred effector $\mathrm{T}_{\mathrm{MBP}-\text { Cherry }}$ cells and ex-memory $\mathrm{T}_{\mathrm{MBP}-\mathrm{GFP}}$ reactivated in the periphery by immunization prior to re-entering the circulation (FIG 11). Interestingly, passively recruited memory $\mathrm{T}_{\mathrm{MBP}-\mathrm{GFP}}$ cells in transfer EAE settings showed much lower activation levels than either of the recently activated T cell populations (FIG 11).

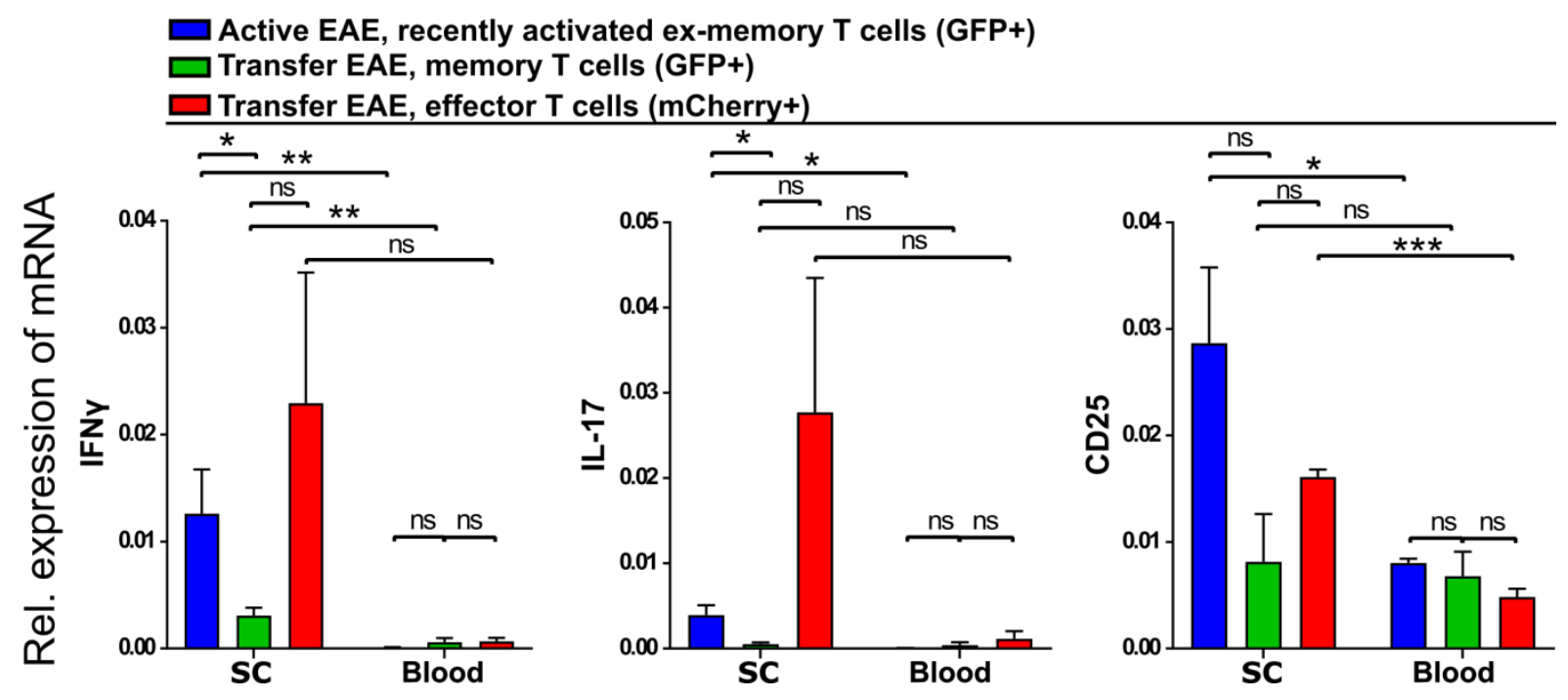

FIG 11 Activation of MBP-specific $T$ cells in the target tissue during transfer and active EAE in $\mathrm{T}_{\mathrm{MBP}}$ memory rats.

IFN $\gamma$, IL-17 and CD25 gene expression in the FACS-sorted T cell populations from memory rats (FIG 10 AC). The data are RT-qPCR results and normalized to the level of $\beta$-actin expression (mean \pm SEM of $n=3$ or more for either type of EAE). The statistical analysis was performed by student's $t$ test. 
Together our data obtained in two different models, TCR transgenic and memory rats, indicate that a memory (antigen-experienced) phenotype of $\mathrm{T}$ cells is prerequisite for them to enter CNS tissue, however the efficient re-activation of T cells in situ requires not only appropriate TCR specificity (MBP) but also a certain functional state characteristic for effector T cells that recently perceived strong antigenic stimuli outside of the CNS.

\subsection{Antigenic stimulation of $T$ cells is followed by the wave of glycolytic activation which subsides over time}

Which functional properties distinguish resting memory and recently activated effector (ex-memory) T cells? One of them might be a metabolic switch, namely activation of glycolysis evoked by TCR-driven signaling (FIG II). To characterize the glycolytic state in $\mathrm{T}_{\text {MвP }}$ cells cultured in vitro, we measured the uptake of glucose by flow cytometry using fluorescent glucose analogue 2-NBDG (FIG 12A). Exposure of $\mathrm{T}_{\mathrm{MBP}}$ cells to cognate antigen presented by thymic APCs resulted in a rapid increase of glucose uptake that peaked 2-3 days after stimulation and subsequently declined to initial low levels (FIG 12A). Further, we compared the glycolytic rate and glycolytic capacity in blast (day 2) versus resting (day 6) effector $\mathrm{T}_{\mathrm{MBP}}$ cells using an extracellular acidification rate (ECAR, measure of lactate production) as read-out (FIG 12B). Thus, we confirmed that TCR engagement transiently boosts glycolysis in effector $\mathrm{T}$ cells in culture. 
A
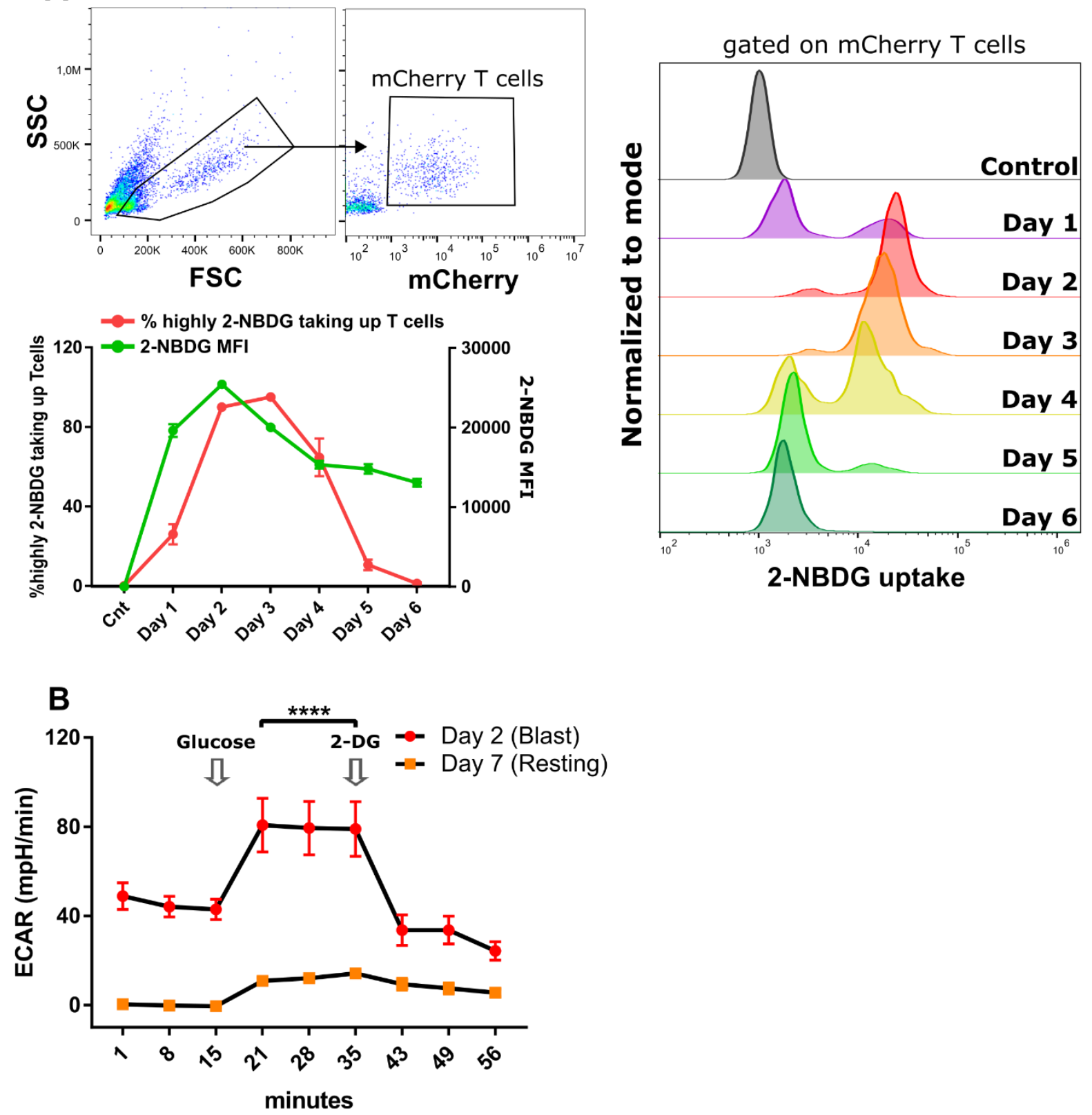

FIG 12 Glucose uptake and glycolysis rate in the effector MBP-specific T cells during their restimulation cycle in vitro.

$\mathrm{T}_{\mathrm{MBP}}$ cherry cells were stimulated in vitro with thymic APCs and MBP antigen (A,B). (A) Results of glucose uptake assay. At the indicated time point after stimulation T cells were collected, stained with 2-NBDG and analyzed by FACS. FACS dot plots show gating strategy to exclude co-cultured thymocytes and dead cells from the analysis. Multicolor histograms depict 2-NBDG fluorescence intensity at different time points. The percentage of T cells with high 2-NBDG signal and its mean fluorescence intensity (MFI) are plotted over time. The control group (Cnt, depicted in grey) represents the $\mathrm{T}_{\mathrm{MBP}}$ cherry cells without 2-NBDG staining. Data are representative of three different $T$ cell lines and are shown as mean $\pm S D$ of $n=4$. (B) Extracellular acidification rate (ECAR) assay performed on Seahorse system. T cells were collected on the day 2 and 7 after stimulation. The graph shows ECAR for blast (day 2) and resting (day 7) effector T cells pre-incubated in glucose-free medium and challenged by addition of glucose and glycolysis inhibitor 2-deoxyglucose (2- 
DG). The data are shown as mean \pm SD of $n=8$ (blast) and $n=6$ (resting) replicates. Student's t test was used for the statistical analysis.

Next, we analyzed the transcriptional response upon activation in vitro. We analyzed genes important for the glycolysis along with classical targets of TCR-driven activation such as IFN $\gamma$ and CD25. The expression of glycolytic enzymes, hexokinase 1 (HK-1) and lactate dehydrogenase A (LdhA), as well as IFN $\gamma$ and CD25, reached a peak within the first 24 hours after stimulation and then decreased (FIG 13A).

We also analyzed mRNA expression of three positive regulators of glycolysis, Irf4, Hif1 $\alpha$ and cMyc (Myc proto-oncogene, bHLH transcription factor) transcription factors, and of $\mathrm{Bcl} 6$, a transcription factor that negatively regulates glycolysis. Irf4 showed a monophasic increase similar to the kinetic of the LdhA gene, whereas Hif1 $\alpha$ mRNA expression exhibited a bimodal response resembling the transcriptional kinetic of HK-1. Interestingly, the Bcl6 gene expression did not show a high regulation in the first 9 days in vitro but, as expected, was found to be increased in "memory" rats. The mRNA expression of cMyc increased soon after stimulation and then decreased over the 9 days in vitro but, unexpectedly, was found to be high in "memory" rats (FIG 13B).

When $\mathrm{T}$ cells were transferred in WT rats 2 days after activation in vitro, the expression of all the analyzed glycolytic genes during the preclinical migratory period throughout the body ( 1 to 3 days after transfer) followed the same trend seen in the corresponding days in vitro (days 3, 4 and 5 after in vitro stimulation) (FIG 13A-C). Indeed, the genes showed a low and stationary level of expression in all the organs analyzed during the 3 days in vivo, and finally, an increase only when the $\mathrm{T}$ cells entered the spinal cord (SC) and become locally reactivated (FIG 13C). 


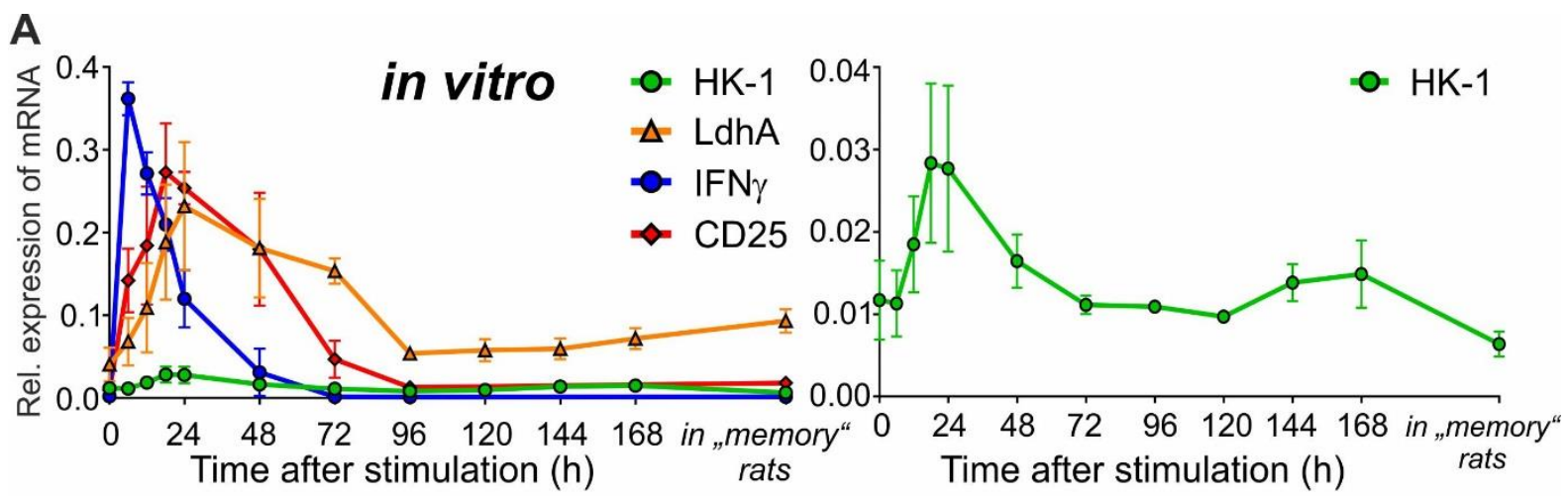

B

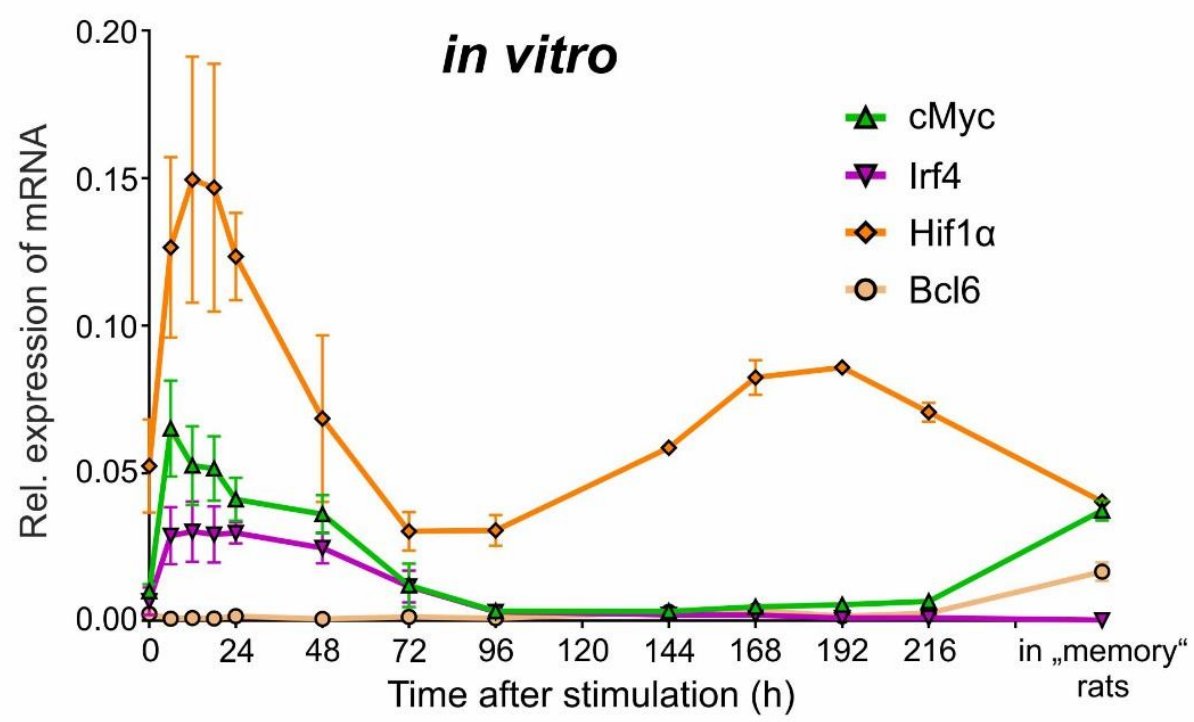

C

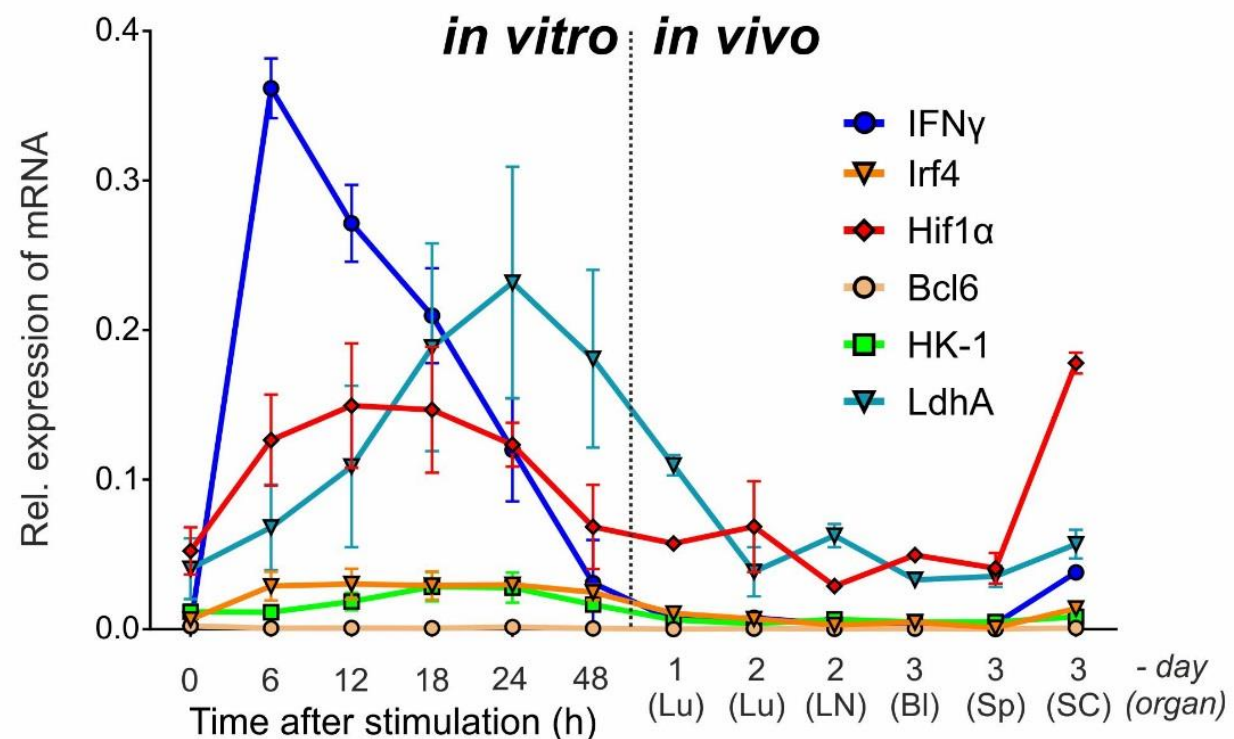

FIG 13 Expression of glycolytic enzymes and regulatory factors in $T$ cells over time upon activation.

TMBP cells were stimulated in vitro with thymocytes and MBP. Two days after stimulation $\mathrm{T}$ cells were either used for transfer EAE or left in culture. RNA was isolated from cultured T cells $(\mathbf{A}, \mathbf{B})$ or from cells sorted at the indicated time point from different organs of animals that received transfer of TMBP-Cherry cells (C) or from not immunized "memory" rats (A,B; pooled LN, blood and spleen, $n=3)$. Expression levels of indicated genes were determined by RT-qPCR and normalized to the level of $\beta$-actin gene expression. (A) Expression 
of HK-1 and LdhA genes encoding glycolytic enzymes. Plot on the right depicts expression of HK-1 gene at smaller scale for better resolution. IFN $\gamma$ and CD25 genes were used as a read-out confirming efficient activation of T cells. (B) Expression of key transcription factors known to regulate metabolism of effector T cells. (C) MBP-specific T cells were sorted from mediastinal lymph nodes (LN), lung (Lu), blood (Bl), spleen (Sp) and spinal cord (SC) tissue by flow cytometry. The graph shows levels of expression in vivo compared to levels in vitro for the same $\mathrm{T}$ cell line before adoptive transfer. All the data in the figure are presented as mean \pm SEM.

As the protein expression is a more adequate measure of pathway activity than mRNA expression, we also analyzed glycolytic and other metabolic enzymes over time in vitro (FIG 14) and in transfer EAE (FIG 15) by Western blot. This analysis also documented that expression of glycolytic enzymes after peaking at day 2 after antigenic stimulation slowly decreases both in culture and in vivo after T-cell transfer. Interestingly, the decline of glycolytic enzyme expression was more pronounced in the ex vivo isolated $\mathrm{T}$ cells (compared normalized values for glycolytic enzymes in FIG 14 and FIG 15). TMBP cells recovered from the spinal cord at the onset of EAE showed reversion of glycolytic enzymes to the levels observed soon after antigenic stimulation in culture (FIG 14-15). Thus, in situ re-activation of $\mathrm{T}_{\mathrm{MB}}$ cells within the target tissue seems to be sufficient for resuming high glycolytic activity. 


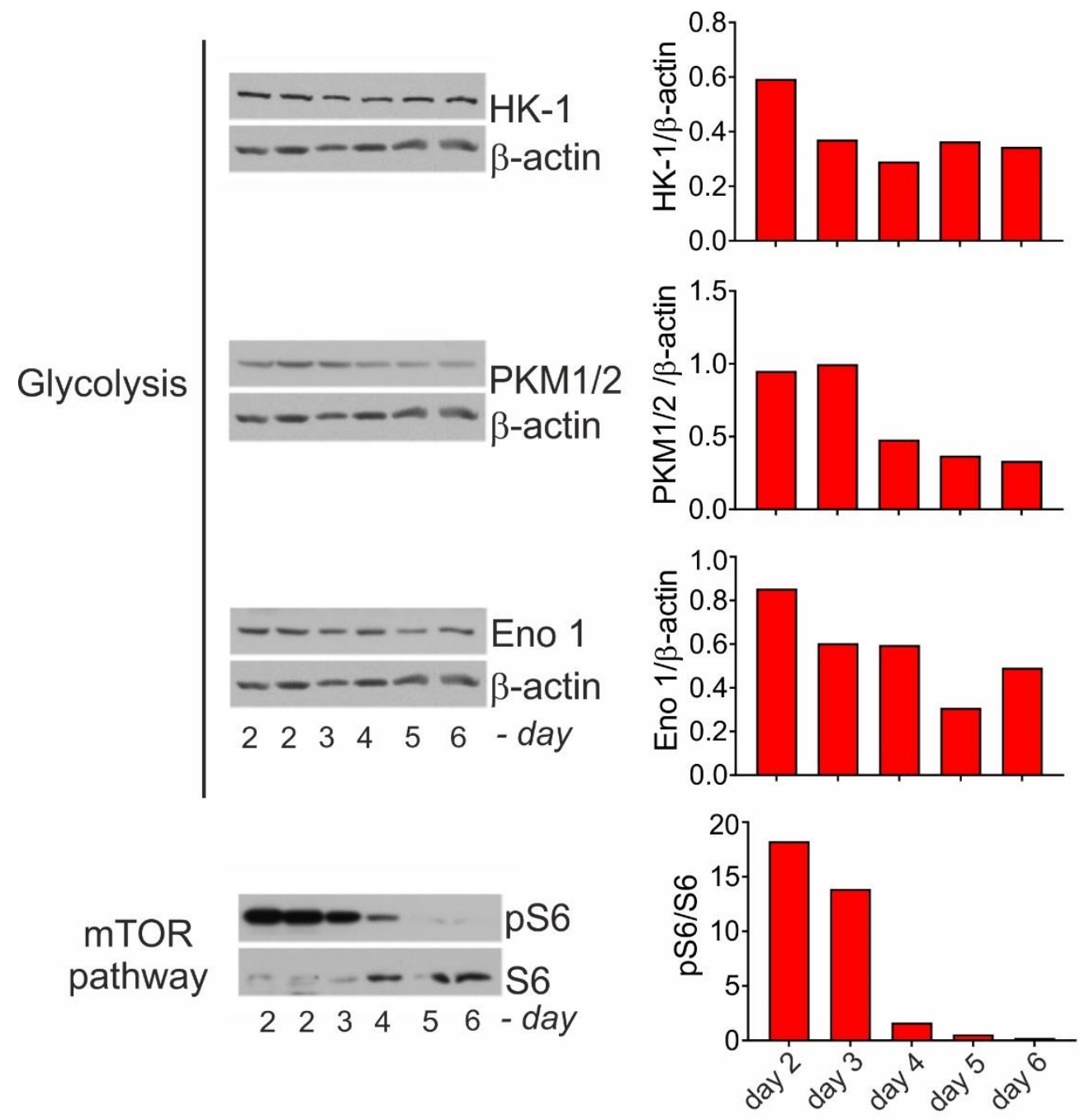

Lipid synthesis

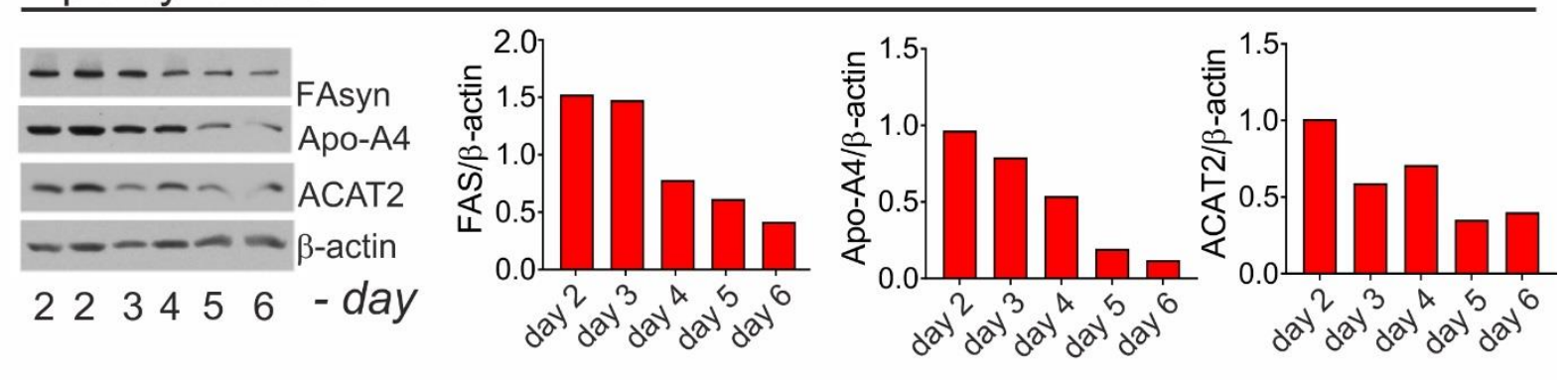

TCA cycle

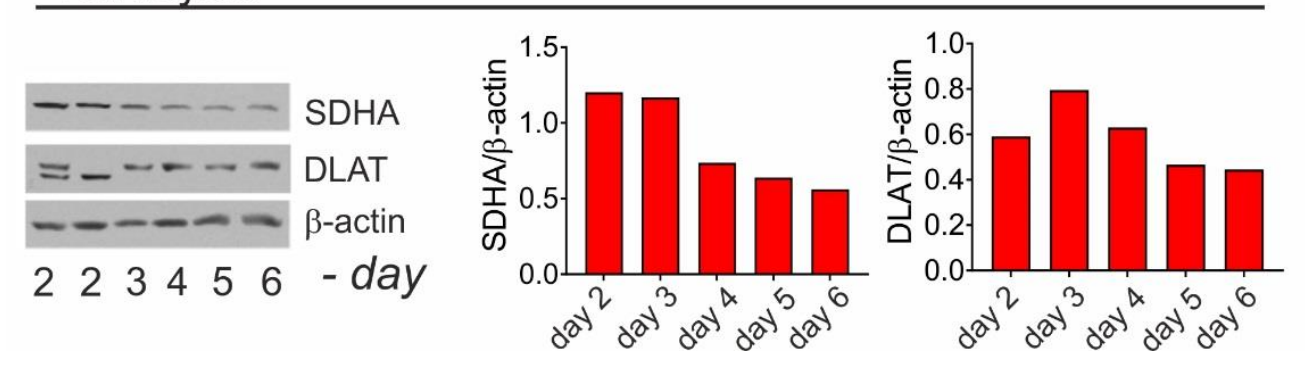

FIG 14 Time course analysis of metabolic pathways in cultured effector $\mathbf{T}_{\mathrm{MBP}}$ cells.

MBP-specific T cells were stimulated in vitro by addition of thymic APCs and cognate antigen. Protein lysates isolated at indicated time points after the T-cell stimulation were analyzed by Western blotting 
using antibodies specific for indicated proteins. $\beta$-actin was used for normalization. (These experiments were performed in collaboration with group of Giuseppe Matarese at the Department of Molecular Medicine and Medical Biotechnology of the University of Napoli, “Federico II").

We also detected a decline of lipid synthesis, which closely followed the profile of changes seen for glycolysis. Furthermore, after entry of the T cells into the CNS and their local reactivation, their lipid synthesis was resumed (FIG 14-15). Remarkably, the induction of mTOR signaling upon entry into the CNS was only moderate compared to levels observed n culture (day 2 FIG 14 versus day 3 SC FIG 15). 


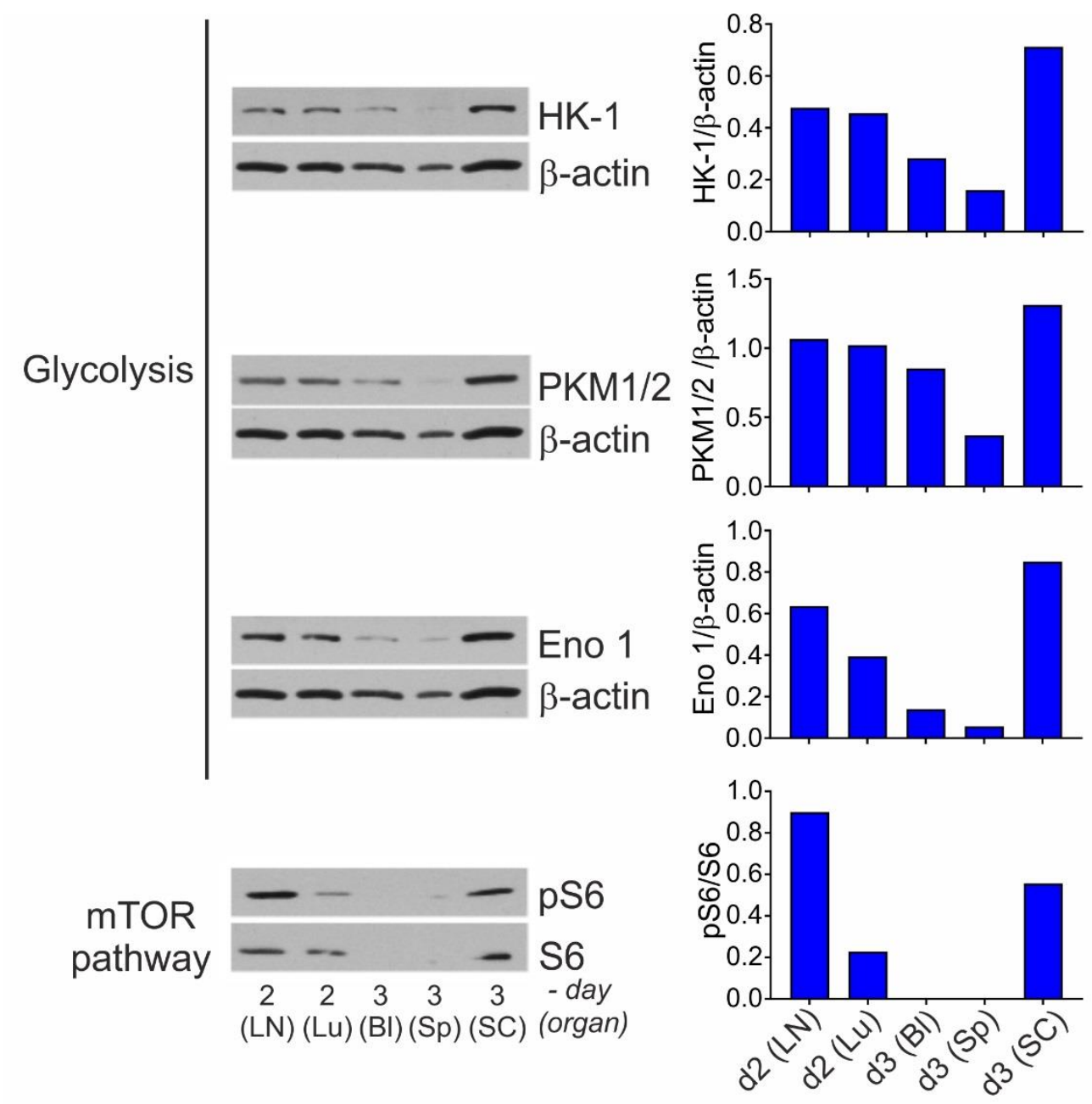

$\underline{\text { Lipid synthesis }}$

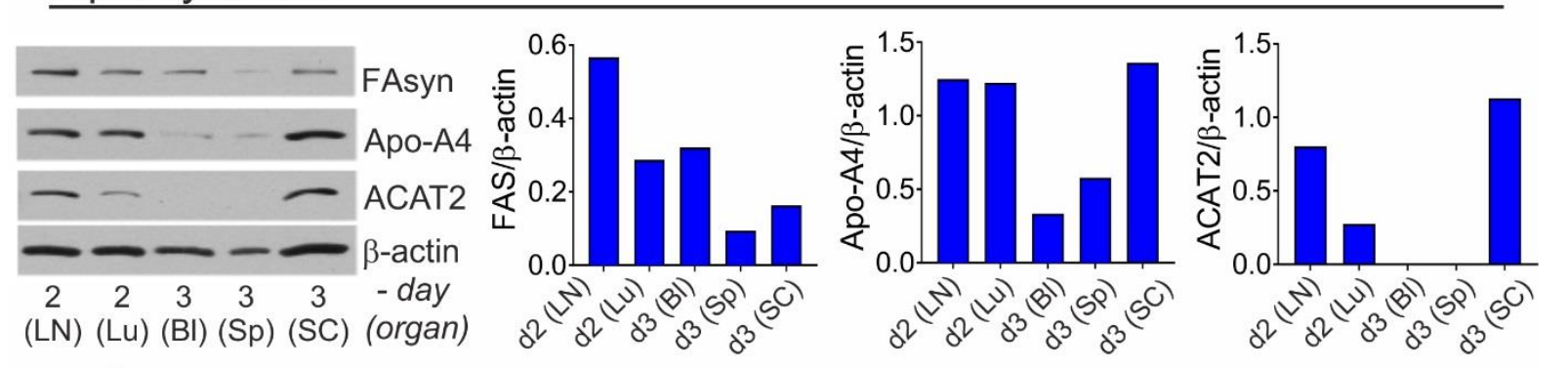

\section{TCA cycle}

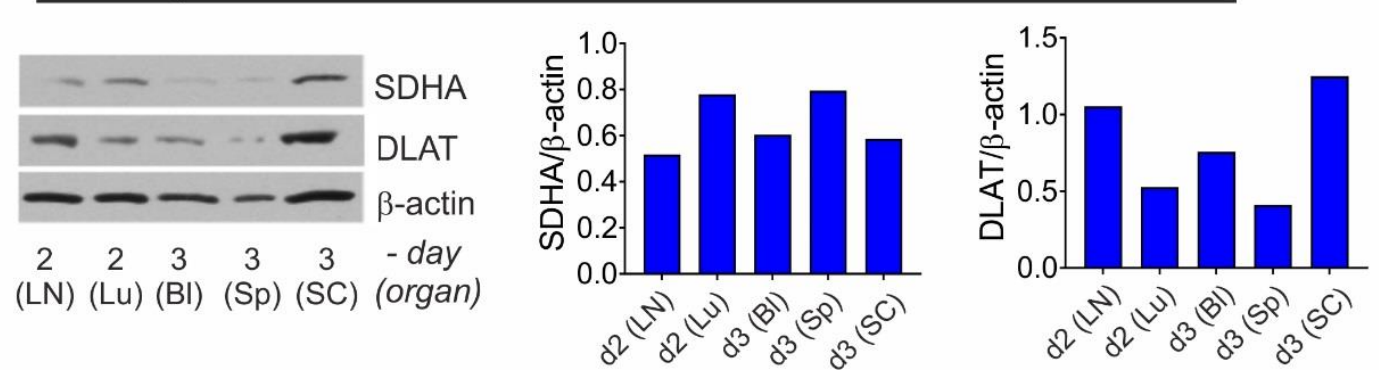

FIG 15 Time course analysis of metabolic pathways in transferred effector $T_{\text {MвP }}$ cells.

MBP-specific T cells were sorted from mediastinal lymph nodes (LN), lung (Lu), blood (Bl), spleen (Sp) and spinal cord (SC) tissue by flow cytometry. Protein lysates isolated from different organs at indicated time points were analyzed by Western blotting using antibodies specific for indicated proteins. $\beta$-actin was used 
for normalization. (These experiments were performed in collaboration with group of Giuseppe Matarese at the Department of Molecular Medicine and Medical Biotechnology of the University of Napoli, "Federico II").

\subsection{Inhibition of glycolysis in vivo affects T-cell encephalogenicity}

As described in the previous sections, the glycolysis rate in T cells rapidly increases upon stimulation and then slowly decreases over time. It is possible that the glycolysis rate present in T cells by the moment of TCR engagement can influence their potential to become activated. We decided to inhibit T-cell glycolysis in vivo and analyze effect of such treatment on the EAE. To this end, we injected MBP-reactive GFP-labeled effector T cells ( $\mathrm{T}_{\mathrm{MBP} \text { GFP }}$ cells) in WT rats, and treated them with daily intraperitoneal administration of 2-Deoxy-D-glucose (2-DG) (FIG 17A). This drug targets glucose metabolism in several ways. First, 2-DG competitively inhibits the glucose transporters (GLUTs). Afterwards, 2DG is phosphorylated by hexokinase to form 2DG-6-P (2-DG-6-phosphate) that cannot be further metabolized via glycolysis and accumulates in the cell. In this way, 2DG-6-P noncompetitively inhibits HK and thus the phosphorylation of glucose to glucose-6phosphate (G-6-P), and competitively inhibits PGI and its action on the conversion of G6-P to fructose 6-phosphate (FIG 16, Zhang et al. 2014).

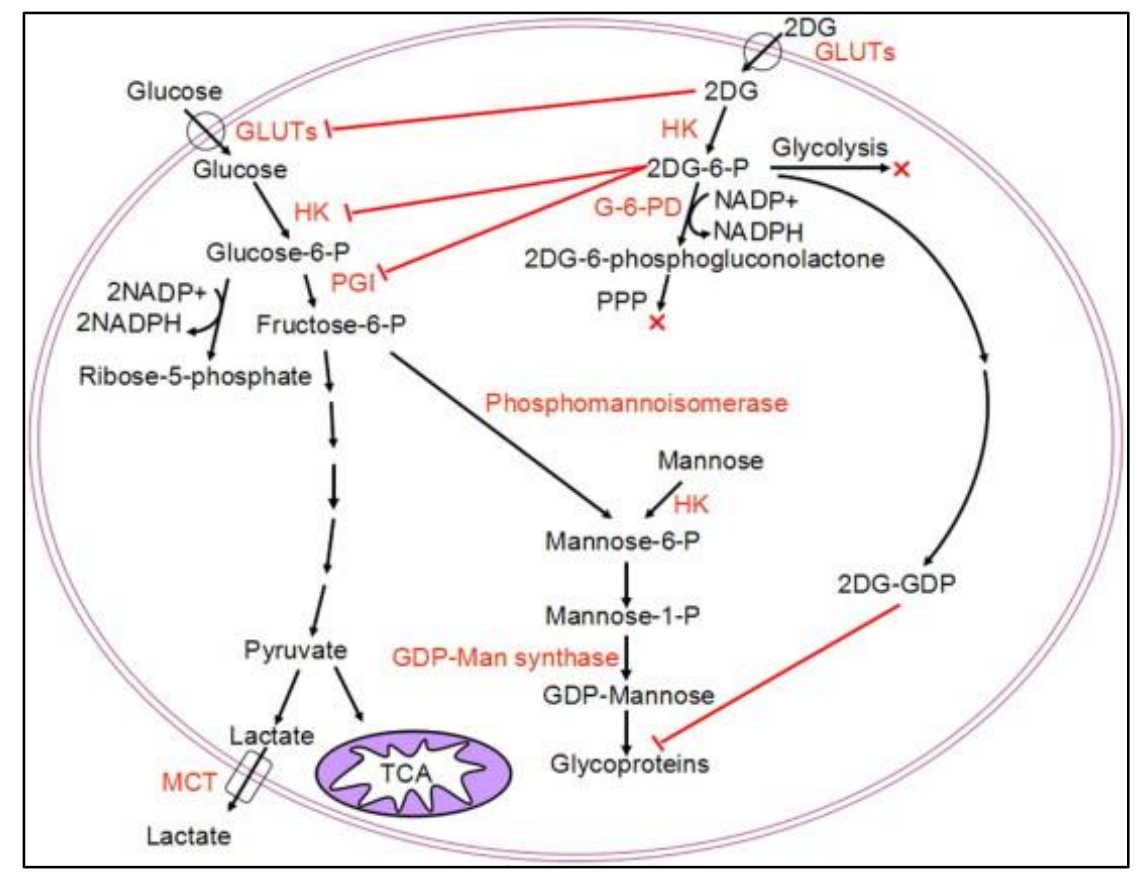

FIG 16 Inhibition of glycolysis by 2-DG (Zhang et al. 2014). 
When animals transferred with $\mathrm{T}_{\text {MBP-GFP }}$ cells were treated with 2-DG during the preclinical period (day 0-3) or until the peak of clinical disease (day 0-6), we observed a delay in the EAE onset comparing to control group but the severity at the peak and recovery phase of disease were similar (FIG 17A). 2-DG treatment did not seem to alter

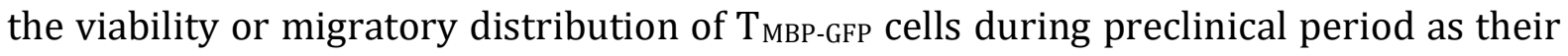
numbers detected in the blood, spleen and mediastinal LNs were not significantly changed (FIG 17B). Instead, we found a reduction in the number of $T_{\text {MBP-GFP }}$ cells infiltrating meninges and parenchyma of SC at day 3.5 after transfer when control and 2DG treated groups showed a difference in the clinical scores (FIG 17C). At this time point the numbers of myeloid cells $\left(\mathrm{OX}_{4} 2^{+}\right)$and recruited host T cells (GFP-) infiltrating SC parenchyma were also reduced in the 2-DG treated group (FIG 17E). Later in the course of EAE at day 4.5, numbers of infiltrating immune cells were no longer significantly different (FIG 17D and F), which was in agreement with the elevation of clinical scores at this stage. In the transfer EAE induced by administration of a lower amount of $\mathrm{T}_{\mathrm{MBP}}$ cells, the clinical effect of glycolysis inhibition was even more evident (FIG 17G).

Immunostaining for CD25 and OX40 surface markers indicates that in the SC meninges and parenchyma of rats treated with 2-DG, $\mathrm{T}_{\mathrm{MBP}-\mathrm{GFP}}$ cells were less activated than in control animals (FIG 18A-C).

Altogether these results support our hypothesis that the glycolytic state of $\mathrm{T}_{\mathrm{MBP}}$ cells entering CNS tissue determines their re-activation efficiency. An alternative explanation of how inhibition of glycolysis influences clinical EAE disease is that 2-DG treatment blocks induction of glycolysis caused by local re-activation of T cells inside the CNS, and this in turn negatively affects the effector function of the T cells. Moreover, 2-DG treatment in vivo may compromise functions of other cell types (not T cells) contributing to the induction of EAE. Therefore, we decided to analyze the relationship between glycolysis and a T cell's ability to become re-activated using a simplified in vitro approach. 


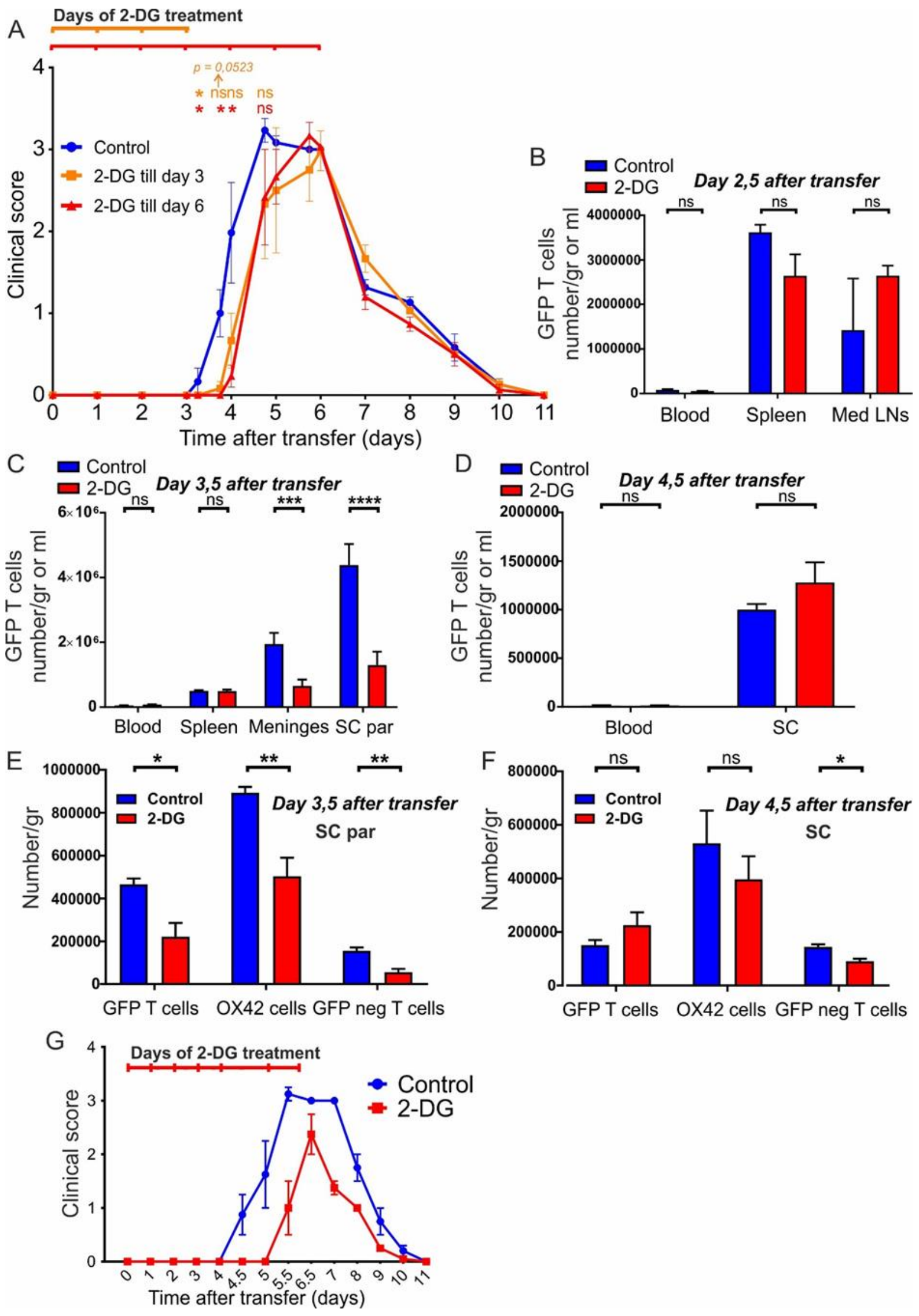

FIG 17 Effects of 2-DG treatment on transfer EAE. 


\section{FIG 17 Effects of 2-DG treatment on transfer EAE.}

TMBP-GFP cells $\left(3 \times 10^{6}\right)$ were injected intravenously in WT rats in order to induce tEAE. (A) One group of animals $(\mathrm{n}=3)$ was daily i.p. injected with $500 \mathrm{mg} / \mathrm{kg} 2-\mathrm{DG}$ from day 0 to day 3 after transfer (orange). Another group was treated in the same way from day 0 to day $6(n=3$; red). The control group was treated with daily injection of PBS from day 0 to day 6 (blue). Mean \pm SEM clinical scores are shown. The data are representative example of 4 independent experiments. Statistical significance was determined by student's $t$ test. (B-E) Analysis of $\mathrm{T}_{\mathrm{MBP}}$ cell numbers and numbers of immune cells infiltrating $\mathrm{SC}$ and the other indicated compartments at the indicated time points - day $2.5(\mathrm{n}=3), 3.5(\mathrm{n}=4)$ and $4.5(\mathrm{n}=3)$ determined by flow cytometry. (G) 2-DG treatment of rats receiving lower number of encephalitogenic T cells $\left(2 \times 10^{6}\right)$ shows stronger therapeutic effect on clinical course of transfer EAE. Shown are mean \pm SEM clinical scores. 
A

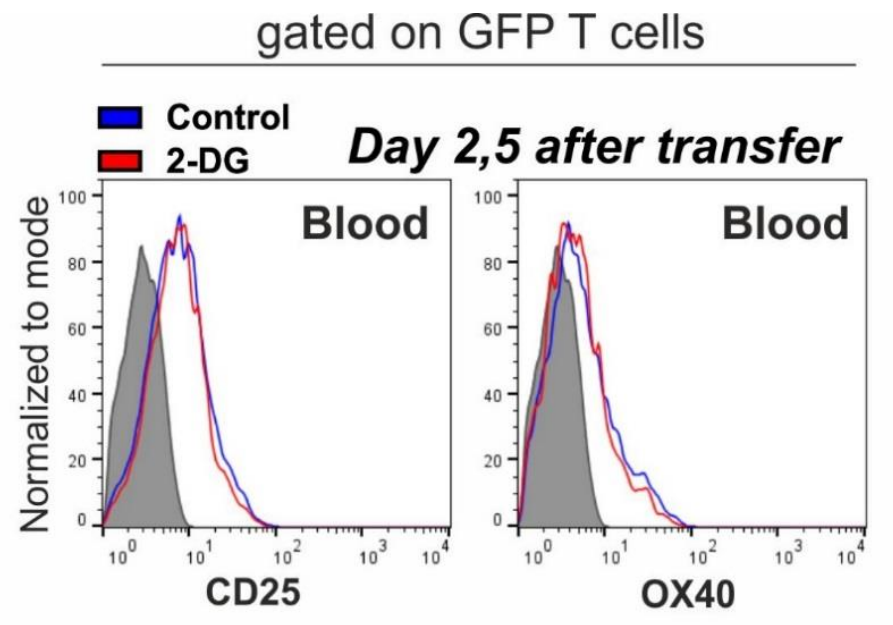

B
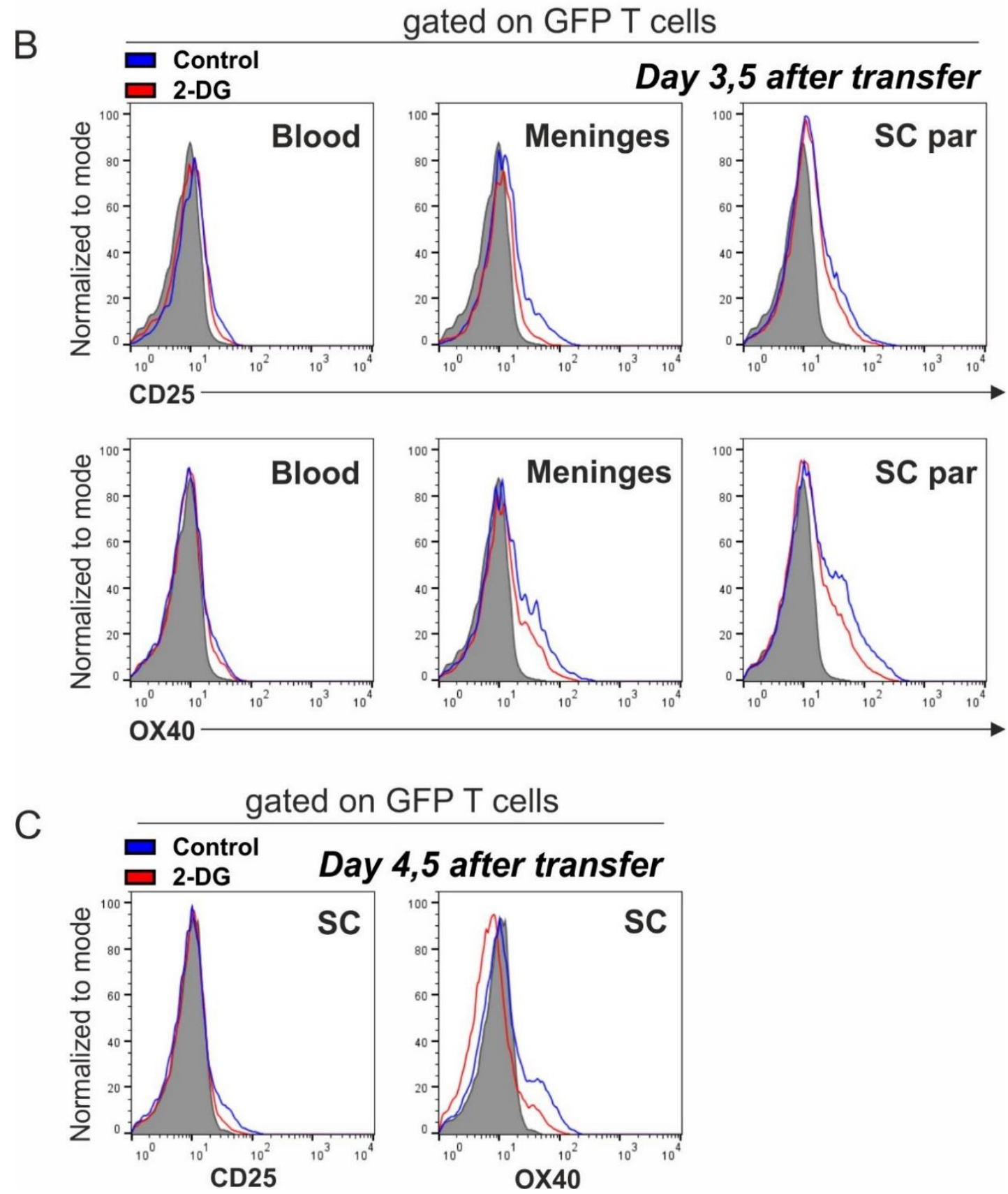

4,5 after transfer

FIG 18 Effects of 2-DG treatment on the activation levels of MBP-specific effector T cells. 
FIG 18 Effects of 2-DG treatment on the activation levels of MBP-specific effector T cells.

Flow cytometry analysis of CD25 and OX40 expression in transferred TMBP-GFP cells in the course of transfer EAE described in the legend of FIG 17. Cells isolated from blood and SC tissue at the day 2.5 (A), day 3.5 (B, onset of clinical symptoms) and day 4.5 (C) were stained with antibodies specific for CD25, OX40 or isotype control IgG (grey histograms) and measured by FACS. Shown are overlay histograms representative of 3 independent experiments.

\subsection{The inhibition of glycolysis in cultured $\mathrm{T}$ cells lowers their level of activation in vitro}

T cells in vitro showed the peak of glycolysis around the second day after stimulation, but then they retained a high rate also after 3 days (FIG 13-15). We decided to start 2-DG treatment 3 days after stimulation and used medium containing no glucose (FIG 20A). In order to compensate for essential metabolites normally produced via glycolysis, e.g. ATP, we used a galactose containing medium for 2-DG treatment. Galactose promotes ATP synthesis mainly by mitochondrial oxidation of pyruvate (Le Goffe et al. 1999; van der Windt et al. 2016). Recent work shows that CD4 T cells activated in galactose fuel proliferation and survival with ATP from oxidative phosphorylation (OXPHOS) and not via aerobic glycolysis and that these cells could also use glutamine as an alternative substrate for OXPHOS (Chang et al. 2013). 2-DG could interfere only partially with the glycolysis and oxidation of galactose (Le Goffe et al. 1999) because, in this case, the formation of glucose-6-P follows a different pathway and makes use of different enzymes compared with what is happening in the glucose catabolism (FIG 19). Therefore, we reasoned that combination of galactose with 2-DG in glucose-free medium would inhibit glycolysis without compromising the viability of T cells.

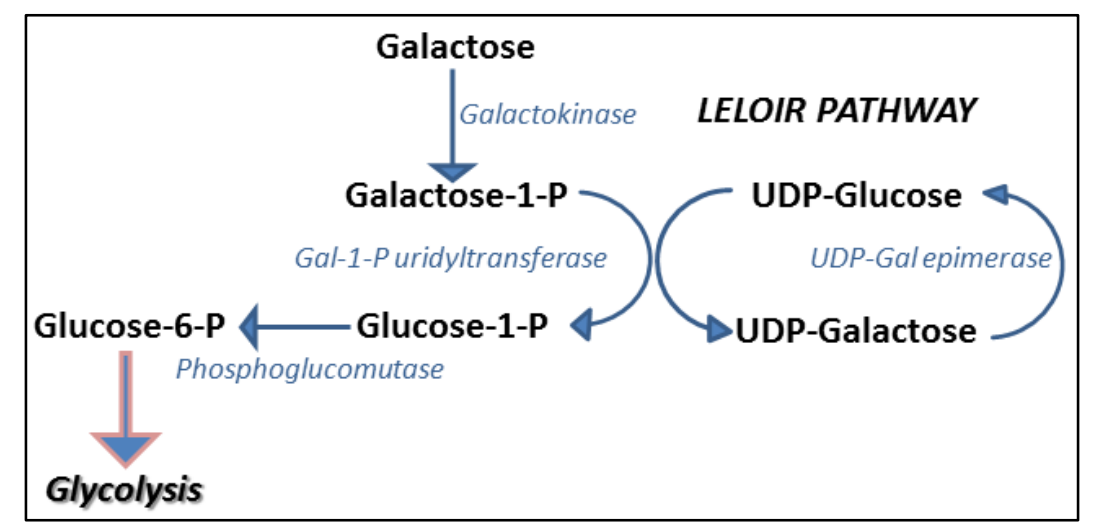

FIG 19 Galactose metabolism: the Leloir pathway. 
After the continued galactose/2-DG treatment for 4 days (FIG 20A), T cells were restimulated under regular conditions (glucose containing medium without 2-DG). Their cytokine production was then analyzed by qPCR and ELISA. This analysis revealed a reduction in IFN $\gamma$, IL-17 and IL-2 mRNA expression in the treated T cells (gala + 2-DG) versus control (glucose) T cells, for both low (1 $\mu \mathrm{g} / \mathrm{ml})$ and high $(8 \mu \mathrm{g} / \mathrm{ml})$ concentration of antigen (FIG 20B). At the protein level, the production of IFN $\gamma$ cytokine by 2-DG pretreated $\mathrm{T}$ cells was found to be slightly reduced relative to control $\mathrm{T}$ cells but this difference did not reach statistical significance (FIG 20C). Inhibition of glycolysis had a much stronger effect on the secretion of the IL-2 cytokine, especially at the lower dose of MBP used for stimulation (FIG 20C). Intracellular staining of re-stimulated $\mathrm{T}$ cells for IFN $\gamma$ showed a reduced amount of this cytokine per cell basis in the 2-DG treated group when a high concentration of MBP was used for stimulation (FIG 20D). Finally, adoptive transfer of $\mathrm{T}_{\mathrm{MBP}}$ cells which prior to re-stimulation in vitro experienced inhibition of glycolysis, resulted in an EAE with a slight delayed onset relative to the control group (FIG 20E). 

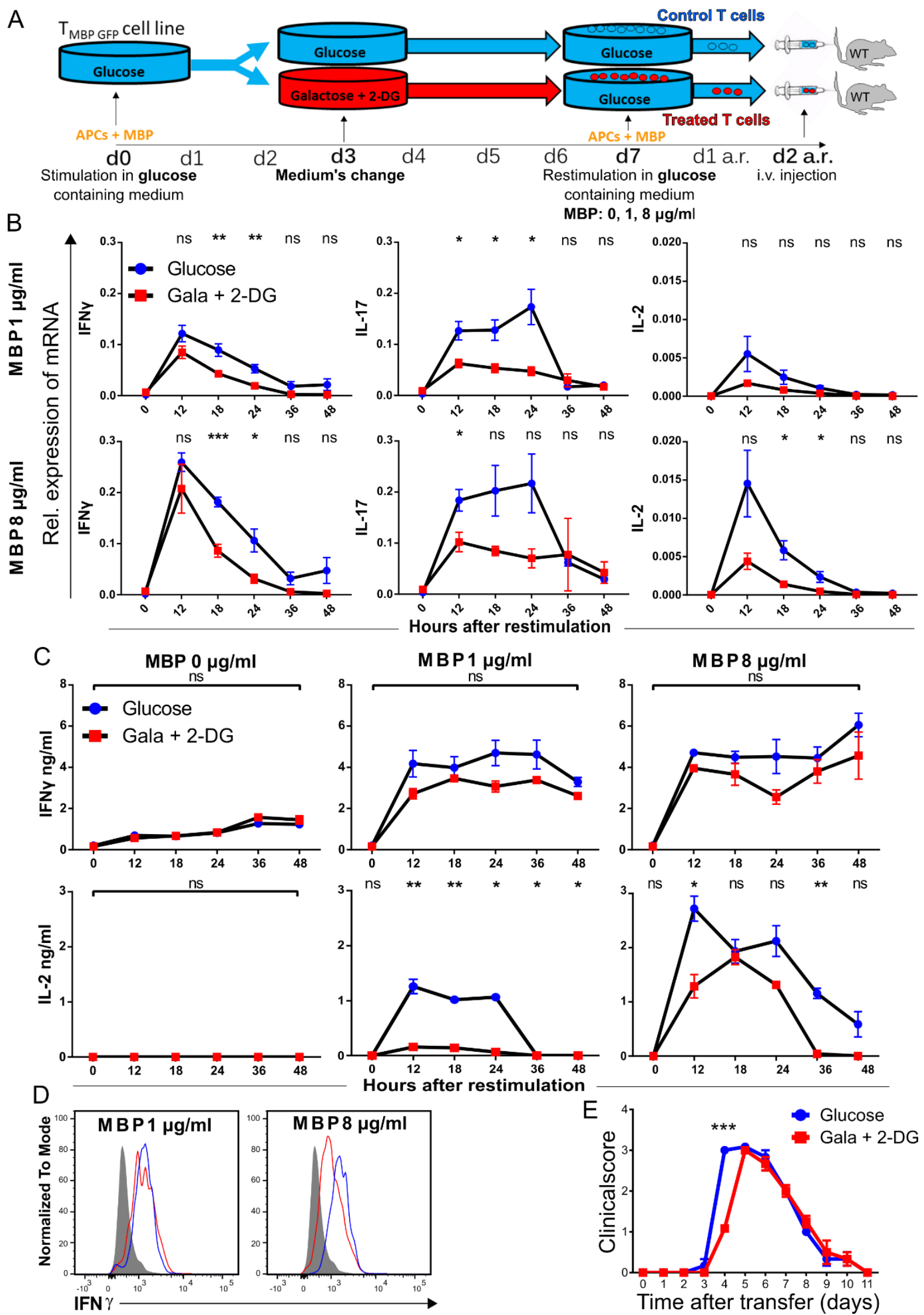

FIG 20 Effects of 2-DG treatment on the activation of effector T cells in vitro.

(A) Outline of experimental approach to test the role of glycolysis in vitro. $\mathrm{T}_{\mathrm{MBP}}$ GFP cells were stimulated with thymocytes and MBP in glucose-containing medium. 3 days after stimulation, half of the cells 
continued to be cultured in the glucose-sufficient medium (glucose, blue) and the other half was cultured in a glucose-free medium, supplemented with galactose and 5 mM 2-DG (gala + 2-DG, red). On day 7 after stimulation, both the control and the treated cells were re-stimulated in glucose-containing medium, with thymocytes and three different MBP concentrations $(0,1$ or $8 \mu \mathrm{g} / \mathrm{ml})$. During the next two days after restimulation ( $\mathrm{d} 1$ a.r., $\mathrm{d} 2$ a.r.), the $\mathrm{T}$ cells and their supernatant were collected at several time points $(0,12$, 18, 24, 36 and $48 \mathrm{~h}$ ), in order to analyze their gene expression by RT-qPCR (B), and cytokine production by ELISA (C). On day 2 after re-stimulation some TMBP GFP cells from both groups were collected and stained for intracellular IFN $\gamma$ (D). (B) Time course of IFN $\gamma$, IL-17 and IL-2 gene expression determined by RT-qPCR (normalized to the levels of $\beta$-actin gene expression). MBP concentrations used for the second stimulation are indicated. Data are mean \pm SEM of $n=2$ replicates of two different experiments. (C) ELISA measurements of IFN $\gamma$ and IL-2 concentration in supernatants of two groups at the indicated time points after re-stimulation with MBP. Data are mean \pm SEM of $n=3$ replicates. The histograms in (D) show results of intracellular IFN $\gamma$ staining in control and treated TMBP GFP cells. Samples were stained $48 \mathrm{~h}$ after restimulation with 1 or $8 \mu \mathrm{g} / \mathrm{ml}$ MBP. The histograms are representative of $n=3$ replicates. (E) Clinical course of EAE induced by transfer of $\mathrm{T}_{\mathrm{MBP}}$ cells that were cultured in the indicated media before the last restimulation in vitro ( $\mathrm{n}=3$ animals per group). All the statistical analyses in the figure were performed by student's t test.

These results show that decreased glycolysis rate prior to re-stimulation in vitro does not completely abolish $\mathrm{T}$ cell activation but it does reduce the level of their activation.

\subsection{The glucose uptake and expression of glycolytic enzymes in $\mathrm{T}$ cells before entry into the CNS is higher in recently activated effector $\mathrm{T}$ cells than in resting memory or naïve $T$ cells}

We performed a transfer experiment in rMT-II rats (FIG 21A) in order to compare the state of glycolysis between effector $\mathrm{T}_{\mathrm{MBP}}$ cells and circulating memory and naïve rMT-II T cells immediately before they enter SC tissue. In the blood-derived effector $\mathrm{T}_{\mathrm{MBP}}$ cells we found higher expression of HK-1 and LdhA genes and similar levels of Eno 1 mRNA transcript comparing to memory or naïve rMT-II T cells (FIG 21B). The levels of Irf4 and Hif1 $\alpha$ expression did not differ significantly between effector $\mathrm{T}_{\mathrm{MBP}}$ and memory $\mathrm{rMT}$-II $\mathrm{T}$ cells found in the blood (FIG 21B). Blood-derived naïve rMT-II T cells showed a slightly lower expression level of Hif1 $\alpha$ gene (FIG 21B). The transition of effector $\mathrm{T}_{\mathrm{MBP}}$ cells from blood to the SC tissue was associated with a moderate increase in glycolytic enzyme expression and a more pronounced increase in Irf4 and Hif1 $\alpha$ levels (FIG 21B) in 
agreement with our results described earlier in this manuscript. Remarkably, memory rMT-II cells isolated from SC tissue also exhibited a higher expression of all five tested genes relative to the levels detected in blood memory rMT-II T cells (FIG 21B).

Further, we measured glucose uptake by effector $\mathrm{T}_{\mathrm{MBP}}$ and rMT-II $\mathrm{T}$ cells isolated from blood at the onset of EAE. Indeed, we found that effector $\mathrm{T}_{\mathrm{MBP}}$ cells accumulate more 2NBDG substrate than rMT-II T cells (FIG 21C,D). Together these results indicate that right before entering target tissue, effector $\mathrm{T}$ cells are more glycolytic than memory $\mathrm{T}$ cells. 

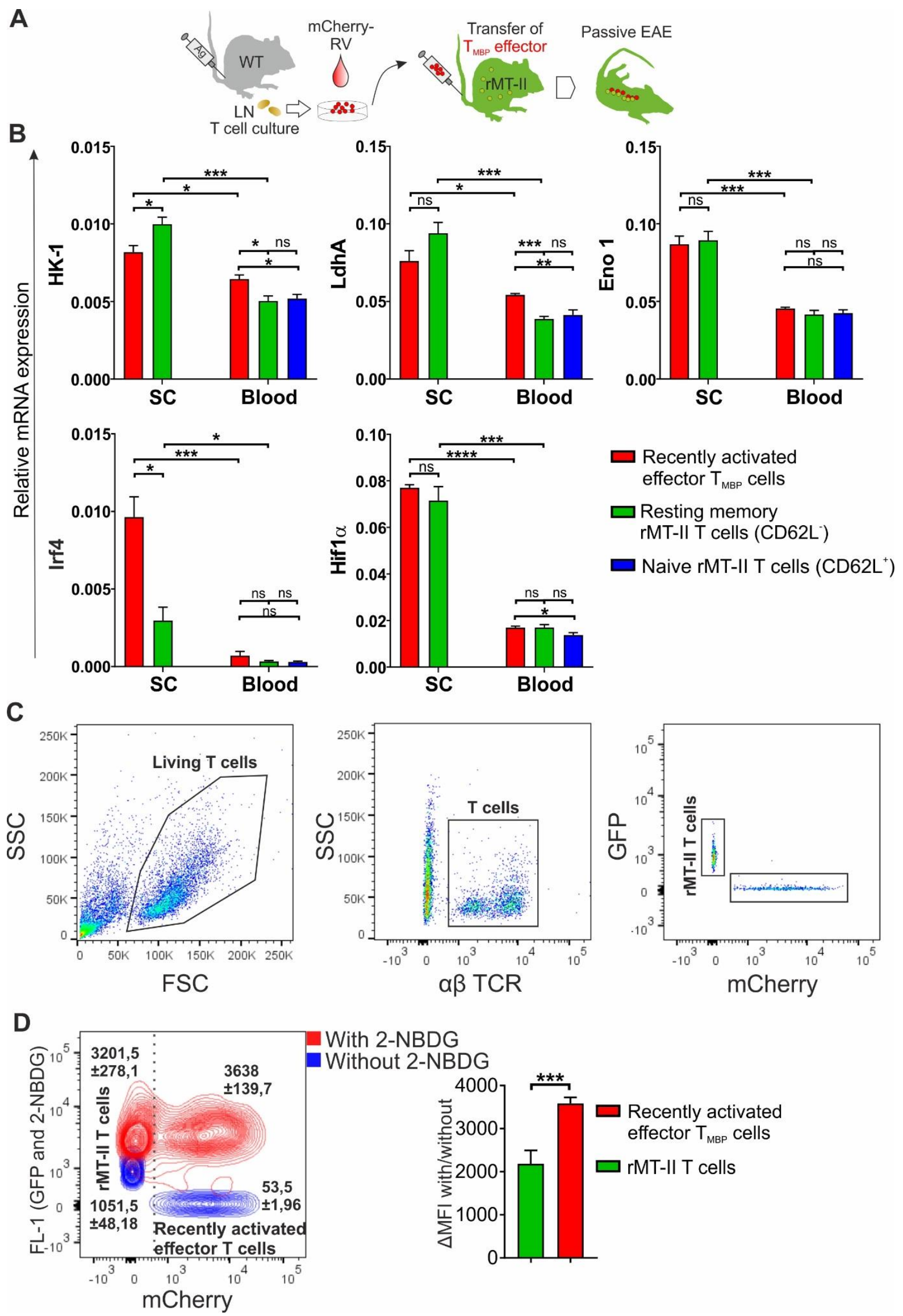

With 2-NBDG

Without 2-NBDG

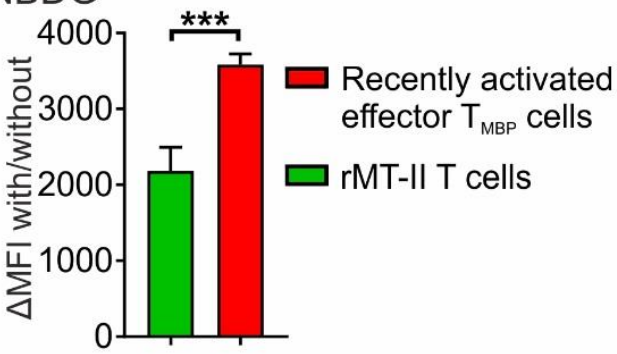

FIG 21 State of glycolysis in different subsets of MBP-specific T cells analyzed during transfer EAE in rMT-II rats. 
FIG 21 State of glycolysis in different subsets of MBP-specific T cells analyzed during transfer EAE in rMT-II rats.

(A) EAE was induced in rMT-II rats by transfer of $4 \times 10^{6}$ effector $\mathrm{T}_{\mathrm{MBP} \text {-Cherry }}$ cells. (A) The rats were sacrificed at the onset of clinical disease. Cells were isolated from blood and spinal cord (SC), stained for $\alpha \beta T C R$ and CD62L and sorted by flow cytometry into three groups: naïve $(\alpha \beta T C R+G F P+C D 62 L+;$ blue), resting memory ( $\alpha \beta T C R+$ GFP+ CD62L-; green) and effector T cells ( $\alpha \beta T C R+$ mCherry+ GFP-; red) (B) . Expression of HK1, LdhA, Eno 1, Irf4 and Hif1 $\alpha$ genes was determined by RT-qPCR and normalized to $\beta$-actin gene expression (mean \pm SEM of $n=4$ for bloods and $n=3$ for SC). (C,D) The cells were isolated from the blood of $n=6$ animals, stained for $\alpha \beta$ TCR; with or without 2-NBDG and analyzed by FACS. Gating strategy (C) and green fluorescence (FL-1) of 2-NBDG and GFP (D, overlay contour plot) are shown. The columns in (D) represent the difference in green fluorescence intensity between cells stained and not stained with 2-NBDG in each $T$ cell population. Data are presented as mean \pm SD $(n=6)$. Statistical analyses performed by student's t test. 


\section{DISCUSSION}

The aim of this study was to get an insight into the mechanisms by which autoreactive $\mathrm{T}$ cells can maintain their tolerance to self CNS tissue. Myelin antigen specific T cells are frequently found in healthy subjects (Bielekova et al. 2004; Tejada-Simon et al. 2001), and only rarely, when unknown factors compromise self-tolerance, do these $\mathrm{T}$ cells acquire pathogenic capacity and induce an autoimmune attack of the CNS leading to disease such as MS. Our initial observation made in MBP-TCR transgenic and in $\mathrm{T}_{\mathrm{MBP}}$ memory Lewis rats was a lack of spontaneous disease and aggravation in transfer EAE. This observation convinced us that these two models would be suitable for addressing mechanisms that help to keep autoreactive T cells in check.

First we could show that T cells isolated from rMT-II animals are not anergic, induce upon activation in the periphery early-onset disease and are able to transfer disease susceptibility to an EAE resistant host (FIG 2-3). Nevertheless, we found that primary rMT-II T cells isolated from naïve animals respond to the antigen in vitro much more weakly and more slowly than effector $\mathrm{T}$ cells of the same genetic background. It is however possible that the type of APCs utilized for the in vitro stimulation, namely thymocytes, is inefficient in activating primary $\mathrm{T}$ cells.

Our analysis of non-inflamed CNS tissue from naïve rMT-II animals revealed that a very low number of $\mathrm{T}$ cells are present there. Those $\mathrm{T}$ cells found had a memory and not a naïve phenotype. When we artificially increased the number of $\mathrm{T}$ cells by intrathecal transfer of primary rMT-II T cells, comprising naïve and memory subsets, this manipulation failed to induce clinical disease. In contrast the intrathecal administration of effector T cells induced classical monophasic EAE as did i.v. transfer (FIG 7). From this we conclude that the entry of MBP-specific rMT-II T cells into CNS per se is not sufficient for the initiation of pathogenic processes but that in addition a certain functional state of T cells is needed in order for them to become re-activated and to launch an inflammatory reaction. Seemingly, such a state characteristic for effector $\mathrm{T}$ cells is missing (or insufficient) in primary rMT-II T cells but could be induced in these cells by immunization. To determine whether highly pathogenic effector $\mathrm{T}$ cells differ from naïve and resting memory rMT-II T cells in their capacity to become activated in the target organ, we performed an analysis of transfer and active EAE in rMT-II rats. Under EAE conditions, 
we observed that the entry of naïve T cells into an inflamed CNS is barely detectable. Importantly, the levels of activation inside the CNS were similar for effector T cells in transfer EAE settings and for recently activated ex-memory T cells in active EAE settings. In contrast, the activation level of memory rMT-II T cells recruited to the CNS during transfer EAE were significantly lower than the activation of co-infiltrating transferred effector T cells. This might well explain why the clinical course of transfer EAE in rMT-II rats is indistinguishable from the one in WT Lewis rats. MBP-specific memory rMT-II T cells, although present in high numbers inside SC, are not efficiently activated in situ and thus do not contribute significantly to the inflammatory process.

We corroborated our findings obtained from EAE experiments in rMT-II animals using an alternative model, $\mathrm{T}_{\mathrm{MBP}}$-"memory" rats which enable the analysis of a well-defined memory $\mathrm{T}$ cell population of the same antigenic specificity and developmental history as an effector $\mathrm{T}_{\mathrm{MBP}}$ cell population. In fact, our data indicate that resting memory $\mathrm{T}_{\mathrm{MBP}}$ entering CNS during transfer EAE are less activated than effector $\mathrm{T}_{\mathrm{MBP}}$ cells, whereas recent antigenic stimulation in the periphery restores the potential for the re-activation in ex-memory $\mathrm{T}_{\mathrm{MBP}}$ cells to the levels seen in transferred effector $\mathrm{T}$ cells.

Effector and memory $\mathrm{T}$ cell subsets drastically differ in their usage of several metabolic pathways. One of these pathways, glycolysis, is induced by TCR-driven signaling (Ho et al. 2015) and itself can regulate effector function of T cells (Chang et al. 2013). We could confirm that effector T cells rapidly upregulate glycolysis after antigenic stimulation. This upregulation was transient and coincided with induction of mRNA of genes encoding transcription factors $\mathrm{cMyc}$, Irf4 and Hif1 $\alpha$ known to positively regulate the expression of glycolytic enzymes. After a period of high glycolytic activity, both in vitro cultured T cells and $\mathrm{T}$ cells transferred to a recipient animal for EAE induction, showed a gradual decline in glycolysis (FIG 13-15). Interestingly, $\mathrm{T}_{\mathrm{MBP}}$ cells re-activated inside the CNS resume their glycolytic activity (FIG 15). Whether this is required for effector function of encephalitogenic $\mathrm{T}$ cells remains unclear.

Pharmacologic inhibition of glycolysis during the preclinical phase of transfer EAE delayed the disease onset but could not block disease development (FIG 17). Therefore, a high glycolytic rate may be a factor contributing to but not solely determining the potential of effector T cells to become re-activated in the CNS. Furthermore, the results of our in vivo 2-DG administration supports the idea that the modulation of metabolic activity can be applied for therapeutic purposes. It should be noted that 2-DG treatment 
targets glycolysis in different types of cells other than T cells, e.g. myeloid immune cells and resident cells in the CNS. Consequently, the clinical effect of 2-DG may not be explicitly linked to T cell activation. Nevertheless, the reduced number of CNS-infiltrating $\mathrm{T}_{\mathrm{MBP}}$ cells and recruited myeloid cells along with the lower expression of $\mathrm{T}$ cell activation markers in animals treated with 2-DG suggest that a lowered glycolysis rate inhibits the activation of $\mathrm{T}_{\mathrm{MBP}}$ cells. It cannot be ruled out that 2-DG treatment also affects the induction of glycolysis in situ after re-activation of T cells in the CNS.

To pinpoint how glycolysis inhibition impacts on $\mathrm{T}$ cell activation we performed an in vitro analysis and showed that 2-DG treatment of $\mathrm{T}$ cells prior to stimulation reduces production of effector cytokines such as IFN $\gamma$ and IL-2. This argues in favor of our hypothesis that the glycolytic state modulates the re-activation potential of T cells. It also suggests that an impediment on re-activation of $\mathrm{T}$ cells might be the main mechanism of the 2-DG effect on transfer EAE.

The results shown in FIG 21 finally demonstrate that during transfer EAE the glycolysis rate of $\mathrm{T}$ cells migrating through the blood to the CNS is higher in recently activated $\mathrm{T}$ cells than in resting memory or naïve $\mathrm{T}$ cells. Together with the evidence pertaining to the different degrees of activation of these $\mathrm{T}$ cell subsets in the SC, the results suggest that the glycolysis rate present in T cells just before they enter the CNS and come into contact with local APC-antigen complexes can play a role in influencing their activation level. Moreover, it is also interesting that rMT-II and recently activated T cells show a similar glycolytic gene expression in the SC, except for Irf4 and, to a minor extent, for HK-1. This leads us to hypothesize that once stimulated, rMT-II T cells switch on their activation machinery as well as the recently activated T cells, but somehow, probably involving Irf4 and related to their previous glycolysis level, keep their inflammatory state low to the point of being undetectably pathogenic in the CNS.

In conclusion, even if we are still not aware of the mechanism behind the role of the glycolysis level in regulating $\mathrm{T}$-cell activation, our findings open up possibilities for treatments aimed at modulating the immune potential of $\mathrm{T}$ cells by targeting the level of glycolysis before activation. This could be useful in reducing the pathogenicity of autoreactive $\mathrm{T}$ cells and at least mitigate the clinical course of autoimmune diseases such as multiple sclerosis. Moreover, it could be possible to enhance the immune capability of exhausted or hyporesponsive T cells such as the tumor-infiltrating lymphocytes, kept in this condition by several mechanisms attributable to tumor cells, including the 
environmental deprivation of oxygen and nutrients (Schietinger and Greenberg 2014; Ho et al. 2015). Therefore, such treatment could help to break the unresponsiveness of tumor-specific T cells and thus, be valuable in treating cancers.

\section{SUMMARY AND CONCLUSIONS}

With this study we have demonstrated that endogenous naïve and memory MBP-reactive $\mathrm{T}$ cells are not pathogenic in Lewis rats and that only recently activated effector $\mathrm{T}$ cells are able to induce EAE, suggesting that the functional state of the cells can determine the disease development. Indeed, we have shown that, after EAE induction, a T cell's level of activation in the CNS strikingly depends upon its functional state, and whereas effector T cells become highly activated, memory cells show just a low degree of activation.

We examined the dynamics of glycolysis over time in T cells upon antigenic stimulation in vitro, and we also studied these dynamics in vivo, and have shown that the glycolysis rate reaches its peak soon after antigen encounter and then gradually decreases over time. In fact, after transfer EAE induction, memory $\mathrm{T}$ cells exhibit a lower level of glycolysis compared to recently activated effector T cells when analyzed in the blood on the last day of their peripheral migratory pathway to the CNS.

These findings suggest that the rate of glycolysis prior to stimulation can influence the level of activation of MBP-reactive T cells in the CNS. To corroborate this hypothesis, we demonstrated that the inhibition of glycolysis in MBP-reactive T cells could lower their level of activation and pathogenicity upon stimulation, even under optimal conditions.

Even though the exact mechanisms behind this phenomenon have yet to be elucidated, our results point to the possibility of influencing the immune potential of $\mathrm{T}$ cells by modulating their level of glycolysis. This could prove useful in the treatment of autoimmune diseases such as multiple sclerosis, or even of cancer, the latter being a pathological condition characterized by a weak immune response by $\mathrm{T}$ lymphocytes to tumor cells. 


\section{BIBLIOGRAPHY}

Ascherio,A. and Munger,K.L. (2007). Environmental risk factors for multiple sclerosis. Part I: the role of infection. Ann. Neurol. 61, 288-299.

Baron,J.L., Madri,J.A., Ruddle,N.H., Hashim,G., and Janeway,C.A., Jr. (1993). Surface expression of alpha 4 integrin by CD4 $\mathrm{T}$ cells is required for their entry into brain parenchyma. J. Exp. Med. 177, 57-68.

Bartholomäus,I., Kawakami,N., Odoardi,F., Schläger,C., Miljkovic,D., Ellwart,J.W., Klinkert,W.E., Flügel-Koch,C., Issekutz,T.B., Wekerle,H., and Flügel,A. (2009). Effector T cell interactions with meningeal vascular structures in nascent autoimmune CNS lesions. Nature. 462, 94-98.

Baxter,A.G. (2007). The origin and application of experimental autoimmune encephalomyelitis. Nat. Rev. Immunol. 7, 904-912.

Beecham,A.H., Patsopoulos,N.A., Xifara,D.K., Davis,M.F., Kemppinen,A., Cotsapas,C., Shah,T.S., Spencer,C., Booth,D., Goris,A., Oturai,A., Saarela,J., Fontaine,B., Hemmer,B., Martin,C., Zipp,F., D'alfonso,S., Martinelli-Boneschi,F., Taylor,B., Harbo,H.F., Kockum,I., Hillert,J., Olsson,T., Ban,M., Oksenberg,J.R., Hintzen,R., Barcellos,L.F., Agliardi,C., Alfredsson,L., Alizadeh,M., Anderson,C., Andrews,R., Sondergaard,H.B., Baker,A., Band,G., Baranzini,S.E., Barizzone,N., Barrett,J., Bellenguez,C., Bergamaschi,L., Bernardinelli,L., Berthele,A., Biberacher,V., Binder,T.M., Blackburn,H., Bomfim,I.L., Brambilla,P., Broadley,S., Brochet,B., Brundin,L., Buck,D., Butzkueven,H., Caillier,S.J., Camu,W., Carpentier,W., Cavalla,P., Celius,E.G., Coman,I., Comi,G., Corrado,L., Cosemans,L., Cournu-Rebeix,I., Cree,B.A., Cusi,D., Damotte,V., Defer,G., Delgado,S.R., Deloukas,P., di,S.A., Dilthey,A.T., Donnelly,P., Dubois,B., Duddy,M., Edkins,S., Elovaara,I., Esposito,F., Evangelou,N., Fiddes,B., Field,J., Franke,A., Freeman,C., Frohlich,I.Y., Galimberti,D., Gieger,C., Gourraud,P.A., Graetz,C., Graham,A., Grummel,V., Guaschino,C., Hadjixenofontos,A., Hakonarson,H., Halfpenny,C., Hall,G., Hall,P., Hamsten,A., Harley,J., Harrower,T., Hawkins,C., Hellenthal,G., Hillier,C., Hobart,J., Hoshi,M., Hunt,S.E., Jagodic,M., Jelcic,I., Jochim,A., Kendall,B., Kermode,A., Kilpatrick,T., Koivisto,K., Konidari,I., Korn,T., Kronsbein,H., Langford,C., Larsson,M., Lathrop,M., LebrunFrenay,C., Lechner-Scott,J., Lee,M.H., Leone,M.A., Leppa,V., Liberatore,G., Lie,B.A., Lill,C.M., Linden,M., Link,J., Luessi,F., Lycke,J., Macciardi,F., Mannisto,S., Manrique,C.P., Martin,R., Martinelli,V., Mason,D., Mazibrada,G., McCabe,C., Mero,I.L., Mescheriakova,J., Moutsianas,L., Myhr,K.M., Nagels,G., Nicholas,R., Nilsson,P., Piehl,F., Pirinen,M., Price,S.E., Quach,H., Reunanen,M., Robberecht,W., Robertson,N.P., Rodegher,M., Rog,D., Salvetti,M., Schnetz-Boutaud,N.C., Sellebjerg,F., Selter,R.C., Schaefer,C., Shaunak,S., Shen,L., Shields,S., Siffrin,V., Slee,M., Sorensen,P.S., Sorosina,M., Sospedra,M., Spurkland,A., Strange,A., Sundqvist,E., Thijs,V., Thorpe,J., Ticca,A., Tienari,P., van,D.C., Visser,E.M., Vucic,S., Westerlind,H., Wiley,J.S., Wilkins,A., Wilson,J.F., Winkelmann,J., Zajicek,J., Zindler,E., Haines,J.L., Pericak-Vance,M.A., Ivinson,A.J., Stewart,G., Hafler,D., Hauser,S.L., Compston,A., McVean,G., De,J.P., Sawcer,S.J., and McCauley,J.L. (2013). Analysis of immune-related loci identifies 48 new susceptibility variants for multiple sclerosis. Nat. Genet. 45, 1353. 
Belbasis,L., Bellou,V., Evangelou,E., Ioannidis,J.P., and Tzoulaki,I. (2015). Environmental risk factors and multiple sclerosis: an umbrella review of systematic reviews and metaanalyses. Lancet Neurol. 14, 263-273.

Bell,J. and Paterson,P.Y. (1960). Rapid induction of allergic encephalomyelitis in rats without the use of mycobacteria. Science 131, 1448.

Ben-Nun,A., Wekerle,H., and Cohen,I.R. (1981). The rapid isolation of clonable antigenspecific T lymphocyte lines capable of mediating autoimmune encephalomyelitis. Eur. J. Immunol. 11, 195-199.

Berod,L., Friedrich,C., Nandan,A., Freitag,J., Hagemann,S., Harmrolfs,K., Sandouk,A., Hesse,C., Castro,C.N., Bahre,H., Tschirner,S.K., Gorinski,N., Gohmert,M., Mayer,C.T., Huehn,J., Ponimaskin,E., Abraham,W.R., Muller,R., Lochner,M., and Sparwasser,T. (2014). De novo fatty acid synthesis controls the fate between regulatory $\mathrm{T}$ and $\mathrm{T}$ helper 17 cells. Nat. Med. 20,1327-1333.

Bettelli,E., Pagany,M., Weiner,H.L., Linington,C., Sobel,R.A., and Kuchroo,V.K. (2003). Myelin oligodendrocyte glycoprotein-specific $\mathrm{T}$ cell receptor transgenic mice develop spontaneous autoimmune optic neuritis. J. Exp. Med. 197, 1073-1081.

Bielekova,B., Sung,M.H., Kadom,N., Simon,R., McFarland,H., and Martin,R. (2004). Expansion and functional relevance of high-avidity myelin-specific CD4+ T cells in multiple sclerosis. J. Immunol. 172, 3893-3904.

Bikker,A., Kruize,A.A., van der Wurff-Jacobs KM, Peters,R.P., Kleinjan,M., Redegeld,F., de,J.W., Lafeber,F.P., and van Roon,J.A. (2014). Interleukin-7 and Toll-like receptor 7 induce synergistic B cell and T cell activation. PLoS. One. 9, e94756.

Brück,W., Popescu,B., Lucchinetti,C.F., Markovic-Plese,S., Gold,R., Thal,D.R., and Metz,I. (2012). Neuromyelitis optica lesions may inform multiple sclerosis heterogeneity debate. Ann. Neurol. 72, 385-394.

Buck,M.D., O'Sullivan,D., Klein Geltink,R.I., Curtis,J.D., Chang,C.H., Sanin,D.E., Qiu,J., Kretz,O., Braas,D., van der Windt,G.J., Chen,Q., Huang,S.C., O'Neill,C.M., Edelson,B.T., Pearce,E.J., Sesaki,H., Huber,T.B., Rambold,A.S., and Pearce,E.L. (2016). Mitochondrial Dynamics Controls T Cell Fate through Metabolic Programming. Cell 166, 63-76.

Bunce,C. and Bell,E.B. (1997). CD45RC isoforms define two types of CD4 memory T cells, one of which depends on persisting antigen. J. Exp. Med. 185, 767-776.

Busch,D.H., Kerksiek,K.M., and Pamer,E.G. (2000). Differing roles of inflammation and antigen in T cell proliferation and memory generation. J. Immunol. 164, 4063-4070.

Chang,C.H., Curtis,J.D., Maggi,L.B., Jr., Faubert,B., Villarino,A.V., O'Sullivan,D., Huang,S.C., van der Windt,G.J., Blagih,J., Qiu,J., Weber,J.D., Pearce,E.J., Jones,R.G., and Pearce,E.L. (2013). Posttranscriptional control of T cell effector function by aerobic glycolysis. Cell $153,1239-1251$.

Chang,J.T., Palanivel,V.R., Kinjyo,I., Schambach,F., Intlekofer,A.M., Banerjee,A., Longworth,S.A., Vinup,K.E., Mrass,P., Oliaro,J., Killeen,N., Orange,J.S., Russell,S.M., 
Weninger,W., and Reiner,S.L. (2007). Asymmetric T lymphocyte division in the initiation of adaptive immune responses. Science 315, 1687-1691.

Chávez-Galán,L., Arenas-Del Angel,M.C., Zenteno,E., Chavez,R., and Lascurain,R. (2009). Cell death mechanisms induced by cytotoxic lymphocytes. Cell Mol. Immunol. 6, 15-25.

Chluba,J., Steeg,C., Becker,A., Wekerle,H., and Epplen,J.T. (1989). T cell receptor beta chain usage in myelin basic protein-specific rat T lymphocytes. Eur. J. Immunol. 19, 279-284.

Codarri,L., Gyulveszi,G., Tosevski,V., Hesske,L., Fontana,A., Magnenat,L., Suter,T., and Becher,B. (2011). RORgammat drives production of the cytokine GM-CSF in helper T cells, which is essential for the effector phase of autoimmune neuroinflammation. Nat. Immunol. 12, 560-567.

Compston,A. and Coles,A. (2008). Multiple sclerosis. Lancet 372, 1502-1517.

Cua,D.J., Sherlock,J., Chen,Y., Murphy,C.A., Joyce,B., Seymour,B., Lucian,L., To,W., Kwan,S., Churakova,T., Zurawski,S., Wiekowski,M., Lira,S.A., Gorman,D., Kastelein,R.A., and Sedgwick,J.D. (2003). Interleukin-23 rather than interleukin-12 is the critical cytokine for autoimmune inflammation of the brain. Nature 421, 744-748.

Dang,E.V., Barbi,J., Yang,H.Y., Jinasena,D., Yu,H., Zheng,Y., Bordman,Z., Fu,J., Kim,Y., Yen,H.R., Luo,W., Zeller,K., Shimoda,L., Topalian,S.L., Semenza,G.L., Dang,C.V., Pardoll,D.M., and Pan,F. (2011). Control of T(H)17/T(reg) balance by hypoxiainducible factor 1 . Cell 146, 772-784.

Deli,M.A., Abraham,C.S., Kataoka,Y., and Niwa,M. (2005). Permeability studies on in vitro blood-brain barrier models: physiology, pathology, and pharmacology. Cell Mol. Neurobiol. 25, 59-127.

Dendrou,C.A., Fugger,L., and Friese,M.A. (2015). Immunopathology of multiple sclerosis. Nat. Rev. Immunol. 15, 545-558.

De Rosa,V., Procaccini,C., Calì,G., Pirozzi,G., Fontana,S., Zappacosta,S., La Cava,A., and Matarese,G. (2007). A key role of leptin in the control of regulatory $T$ cell proliferation. Immunity. 26, 241-255.

Engelhardt,B. and Ransohoff,R.M. (2005). The ins and outs of T-lymphocyte trafficking to the CNS: anatomical sites and molecular mechanisms. Trends Immunol. 26, 485-495.

Eylar,E.H., Kniskern,P.J., and Jackson,J.J. (1974). Myelin basic proteins. Meth. Enzymol. 32, 323-341.

Flügel,A., Berkowicz,T., Ritter,T., Labeur,M., Jenne,D.E., Li,Z., Ellwart,J.W., Willem,M., Lassmann,H., and Wekerle,H. (2001). Migratory activity and functional changes of green fluorescent effector cells before and during experimental autoimmune encephalomyelitis. Immunity. 14, 547-560.

Flügel,A., Labeur,M.S., Grasbon-Frodl,E.M., Kreutzberg,G.W., and Graeber,M.B. (1999b). Microglia only weakly present glioma antigen to cytotoxic T cells. Int. J. Dev. Neurosci. $17,547-556$. 
Flügel,A., Willem,M., Berkowicz,T., and Wekerle,H. (1999). Gene transfer into CD4+ T lymphocytes: green fluorescent protein-engineered, encephalitogenic $\mathrm{T}$ cells illuminate brain autoimmune responses. Nat. Med. 5, 843-847.

Frebel,H., Nindl,V., Schuepbach,R.A., Braunschweiler,T., Richter,K., Vogel,J., Wagner,C.A., Loffing-Cueni,D., Kurrer,M., Ludewig,B., and Oxenius,A. (2012). Programmed death 1 protects from fatal circulatory failure during systemic virus infection of mice. J. Exp. Med. 209, 2485-2499.

Freund,J. and McDermott,K. (1942). Sensitization to horse serum by means of adjuvants. Proceedings of the Society for Experimental Biology and Medicine. 49, 548-553.

Frischer,J.M., Bramow,S., Dal-Bianco,A., Lucchinetti,C.F., Rauschka,H., Schmidbauer,M., Laursen,H., Sorensen,P.S., and Lassmann,H. (2009). The relation between inflammation and neurodegeneration in multiple sclerosis brains. Brain 132, 1175-1189.

Fujinami,R.S., von Herrath,M.G., Christen,U., and Whitton,J.L. (2006). Molecular mimicry, bystander activation, or viral persistence: infections and autoimmune disease. Clin. Microbiol. Rev. 19, 80-94.

Gebhardt,T., Mueller,S.N., Heath,W.R., and Carbone,F.R. (2013). Peripheral tissue surveillance and residency by memory T cells. Trends Immunol. 34, 27-32.

Gourraud,P.A., Harbo,H.F., Hauser,S.L., and Baranzini,S.E. (2012). The genetics of multiple sclerosis: an up-to-date review. Immunol. Rev. 248, 87-103.

Griffiths,M. and Keast,D. (1990). The effect of glutamine on murine splenic leukocyte responses to T and B cell mitogens. Immunology and Cell Biology. 68, 405-408.

Harkiolaki,M., Holmes,S.L., Svendsen,P., Gregersen,J.W., Jensen,L.T., McMahon,R., Friese,M.A., van,B.G., Etzensperger,R., Tzartos,J.S., Kranc,K., Sainsbury,S., Harlos,K., Mellins,E.D., Palace,J., Esiri,M.M., van der Merwe,P.A., Jones,E.Y., and Fugger,L. (2009). T cell-mediated autoimmune disease due to low-affinity crossreactivity to common microbial peptides. Immunity. 30, 348-357.

Hedström,A.K., Akerstedt,T., Hillert,J., Olsson,T., and Alfredsson,L. (2011). Shift work at young age is associated with increased risk for multiple sclerosis. Ann. Neurol. 70, 733741.

Hellings,N., Baree,M., Verhoeven,C., D'hooghe,M.B., Medaer,R., Bernard,C.C., Raus,J., and Stinissen,P. (2001). T-cell reactivity to multiple myelin antigens in multiple sclerosis patients and healthy controls. J. Neurosci. Res. 63, 290-302.

Ho,P.C., Bihuniak,J.D., Macintyre,A.N., Staron,M., Liu,X., Amezquita,R., Tsui,Y.C., Cui,G., Micevic,G., Perales,J.C., Kleinstein,S.H., Abel,E.D., Insogna,K.L., Feske,S., Locasale,J.W., Bosenberg,M.W., Rathmell,J.C., and Kaech,S.M. (2015). Phosphoenolpyruvate Is a Metabolic Checkpoint of Anti-tumor T Cell Responses. Cell 162, 1217-1228.

Hohlfeld,R., Dornmair,K., Meinl,E., and Wekerle,H. (2016). The search for the target antigens of multiple sclerosis, part 1: autoreactive CD4+ T lymphocytes as pathogenic effectors and therapeutic targets. Lancet. Neurol. 15, 198-209. 
Huber,M. and Lohoff,M. (2014). IRF4 at the crossroads of effector T-cell fate decision. Eur. J. Immunol. 44, 1886-1895.

Huitinga,I., Ruuls,S.R., Jung,S., van,R.N., Hartung,H.P., and Dijkstra,C.D. (1995). Macrophages in $\mathrm{T}$ cell line-mediated, demyelinating, and chronic relapsing experimental autoimmune encephalomyelitis in Lewis rats. Clin. Exp. Immunol. 100, 344-351.

Huseby,E.S., Sather,B., Huseby,P.G., and Goverman,J. (2001). Age-dependent T cell tolerance and autoimmunity to myelin basic protein. Immunity. 14, 471-481.

Jenkins,M.K. and Schwartz,R.H. (1987). Antigen presentation by chemically modified splenocytes induces antigen-specific T cell unresponsiveness in vitro and in vivo. J. Exp. Med. 165, 302-319.

Kawakami,N., Lassmann,S., Li,Z., Odoardi,F., Ritter,T., Ziemssen,T., Klinkert,W.E., Ellwart,J.W., Bradl,M., Krivacic,K., Lassmann,H., Ransohoff,R.M., Volk,H.D., Wekerle,H., Linington,C., and Flügel,A. (2004). The activation status of neuroantigen-specific T cells in the target organ determines the clinical outcome of autoimmune encephalomyelitis. J Exp Med. 199, 185-197.

Kawakami,N., Nägerl,U.V., Odoardi,F., Bonhoeffer,T., Wekerle,H., and Flügel,A. (2005b). Live imaging of effector cell trafficking and autoantigen recognition within the unfolding autoimmune encephalomyelitis lesion. J Exp Med. 201, 1805-1814.

Kawakami,N., Odoardi,F., Ziemssen,T., Bradl,M., Ritter,T., Neuhaus,O., Lassmann,H., Wekerle,H., and Flügel,A. (2005). Autoimmune CD4+ T cell memory: lifelong persistence of encephalitogenic $\mathrm{T}$ cell clones in healthy immune repertoires. J. Immunol. 175, 69-81.

Kaye,J.F., Kerlero de,R.N., Mendel,I., Flechter,S., Hoffman,M., Yust,I., and Ben-Nun,A. (2000). The central nervous system-specific myelin oligodendrocytic basic protein (MOBP) is encephalitogenic and a potential target antigen in multiple sclerosis (MS). J. Neuroimmunol. 102, 189-198.

Kearney,H., Altmann,D.R., Samson,R.S., Yiannakas,M.C., Wheeler-Kingshott,C.A.M., Ciccarelli,O., and Miller,D.H. (2015). Cervical cord lesion load is associated with disability independently from atrophy in MS. Neurology. 84, 367-373.

Knosp,C.A. and Johnston,J.A. (2012). Regulation of CD4+ T-cell polarization by suppressor of cytokine signalling proteins. Immunology 135, 101-111.

Kojima,K., Berger,T., Lassmann,H., Hinze-Selch,D., Zhang,Y., Gehrmann,J., Reske,K., Wekerle,H., and Linington,C. (1994). Experimental autoimmune panencephalitis and uveoretinitis transferred to the Lewis rat by T lymphocytes specific for the S100 beta molecule, a calcium binding protein of astroglia. J. Exp. Med. 180, 817-829.

Krakowski,M.L. and Owens,T. (2000). Naive T lymphocytes traffic to inflamed central nervous system, but require antigen recognition for activation. Eur. J. Immunol. 30, 1002-1009. 
Kurts,C., Sutherland,R.M., Davey,G., Li,M., Lew,A.M., Blanas,E., Carbone,F.R., Miller,J.F., and Heath,W.R. (1999). CD8 T cell ignorance or tolerance to islet antigens depends on antigen dose. Proc. Natl. Acad. Sci. U. S. A 96, 12703-12707.

Laky,K., Evans,S., Perez-Diez,A., and Fowlkes,B.J. (2015). Notch signaling regulates antigen sensitivity of naive CD4+ T cells by tuning co-stimulation. Immunity. 42, 80-94.

Lang,K.S., Recher,M., Junt,T., Navarini,A.A., Harris,N.L., Freigang,S., Odermatt,B., Conrad,C., Ittner,L.M., Bauer,S., Luther,S.A., Uematsu,S., Akira,S., Hengartner,H., and Zinkernagel,R.M. (2005). Toll-like receptor engagement converts T-cell autoreactivity into overt autoimmune disease. Nat. Med. 11, 138-145.

Langenkamp,A., Messi,M., Lanzavecchia,A., and Sallusto,F. (2000). Kinetics of dendritic cell activation: impact on priming of TH1, TH2 and nonpolarized T cells. Nat. Immunol. 1, 311-316.

Le Goffe,C., Vallette,G., Jarry,A., Bou-Hanna,C., and Laboisse,C.L. (1999). The in vitro manipulation of carbohydrate metabolism: a new strategy for deciphering the cellular defence mechanisms against nitric oxide attack. Biochem. J. 344 Pt 3, 643-648.

Lennon,V.A., Kryzer,T.J., Pittock,S.J., Verkman,A.S., and Hinson,S.R. (2005). IgG marker of optic-spinal multiple sclerosis binds to the aquaporin-4 water channel. J. Exp. Med. 202, 473-477.

Lennon,V.A., Wingerchuk,D.M., Kryzer,T.J., Pittock,S.J., Lucchinetti,C.F., Fujihara,K., Nakashima,I., and Weinshenker,B.G. (2004). A serum autoantibody marker of neuromyelitis optica: distinction from multiple sclerosis. The Lancet. 364, $2106-2112$.

Linington,C., Bradl,M., Lassmann,H., Brunner,C., and Vass,K. (1988). Augmentation of demyelination in rat acute allergic encephalomyelitis by circulating mouse monoclonal antibodies directed against a myelin/oligodendrocyte glycoprotein. Am. J. Pathol 130, 443-454.

Lipton,M.M. and Freund,J. (1953). Allergic encephalomyelitis in the rat induced by the intracutaneous injection of central nervous system tissue and adjuvants. J. Immunol. 71, 98-109.

Lipton,M.M. and Freund,J. (1952). Encephalomyelitis in the rat following intracutaneous injection of central nervous system tissue with adjuvant. Proc. Soc. Exp. Biol. Med. 81, $260-261$.

Lodygin,D., Odoardi,F., Schläger,C., Körner,H., Kitz,A., Nosov,M., van den Brandt,J., Reichardt,H.M., Haberl,M., and Flügel,A. (2013). A combination of fluorescent NFAT and H2B sensors uncovers dynamics of $\mathrm{T}$ cell activation in real time during CNS autoimmunity. Nat. Med. 19, 784-790.

Lucchinetti,C., Bruck,W., Parisi,J., Scheithauer,B., Rodriguez,M., and Lassmann,H. (2000). Heterogeneity of multiple sclerosis lesions: implications for the pathogenesis of demyelination. Ann. Neurol. 47, 707-717. 
MacIver,N.J., Michalek,R.D., and Rathmell,J.C. (2013). Metabolic regulation of T lymphocytes. Annu. Rev. Immunol. 31, 259-283.

Man,K. and Kallies,A. (2015). Synchronizing transcriptional control of T cell metabolism and function. Nat. Rev. Immunol. 15, 574-584.

Man,K., Miasari,M., Shi,W., Xin,A., Henstridge,D.C., Preston,S., Pellegrini,M., Belz,G.T., Smyth,G.K., Febbraio,M.A., Nutt,S.L., and Kallies,A. (2013). The transcription factor IRF4 is essential for TCR affinity-mediated metabolic programming and clonal expansion of T cells. Nat. Immunol. 14, 1155-1165.

McLaughlin,K.A., Richardson,C.C., Williams,S., Bonifacio,E., Morgan,D., Feltbower,R.G., Powell,M., Rees,S.B., Furmaniak,J., and Christie,M.R. (2015). Relationships between major epitopes of the IA-2 autoantigen in Type 1 diabetes: Implications for determinant spreading. Clin. Immunol. 160, 226-236.

McMahon,E.J., Bailey,S.L., Castenada,C.V., Waldner,H., and Miller,S.D. (2005). Epitope spreading initiates in the CNS in two mouse models of multiple sclerosis. Nat. Med. 11, 335-339.

Mendel,I., Kerlero de R,N., and Ben-Nun,A. (1995). A myelin oligodendrocyte glycoprotein peptide induces typical chronic experimental autoimmune encephalomyelitis in $\mathrm{H}-2 \mathrm{~b}$ mice: fine specificity and $\mathrm{T}$ cell receptor $\mathrm{V}$ beta expression of encephalitogenic $\mathrm{T}$ cells. Eur. J. Immunol. 25, 1951-1959.

Menk,A.V., Scharping,N.E., Moreci,R.S., Zeng,X., Guy,C., Salvatore,S., Bae,H., Xie,J., Young,H.A., Wendell,S.G., and Delgoffe,G.M. (2018). Early TCR Signaling Induces Rapid Aerobic Glycolysis Enabling Distinct Acute T Cell Effector Functions. Cell Rep. 22, 15091521.

Münz,C., Lunemann,J.D., Getts,M.T., and Miller,S.D. (2009). Antiviral immune responses: triggers of or triggered by autoimmunity? Nat. Rev. Immunol. 9, 246-258.

Nogai,A., Siffrin,V., Bonhagen,K., Pfueller,C.F., Hohnstein,T., Volkmer-Engert,R., Bruck,W., Stadelmann,C., and Kamradt,T. (2005). Lipopolysaccharide injection induces relapses of experimental autoimmune encephalomyelitis in nontransgenic mice via bystander activation of autoreactive CD4+ cells. J. Immunol. 175, 959-966.

Odoardi,F., Sie,C., Streyl,K., Ulaganathan,V.K., Schläger,C., Lodygin,D., Heckelsmiller,K., Nietfeld,W., Ellwart,J., Klinkert,W.E., Lottaz,C., Nosov,M., Brinkmann,V., Spang,R., Lehrach,H., Vingron,M., Wekerle,H., Flügel-Koch,C., and Flügel,A. (2012). T cells become licensed in the lung to enter the central nervous system. Nature 488, 675-679.

Oldstone,M.B., Nerenberg,M., Southern,P., Price,J., and Lewicki,H. (1991). Virus infection triggers insulin-dependent diabetes mellitus in a transgenic model: role of anti-self (virus) immune response. Cell 65, 319-331.

Olitsky,P.K. and YAGER,R.H. (1949). Experimental disseminated encephalomyelitis in white mice. J. Exp. Med. 90, 213-224. 
Owens,T., Tran,E., Hassan-Zahraee,M., and Krakowski,M. (1998). Immune cell entry to the CNS--a focus for immunoregulation of EAE. Res. Immunol. 149, 781-789.

Ota,K., Matsui,M., Milford,E.L., Mackin,G.A., Weiner,H.L., and Hafle,D.A. (1990). T-cell recognition of an immuno-dominant myelin basic protein epitope in multiple sclerosis. Nature. 346, 183-187.

Pearce,E.L., Poffenberger,M.C., Chang,C.H., and Jones,R.G. (2013). Fueling immunity: insights into metabolism and lymphocyte function. Science 342, 1242454.

Pearce,E.L., Walsh,M.C., Cejas,P.J., Harms,G.M., Shen,H., Wang,L.S., Jones,R.G., and Choi,Y. (2009). Enhancing CD8 T-cell memory by modulating fatty acid metabolism. Nature $460,103-107$.

Pepper,M. and Jenkins,M.K. (2011). Origins of CD4(+) effector and central memory T cells. Nat. Immunol. 12, 467-471.

Pette,M., Fujita,K., Kitze,B., Whitaker,J.,N., Albert,E., Kappos,L., and Wekerle,H. (1990). Myelin basic protein-specific T lymphocyte lines from MS patients and healthy individuals. Neurology. 40, 1770-1776.

Piddlesden,S.J., Lassmann,H., Zimprich,F., Morgan,B.P., and Linington,C. (1993). The demyelinating potential of antibodies to myelin oligodendrocyte glycoprotein is related to their ability to fix complement. Am. J. Pathol 143, 555-564.

Pollinger,B., $\quad$ Krishnamoorthy,G., $\quad$ Berer,K., Lassmann,H., $\quad$ Bosl,M.R., $\quad$ Dunn,R., Domingues,H.S., Holz,A., Kurschus,F.C., and Wekerle,H. (2009). Spontaneous relapsingremitting EAE in the SJL/J mouse: MOG-reactive transgenic T cells recruit endogenous MOG-specific B cells. J. Exp. Med. 206, 1303-1316.

Pollizzi,K.N., Sun,I.H., Patel,C.H., Lo,Y.C., Oh,M.H., Waickman,A.T., Tam,A.J., Blosser,R.L., Wen,J., Delgoffe,G.M., and Powell,J.D. (2016). Asymmetric inheritance of mTORC1 kinase activity during division dictates CD8(+) T cell differentiation. Nat. Immunol. 17, 704-711.

Ramana,C.V., Gil,M.P., Schreiber,R.D., and Stark,G.R. (2002). Stat1-dependent and independent pathways in IFN-gamma-dependent signaling. Trends Immunol. 23, 96101.

Rao,R.R., Li,Q., Odunsi,K., and Shrikant,P.A. (2010). The mTOR kinase determines effector versus memory CD8+ T cell fate by regulating the expression of transcription factors T-bet and Eomesodermin. Immunity. 32, 67-78.

Redmond,W.L., Ruby,C.E., and Weinberg,A.D. (2009). The role of OX40-mediated costimulation in T-cell activation and survival. Crit Rev. Immunol. 29, 187-201.

Reißig,S., Hackenbruch,C., and Hövelmeyer,N. (2014). Isolation of T cells from the gut. Methods. Mol. Biol. 1193, 21-25.

Remlinger,P. (1928). Les paralysies du traitement antirabique. Annales de l'Institut Pasteur 55, 35-68. 
Restifo,N.P. and Gattinoni,L. (2013). Lineage relationship of effector and memory T cells. Curr. Opin. Immunol. 25, 556-563.

Rivers,T.M. and Schwentker,F.F. (1935). Encephalomyelitis accompanied by myelin destruction experimentally produced in monkeys. J. Exp. Med. 61, 689-702.

Rivers,T.M., Sprunt,D.H., and Berry,G.P. (1933). Observations on attempts to produce acute disseminated encephalomyelitis in monkeys. J. Exp. Med. 58, 39-53.

Rosenberg,S.A., Spiess,P.J., and Schwarz,S. (1978). In vitro growth of murine T cells. I. Production of factors necessary for T cell growth. J. Immunol. 121, 1946-1950.

Sallusto,F., Geginat,J., and Lanzavecchia,A. (2004). Central memory and effector memory $\mathrm{T}$ cell subsets: function, generation, and maintenance. Annu. Rev. Immunol. 22, 745763.

Sallusto,F., Lenig,D., Forster,R., Lipp,M., and Lanzavecchia,A. (1999). Two subsets of memory T lymphocytes with distinct homing potentials and effector functions. Nature $401,708-712$.

Schietinger,A. and Greenberg,P.D. (2014). Tolerance and exhaustion: defining mechanisms of T cell dysfunction. Trends Immunol. 35, 51-60.

Schläger,C., Körner,H., Krueger,M., Vidoli,S., Haberl,M., Mielke,D., Brylla,E., Issekutz,T., Cabañas,C., Nelson,P.J., Ziemssen,T., Rohde,V., Bechmann,I., Lodygin,D., Odoardi,F., and Flügel,A. (2016). Effector T-cell trafficking between the leptomeninges and the cerebrospinal fluid. Nature. 530, 349-353.

Schwartz,R.H. (2003). T cell anergy. Annu. Rev. Immunol. 21, 305-334.

Schwentker,F.F. and Rivers,T.M. (1934). The antibody response of rabbits to injections of emulsions and extracts of homologous brain. J. Exp. Med. 60, 559-574.

Segal,B.M. and Shevach,E.M. (1996). IL-12 unmasks latent autoimmune disease in resistant mice. J. Exp. Med. 184, 771-775.

Serafini,B., Rosicarelli,B., Magliozzi,R., Stigliano,E., and Aloisi,F. (2004). Detection of ectopic B-cell follicles with germinal centers in the meninges of patients with secondary progressive multiple sclerosis. Brain Pathol. 14, 164-174.

Serafini,B., Severa,M., Columba-Cabezas,S., Rosicarelli,B., Veroni,C., Chiappetta,G., Magliozzi,R., Reynolds,R., Coccia,E.M., and Aloisi,F. (2010). Epstein-Barr virus latent infection and BAFF expression in B cells in the multiple sclerosis brain: implications for viral persistence and intrathecal B-cell activation. J. Neuropathol Exp. Neurol. 69, 677693.

Shackelford,D.B. and Shaw,R.J. (2009). The LKB1-AMPK pathway: metabolism and growth control in tumour suppression. Nat. Rev. Cancer 9, 563-575. 
Shaw,J.P., Utz,P.J., Durand,D.B., Toole,J.J., Emmel,E.A., and Crabtree,G.R. (1988). Identification of a putative regulator of early T cell activation genes. Science 241, 202205.

Shechter,R., London,A., and Schwartz,M. (2013). Orchestrated leukocyte recruitment to immune-privileged sites: absolute barriers versus educational gates. Nat. Rev. Immunol. 13, 206-218.

Sprent,J. and Surh,C.D. (2001). Generation and maintenance of memory T cells. Curr. Opin. Immunol. 13, 248-254.

Srivastava,R., Aslam,M., Kalluri,S.R., Schirmer,L., Buck,D., Tackenberg,B., Rothhammer,V., Chan,A., Gold,R., Berthele,A., Bennett,J.L., Korn,T., and Hemmer,B. (2012). Potassium channel KIR4.1 as an immune target in multiple sclerosis. N. Engl. J. Med. 367, 115-123.

Sukumar,M., Liu,J., Ji,Y., Subramanian,M., Crompton,J.G., Yu,Z., Roychoudhuri,R., Palmer,D.C., Muranski,P., Karoly,E.D., Mohney,R.P., Klebanoff,C.A., Lal,A., Finkel,T., Restifo,N.P., and Gattinoni,L. (2013). Inhibiting glycolytic metabolism enhances CD8+ $\mathrm{T}$ cell memory and antitumor function. J. Clin. Invest 123, 4479-4488.

Sun,D., Whitaker,J.N., and Wilson,D.B. (1999). Regulatory T cells in experimental allergic encephalomyelitis. I. Frequency and specificity analysis in normal and immune rats of a $\mathrm{T}$ cell subset that inhibits disease. Int. Immunol. 11, 307-315.

Tejada-Simon,M.V., Hong,J., Rivera,V.M., and Zhang,J.Z. (2001). Reactivity pattern and cytokine profile of $\mathrm{T}$ cells primed by myelin peptides in multiple sclerosis and healthy individuals. Eur. J. Immunol. 31, 907-917.

Thomas,L., Paterson,P.Y., and Smithwick,B. (1950). Acute disseminated encephalomyelitis following immunization with homologous brain extracts; studies on the role of a circulating antibody in the production of the condition in dogs. J. Exp. Med. $92,133-152$.

Tough,D.F. and Sprent,J. (1995). Life span of naive and memory T cells. Stem Cells 13, 242249.

Tuohy,V.K., Sobel,R.A., and Lees,M.B. (1988). Myelin proteolipid protein-induced experimental allergic encephalomyelitis. Variations of disease expression in different strains of mice. J. Immunol. 140, 1868-1873.

Vaeth,M., Maus,M., Klein-Hessling,S., Freinkman,E., Yang,J., Eckstein,M., Cameron,S., Turvey,S.E., Serfling,E., Berberich-Siebelt,F., Possemato,R., and Feske,S. (2017). StoreOperated $\mathrm{Ca}(2+)$ Entry Controls Clonal Expansion of $\mathrm{T}$ Cells through Metabolic Reprogramming. Immunity. 47, 664-679.

van der Windt,G.J., Chang,C.H., and Pearce,E.L. (2016). Measuring Bioenergetics in T Cells Using a Seahorse Extracellular Flux Analyzer. Curr. Protoc. Immunol. 113, 3.

van der Windt,G.J., Everts,B., Chang,C.H., Curtis,J.D., Freitas,T.C., Amiel,E., Pearce,E.J., and Pearce,E.L. (2012). Mitochondrial respiratory capacity is a critical regulator of CD8+ T cell memory development. Immunity. 36, 68-78. 
van der Windt,G.J., O'Sullivan,D., Everts,B., Huang,S.C., Buck,M.D., Curtis,J.D., Chang,C.H., Smith,A.M., Ai,T., Faubert,B., Jones,R.G., Pearce,E.J., and Pearce,E.L. (2013). CD8 memory $\mathrm{T}$ cells have a bioenergetic advantage that underlies their rapid recall ability. Proc. Natl. Acad. Sci. U. S. A 110, 14336-14341.

Wang,R., Dillon,C.P., Shi,L.Z., Milasta,S., Carter,R., Finkelstein,D., McCormick,L.L., Fitzgerald,P., Chi,H., Munger,J., and Green,D.R. (2011). The transcription factor Myc controls metabolic reprogramming upon T lymphocyte activation. Immunity. 35, 871882.

Wekerle,H. (2008). Lessons from multiple sclerosis: models, concepts, observations. Ann. Rheum. Dis. 67 Suppl 3, iii56-iii60.

Wekerle,H., Kojima,K., Lannes-Vieira,J., Lassmann,H., and Linington,C. (1994). Animal models. Ann. Neurol. 36 Suppl, S47-S53.

Wlodarczyk,A., Lobner,M., Cedile,O., and Owens,T. (2014). Comparison of microglia and infiltrating $\mathrm{CD} 11 \mathrm{c}(+)$ cells as antigen presenting cells for $\mathrm{T}$ cell proliferation and cytokine response. J. Neuroinflammation. 11, 57.

Yatsunenko,T., Rey,F.E., Manary,M.J., Trehan,I., Dominguez-Bello,M.G., Contreras,M., Magris,M., Hidalgo,G., Baldassano,R.N., Anokhin,A.P., Heath,A.C., Warner,B., Reeder,J., Kuczynski,J., Caporaso,J.G., Lozupone,C.A., Lauber,C., Clemente,J.C., Knights,D., Knight,R., and Gordon,J.I. (2012). Human gut microbiome viewed across age and geography. Nature 486, 222-227.

Zepp,J., Wu,L., and Li,X. (2011). IL-17 receptor signaling and T helper 17-mediated autoimmune demyelinating disease. Trends Immunol. 32, 232-239.

Zhang,D., Li,J., Wang,F., Hu,J., Wang,S., and Sun,Y. (2014). 2-Deoxy-D-glucose targeting of glucose metabolism in cancer cells as a potential therapy. Cancer Lett. 355, 176-183. 


\section{LIST OF ABBREVIATIONS}

2-DG: 2-deoxy-D-glucose.

2DG-6-P: 2-Deoxyglucose-6-phosphate.

2-NBDG: 2-(N-(7-Nitrobenz-2-oxa-1,3-diazol-4-yl)Amino)-2-Deoxyglucose.

Ab: Antibody.

ACAT2: $\quad$ Acetyl-CoA C-acetyltransferase 2.

ACK: Ammonium chloride potassium.

aEAE: Active EAE.

Ag: $\quad$ Antigen.

AKT1: $\quad$ AKT serine/threonine kinase 1.

AMPK: $\quad$ AMP-activated protein kinase.

APC: $\quad$ Antigen presenting cell.

Apo-A4: Apolipoprotein A-IV.

AQP4: $\quad$ Aquaporin-4.

ATP: $\quad$ Adenosine triphosphate.

BBB: Blood-brain barrier.

Bcl6: $\quad$ B cell lymphoma 6.

Bl: $\quad$ Blood.

BLIMP1: $\quad$ B lymphocyte-induced maturation protein-1.

BSA: Bovine serum albumin.

CCR7: $\quad$ C-C motif chemokine receptor 7.

CD: $\quad$ Cluster of differentiation.

CD25: Interleukin 2 receptor alpha.

CD62L: L-selectin.

cDNA: Complementary deoxyribonucleic acid.

CFA: $\quad$ Complete Freund's adjuvant.

cMyc: $\quad$ Myc proto-oncogene, bHLH transcription factor.

CNS: $\quad$ Central nervous system.

CRAC: $\quad \mathrm{Ca}^{2+}$ release-activated $\mathrm{Ca}^{2+}$ channels.

CSF: Cerebrospinal fluid.

CXCR3: $\quad \mathrm{C}-\mathrm{X}-\mathrm{C}$ motif chemokine receptor 3.

CXCR4: $\quad$ C-X-C motif chemokine receptor type 4 .

DLAT: Dihydrolipoamide S-Acetyltransferase.

DMEM: Dulbecco's modified Eagle's medium.

DMSO: Dimethyl sulfoxide.

DNA: Deoxyribonucleic acid.

EAE: Experimental autoimmune encephalomyelitis.

ECAR: Extracellular acidification rate.

EDTA: Ethylenediaminetetraacetic acid.

EH: $\quad$ Eagle's HEPES. 
ELISA: Enzyme-like immunosorbent assay.

Eno 1: $\quad$ Enolase 1.

EOMES: Eomesodermin.

ER: Endoplasmic reticulum.

ETC: $\quad$ Electron transport chain.

FACS: $\quad$ Fluorescence-activated cell sorting.

FADH $_{2}$ : Flavin adenine dinucleotide.

FA0: $\quad$ Fatty acid oxidation.

FAsyn: $\quad$ Fatty acid synthase.

FAS: $\quad$ Fatty acid synthesis.

FCS: $\quad$ Fetal calf serum.

FSC: $\quad$ Forward scatter.

G-6-P: $\quad$ Glucose-6-phosphate.

Gala + 2DG: Galactose + 2 Deoxy-D-glucose .

GAPDH: Glyceraldehyde-3-phosphate dehydrogenase.

GFP: Green fluorescent protein.

GLUT: Glucose transporter.

GM-CSF: Granulocyte-macrophage colony-stimulating factor.

GPE: $\quad$ GP+E86 packaging cell.

Hif1 $\alpha$ : Hypoxia-inducible factor $1 \alpha$.

HK-1: $\quad$ Hexokinase 1.

HLA: Human leucocyte antigen.

i.p.: Intraperitoneal.

i.t.: Intrathecal.

i.v.: Intravenous.

IEL: Intraepithelial lymphocytes.

IFN $\gamma$ : Interferon gamma.

IL15: Interleukin 15.

IL-17: $\quad$ Interleukin 17.

IL-2: $\quad$ Interleukin 2.

IL7: $\quad$ Interleukin 7.

IP3: Inositol 1,4,5-trisphosphate.

Irf4: interferon-regulatory factor 4.

LdhA: $\quad$ Lactate dehydrogenase A.

LFA-1: $\quad$ Lymphocyte function-associated antigen 1.

LN: $\quad$ Lymph node.

LSM 1077: $\quad$ Lymphocyte separation medium.

Lu: Lung.

MACS: Magnetic-activated cell sorting.

MAG: $\quad$ Myelin-associated glycoprotein.

MBP: $\quad$ Myelin basic protein.

Med LN: $\quad$ Mediastinal lymph node.

MHC: $\quad$ Major histocompatibility complex. 
MFI: Mean fluorescence intensity.

MOG: $\quad$ Myelin oligodendrocyte glycoprotein.

mRNA: Messenger ribonucleic acid.

MS: $\quad$ Multiple sclerosis.

mTOR: Mammalian target of rapamycin.

mTORC1: Mammalian target of rapamycin complex 1.

Myc: $\quad$ MYC proto-oncogene, bHLH transcription factor.

NAD+: $\quad$ Nicotinamide adenine dinucleotide (oxidized form).

NADH: Nicotinamide adenine dinucleotide (reduced form).

NFAT: $\quad$ Nuclear factor of activated T cells.

NF-M: $\quad$ Neurofilament.

NMO: $\quad$ Neuromyelitis optica.

OVA: Chicken egg ovalbumin.

OX40: $\quad$ Tumor necrosis factor receptor superfamily, member 4. Also cluster of differentiation 134 (CD134).

OXPHOS: Oxidative phosphorylation.

PAMP: $\quad$ Pathogen-associated molecular pattern.

PBS: $\quad$ Phosphate buffered saline.

PCR: $\quad$ Polymerase chain reaction.

PEP: $\quad$ Phosphoenolpyruvate.

PGI: $\quad$ Phosphoglucose isomerase.

PI3K: $\quad$ Phosphoinositide 3-kinase.

PKM1/2: Pyruvate kinase isozymes M1/M2.

PLP: $\quad$ Proteolipid protein.

pPCR: Quantitative polymerase chain reaction. Also, real-time polymerase chain reaction.

PP-MS: $\quad$ Primary progressive multiple sclerosis.

PPP: $\quad$ Pentose phosphate pathway.

PRR: pattern recognition receptor.

pS6: $\quad$ Phospho-S6 ribosomal protein.

qPCR: $\quad$ Quantitative (or real time) PCR.

RM: $\quad$ Restimulation medium.

rMT-II: $\quad$ Rat MBP-specific T cell receptor MHC class II-restricted.

RNA: Ribonucleic acid.

rOT-II: $\quad$ Rat OVA-specific TCR transgenic MHC class II restricted.

RR-MS: $\quad$ Relapsing-remitting multiple sclerosis.

RT-qPCR: Quantitative reverse transcription polymerase chain reaction.

S.c.: Subcutaneous.

S-100ß: $\quad$ S100 calcium binding protein B.

S1P1: $\quad$ Sphingosine-1-phosphate receptor 1.

S6: $\quad$ S6 ribosomal protein.

SC par: $\quad$ Spinal cord parenchyma.

SC: Spinal cord. 
SDHA: Succinate dehydrogenase complex flavoprotein subunit.

SERCA: $\quad$ Sarco/endoplasmic reticulum $\mathrm{Ca}^{2+}$-ATPase.

SOCE: $\quad$ Store-operated $\mathrm{Ca}^{2+}$ entry.

Sp: Spleen.

SP-MS: $\quad$ Secondary progressive multiple sclerosis.

SRC: $\quad$ Spare respiratory capacity.

SSC: $\quad$ Side scatter.

STIM: $\quad$ Stromal interaction molecule.

TCA: $\quad$ Tricarboxylic acid.

TCGF: $\quad$ T cell growth factor.

Tcm: Central memory T cells.

TCM: $\quad$ T cell medium.

TCR: $\quad$ T cell receptor.

Tem: $\quad$ Effector memory T cells.

tEAE: Transfer EAE.

Th1: $\quad$ T-helper 1.

Th17: T-helper 17.

TLR: Toll-like receptors.

TNFo: $\quad$ Tumor necrosis factor alpha.

VLA-4: $\quad$ Very late antigen 4.

WT: Wild-type.

$\boldsymbol{\alpha}$-KG: $\quad \alpha$-ketoglutarate.

$\boldsymbol{\alpha} \boldsymbol{\beta}$ TCR: $\quad$ T cell receptor alpha and beta chains. 